\title{
GAS HYDRATES RESEARCH PROGRAMS: AN INTERNATIONAL REVIEW
}

FINAL REPORT

CONTRACT NUMBER: DE-FG26-06NT42746

PERIOD: FEB. 2006-DEC 2009

March 2010

TECHNICAL POINTS OF CONTACT:

Jorge Gabitto

Prairie View A\&M State University

Department of Chemical Engineering

Prairie View, TX 77429

TELE:(936) 261-9409

FAX: (936) 261-9419

EMAIL:jgabitto@aol.com
Maria Barrufet

Texas A\&M University

Petroleum Engineering

Department

College Station TX, 77204

TELE:(979) 845-0314

FAX:(979) 845-0325

EMAIL:maria.barrufet@pe.

tamu.edu 


\section{GAS HYDRATES RESEARCH PROGRAMS: AN INTERNATIONAL REVIEW}

\section{DISCLAIMER}

This report was prepared as an account of work sponsored by an agency of the United States Government. Neither the United States Government nor any agency thereof, nor any of their employees, makes any warranty, express or implied, or assumes any legal liability or responsibility for the accuracy, completeness, or usefulness of any information, apparatus, product, or process disclosed, or represents that its use would not infringe privately owned rights. Reference herein to any specific commercial product, process, or service by trade name, trademark, manufacturer, or otherwise does not necessarily constitute or imply its endorsement, recommendation, or favoring by the United States Government or any agency thereof. The views and opinions of authors expressed herein do not necessarily state of reflect those of the United States Government or any agency thereof. 


\title{
GAS HYDRATES RESEARCH PROGRAMS: AN INTERNATIONAL REVIEW
}

\begin{abstract}
Gas hydrates sediments have the potential of providing a huge amount of natural gas for human use. Hydrate sediments have been found in many different regions where the required temperature and pressure conditions have been satisfied. Resource exploitation is related to the safe dissociation of the gas hydrate sediments. Basic depressurization techniques and thermal stimulation processes have been tried in pilot efforts to exploit the resource.

There is a growing interest in gas hydrates all over the world due to the inevitable decline of oil and gas reserves. Many different countries are interested in this valuable resource. Unsurprisingly, developed countries with limited energy resources have taken the lead in worldwide gas hydrates research and exploration.

The goal of this research project is to collect information in order to record and evaluate the relative strengths and goals of the different gas hydrates programs throughout the world. A thorough literature search about gas hydrates research activities has been conducted. The main participants in the research effort have been identified and summaries of their past and present activities reported. An evaluation section discussing present and future research activities has also been included.
\end{abstract}


GAS HYDRATES RESEARCH PROGRAMS: AN INTERNATIONAL REVIEW

TABLE OF CONTENTS

DISCLAIMER 2

ABSTRACT 3

TABLE OF CONTENTS

$\begin{array}{ll}\text { EXECUTIVE SUMMARY } & 7\end{array}$

TECHNICAL REPORT 9

INTRODUCTION 9

Individual Gas Hydrates Research Programs

$\begin{array}{ll}\text { JAPAN } & 11\end{array}$

$\begin{array}{ll}\text { Introduction } & 11\end{array}$

Japan R\&D

Gas Hydrate R\&D

International Cooperative Projects 15

Japan's National Methane Hydrate R\&D Program 19

Phase I (fiscal 2001-2008) 20

Phase II (fiscal 2009-2011) $\quad 20$

Phase III (fiscal 2012-2016) 21

Nankai Trough $\quad 21$

CANADA

Introduction $\quad 22$

Research on the Canadian Arctic 23

Depressurization Experiments 26

Thermal Heating Experiments 26

Research Offshore Western Canada 27

$\begin{array}{ll}\text { RUSSIA } & \mathbf{2 8}\end{array}$

$\begin{array}{ll}\text { Introduction } & \mathbf{2 8}\end{array}$

$\begin{array}{ll}\text { Historical Perspective } & 28\end{array}$

International Activities

Gas Hydrate-Bearing Sediments Offshore Sakhalin 29

Free Gas in Gas Hydrate Stability Zone-Data

from Okhotsk Sea $\quad 30$ 
Russia-Japan $\quad 30$

$\begin{array}{ll}\text { Russia-India } & 31\end{array}$

Russia-Spain $\quad 32$

Geographical Areas of Interest 33

West Siberia $\quad 33$

Bering Sea $\quad 34$

Laptev Sea $\quad 35$

Gas Hydrates Research in the Black Sea 36

Lake Baikal $\quad 36$

Who Work On Gas Hydrates in Russia 37

SOUTH KOREA

$\begin{array}{ll}\text { Introduction } & 38\end{array}$

Organization of Public Science \& Technology in South Korea 38

South Korean Organizations Involved in Gas Hydrate Research 40

South Korean Gas Hydrate Research Program 42

International Cooperative Research Projects 44

INDIA $\quad 45$

Introduction 45

Gas Hydrate ResearchProgram 45

International Cooperative Research Projects 47

CHINA

MINOR PLAYERS

Research in Taiwan

Research in Spain

Research in Nigeria $\quad 54$

Research in Chile

Research in Colombia

Research in New Zealand

Research in Peru

RECENT CORPORATE/JOINT-PROJECTS

Japanese Companies Involved in Gas Hydrates Research 57

Preliminary Results from the Chevron-Texaco Gulf of Mexico

Gas Hydrates Joint Industrial Project (JIP): Hydrocarbon

Gases in Sediments 
BP Drills Alaska North Slope Gas Hydrate Test Well

to Assess Potential Energy Resource

Findings from the 2005 Drilling Campaign of the Gulf of

Mexico Gas Hydrates Joint Industry Project

59

Comparison of Drilling Results to Pre-Drill estimates of

Gas Hydrate Occurrence in 'Mount Elbert' Test Site in

Alaska North Slope

60

MMS Releases Preliminary Results of Gulf of Mexico

In-Place Natural Gas Hydrate Assessment

60

Analysis of Pressure Test Data from the 'Mount Elbert' Gas

Hydrates Well

61

Acoustic Imaging of Gas Hydrate and Free Gas at the

Storegga Slide

62

DOE-Sponsored Beaufort Sea Climate Studies

62

Brief Review of Gas Hydrate Research by USA Agencies and

Companies

63

SUMMARY

64

CONCLUSIONS

69

ACKNOWLEDMENTS

REFERENCES

71 


\section{GAS HYDRATES RESEARCH PROGRAMS: AN INTERNATIONAL REVIEW}

\section{EXECUTIVE SUMMARY}

Gas hydrates are solid, ice like substances containing molecules of methane bound in a lattice of water molecules. Gas hydrates occur naturally in areas of the world where methane and water occur together under the appropriate conditions of low temperature and high pressure. These conditions are found in Arctic regions and in deepwater basins adjacent to continental shelves, including the Gulf of Mexico, the North Sea, West Africa, and other places.

Gas hydrates are a potentially enormous source of natural gas. Although the technology needed for accurate estimation of the resource is not yet fully developed, significant progress has been made over the past years in narrowing the range of values. Current estimates range from 100,000 to 700,000 trillion cubic feet (Tcf) worldwide, including 200 to 2,000 Tcf in the Gulf of Mexico and 500 to 700 Tcf in Northern Alaska.

The main objective of this proposal is the critical review of gas hydrates programs throughout the world, especially outside North America. Relevant information has been collected, classified and critically reviewed. The goals, achievements, funding, and possible future directions of these research programs have also been determined. Careful analysis of the literature has led to preparation of a detailed report of the past and present activities of the different international gas hydrates research programs. The list of all the collected references during the project duration has been recorded in a computer database on gas hydrate research programs classified by subject, country and authors.

This study concluded that Russia, through the late Soviet Union, conducted the most important work from the historical point of view. There has a disruption of these efforts after the breakup of the Soviet Union. However, some recovery has occurred recently. Research in the Canadian Arctic has also a long story of significant accomplishments. Currently, Japan has the most advanced research program with well set goals and adequate infrastructure to develop the resource once adequate exploitation processes are available. Several countries, India, South Korea, China, among others, have started recently important projects with the goal of developing the resource. The United States, while not formally included in this study, has also a long history of achievements in this area and shows increased interest on this type of research.

The long trajectory of the Deep Sea Drilling Project (DSDP) and successive programs of geophysical exploration throughout the world oceans has also made a significant contribution to the development of knowledge in the gas hydrate area.

One important feature in almost all the gas hydrates research projects is the willingness of different international research organizations to team up together in large consortia. These endeavors even include active industry participation. Important 
advances have been achieved in this way and significant breakthroughs are expected from this particular research approach.

Several industrial companies have shown interest on this research area for a long time. They have participated singly, and with other partners, in many important projects throughout the world. Significant expertise has been developed through these partnerships.

Formation of adequate human resources on scientific areas has also been an important goal of this project. Several graduate and undergraduate students have participated of different activities related to the project. They have acquired valuable experience on the subject area.

Research described in this proposal was performed jointly by Prairie View A\&M University, a Historically Black College and University, and Texas A\&M University, a majority school, through a subcontract. This collaboration has exposed the minority institution students to work at a world-class institution using state of the art research techniques. 


\section{GAS HYDRATES RESEARCH PROGRAMS: AN INTERNATIONAL REVIEW}

\section{TECHNICAL REPORT}

\section{INTRODUCTION}

Gas hydrates are naturally occurring crystalline substances composed of water and gas, in which a solid water-lattice accommodates gas molecules in a cage-like structure, or clathrate. Gas hydrates are widespread in permafrost regions and beneath the sea in sediments of outer continental margins. While methane, propane, and other gases can be included in the clathrate structure, methane hydrates appear to be the most common ${ }^{1}$. The amount of methane sequestered in gas hydrates is enormous, but estimates of the amounts are speculative and range over three orders-of-magnitude from about 100,000 to a maximum of 270,000,000 trillion cubic feet ${ }^{2}$. Per unit volume, gas hydrates contain a tremendous amount of gas. For example, $1 \mathrm{~m}^{3}$ of hydrate disassociates at atmospheric temperature and pressure to form $164 \mathrm{~m}^{3}$ of natural gas $+0.8 \mathrm{~m}^{3}$ of water ${ }^{3}$. It is likely that the amount of gas in the hydrate reservoirs of the world greatly exceeds the volume of known conventional gas reserves.

Gas hydrates are stable only under specific pressure-temperature conditions. Under the appropriate pressure, they can exist at temperatures significantly above the freezing point of water. The maximum temperature at which gas hydrate can exist depends on pressure and gas composition. For example, methane plus water at 600 psia forms hydrate at $41^{\circ} \mathrm{F}$, while at the same pressure, methane $+1 \%$ propane forms a gas hydrate at $49^{\circ} \mathrm{F}$. Hydrate stability can also be influence by other factors, such as salinity ${ }^{4}$

Under appropriate conditions of temperature and pressure, gas hydrates usually form one of two basic crystal structures known as Structure I and Structure II. Each unit cell of Structure I gas hydrate consists of 46 water molecules that form two small dodecahedral voids and six large tetradecahedral voids. Structure I gas hydrates can only hold small gas molecules such as methane and ethane, with molecular diameters not exceeding 5.2 angstroms. The unit cell of Structure II gas hydrate consists of 16 small dodecahedral and 8 large hexakaidecahedral voids formed by 136 water molecules. Structure II gas hydrates may contain gases with molecular dimensions in the range of 5.9 to 6.9 angstroms, such as propane and isobutene ${ }^{5}$.

On a macroscopic level, many of the gas hydrate mechanical properties resemble those of ice, because hydrates contain a minimum of 85 percent water on a molecular basis. Of interest are the phase-equilibrium properties of gas hydrates, which are mostly controlled by the fit of the guest gas molecules within the hydrate water cages. For a complete description of the structure and properties of hydrates see the summary by Sloan ${ }^{6}$.

Gas hydrate samples have currently been recovered from 19 or more areas worldwide and are believed to occur at about 77 locations including Antarctica and Siberia 
$\left(\right.$ Kvenvolden and Lorenson ${ }^{7}$ ). In general, gas hydrates are found in marine shelf sediments and on-shore polar regions beneath the permafrost because in these two types of settings the pressure-temperature conditions are within the hydrate stability field (Lerche and Bagirov ${ }^{8}$ ). Offshore hydrate-bearing sediments have generally been found in waters deeper than $300 \mathrm{~m}$; their zone of existence is from the seafloor to a depth of a few hundred meters, depending upon the local thermal gradient. Enormous amounts of methane are believed to be trapped by hydrates, both in the hydrate crystal structure itself and also in sediments beneath hydrate deposits ${ }^{9}$. The physical properties of gas hydrates trapped in sediments are very important in detecting the presence of these compounds, estimating the amount of gas hydrates trapped in the sediments, and developing processes to exploit this resource. Unfortunately, little is known about the physical properties of natural gas hydrate deposits in nature, making their detection by remote geophysical surveys difficult. The presence of gas hydrates in marine sediments dramatically alters some of the normal physical properties of the sediment, which can be detected by field measurements and by downhole $\log s^{10}$.

Recently, Gabitto and Tsouris ${ }^{11}$ reviewed some of the efforts made to determine physical property values for sediments partially, or completely, filled with gas hydrates. The authors reviewed literature information related to detection methods, morphology, and relevant physical properties of gas-hydrate-bearing sediments.

The presence of gas hydrates in offshore continental margins has been inferred mainly from seismic processing techniques. Seismic image processing visualizes the subsurface structure by means of reflected acoustic signals. The seafloor signal is marked by a white/black reflection, which means that the subsurface volume is harder than the volume above. In acoustic terms, the acoustic impedance (the product of medium density and speed of sound) below the seafloor in the sediment is higher than the impedance of the water column. In contrast, the bottom-simulating reflector (BSR) is marked by a black/white reflection indicating possibly high hydrate impedance above gas-filled sediments with low impedance. As the resolution of the seismic image is limited by the seismic source bandwidth and as the physical parameters describing the seismic subsurface response are frequency dependent, multiple surveys with different acquisition parameters are needed to obtain a more complete knowledge of the sediment parameters $^{12}$.

Gas hydrates are important due to four factors:

1. Gas hydrates are a potentially abundant energy resource. Considering the planet as a whole, the quantity of natural gas in sedimentary gas hydrates greatly exceeds the conventional natural gas resources ${ }^{3}$. A variety of different mechanisms have been proposed for economically developing gas hydrates as an unconventional gas source (e.g., see discussions in Goel et al. ${ }^{13}, 2001$, Sawyer et al. ${ }^{14}, 2000$, among others). Thus far, the only method that has been successfully used to economically produce gas from gas hydrates is the "depressurization method". This method is applicable only to hydrates that exist in polar regions beneath permafrost. 
2. The role of gas hydrates in real and potential climate changes. Gas hydrates in continental shelf sediments can become unstable either as a result of warming bottom water, or as a result of a pressure drop due to a reduction in sea level (such as during an ice age). If these marine gas hydrates begin to rapidly disassociate into gas + water, then the methane trapped in the gas hydrates can be released to the atmosphere. Methane is a greenhouse gas. In fact, methane is many times more effective as a greenhouse gas than is $\mathrm{CO}_{2}$. Therefore, methane can cause global warming.

3. Production (transportation) problems. Gas hydrates can spontaneously form in petroleum production equipment and pipelines associated with deep-water petroleum production, and arctic on-shore petroleum production. These unwanted hydrates can clog equipment, preventing the optimum production of hydrocarbons.

4. Utilization of gas hydrates in other potential roles. Carbon dioxide and methane can produce a mixed hydrate due to their similar molecular size and cage structure. Furthermore, $\mathrm{CO}_{2}$ presence has been detected in samples of natural gas hydrates obtained from the seafloor (Booth et al. ${ }^{15}$ ). Ohgaki et al. ${ }^{16}$ proposed to combine carbon dioxide storage with methane exploitation. In Ohgaki et al. ${ }^{16}$ process the $\mathrm{CO}_{2}$ is poured into the natural gas hydrate field and it reacts with water to form $\mathrm{CO}_{2}$ hydrate. The heat generated by $\mathrm{CO}_{2}$ hydration supplies adequate heat to decompose the methane hydrate. Ohgaki et al. ${ }^{17}$ reported the phase equilibrium of the $\mathrm{CO}_{2}-\mathrm{CH}_{4}$ mixed hydrate. It was found that the molar fraction of $\mathrm{CO}_{2}$ in the mixed hydrate phase is considerably larger that that of the gas hydrate phase under equilibrium conditions. Gabitto and Tsouris ${ }^{18}$ have suggested the possibility of storing hydrogen as the host gas trapped in hydrate compounds. At high pressures, above $200 \mathrm{MPa}$, and low temperatures, below $259 \mathrm{~K}$, hydrogen forms solid compounds with water known as hydrogen clathrates or more commonly hydrogen hydrates (Mao et al. ${ }^{19}$ ). The product of the reaction at the aforementioned temperature and pressure has been found to be stable under less severe conditions, therefore, creating the opportunity for storage using technically feasible technologies.

\section{Individual Gas Hydrates Research Programs}

\section{JAPAN}

\section{Introduction}

Methane hydrate is currently being eagerly examined in Japan as a next-generation energy resource to replace oil and natural gas. It is estimated that the methane hydrate reserves around Japan, a nation otherwise poor in energy resources, would be sufficient to last over 100 years, based on present levels of natural gas consumption ${ }^{20}$. 


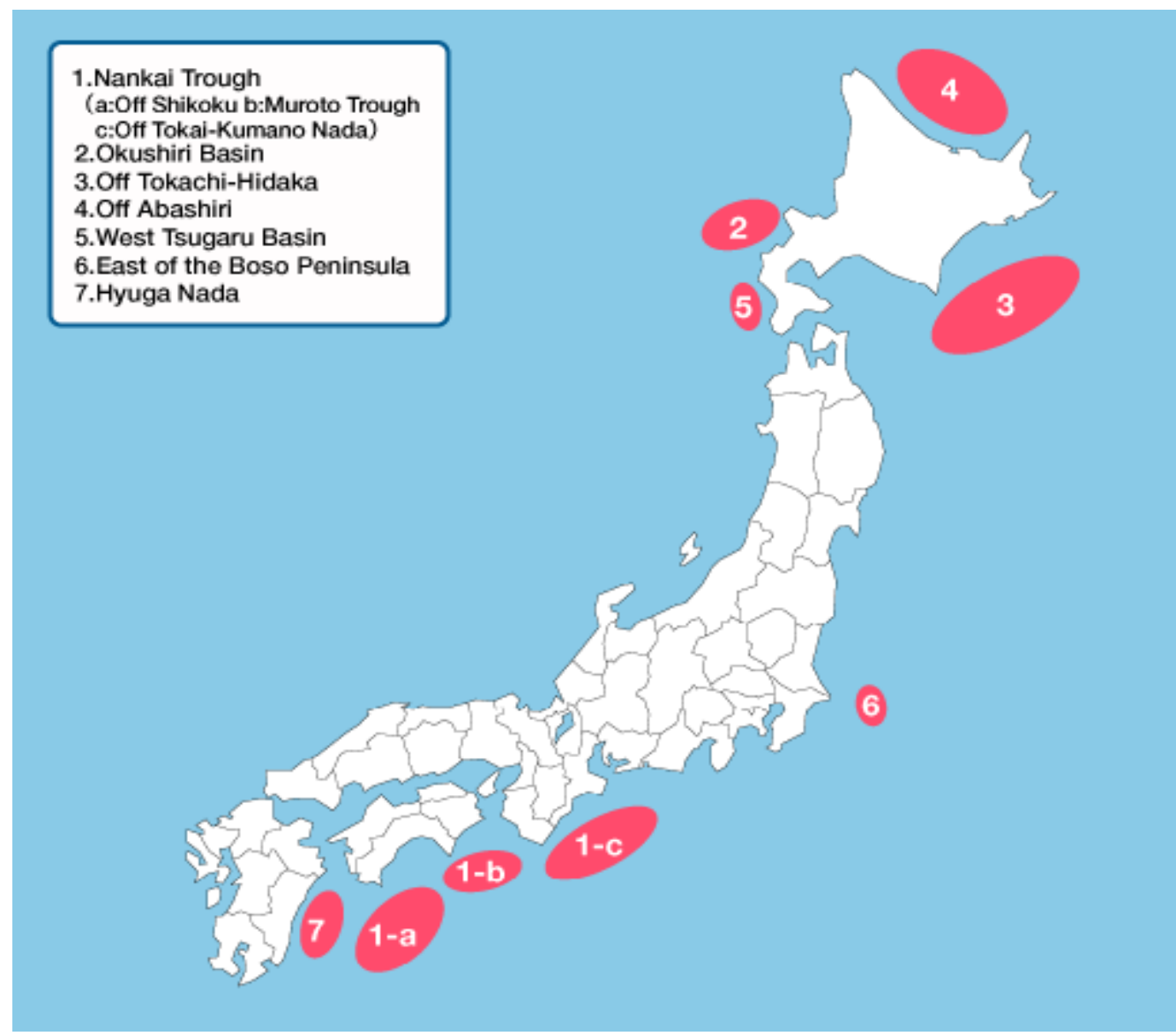

Figure 1. Gas hydrates areas around Japanese home islands (Ref. 20).

The Japanese research program in gas hydrates is currently the most advanced in the world $^{21}$. This program comprises strong basic and applied research components. The program includes scientific studies, exploration and production tests. Main domestic research activities are directed to the area around the Japanese home islands, especially the Nankai Trough area in the southern Sea of Japan. Japan participates in many international activities in cooperation with several nations within the framework of several international organizations ${ }^{22,23,24,25}$.

The gas hydrate research program is funded by an array of government and private organizations. The most important governmental institution is the Ministry of Economy, Trade and Industry (METI) ${ }^{26}$. Other important public organizations involved in gas hydrates research are, Japan Oil Gas and Metals National Corporation (JOGMEC), Geological Survey of Japan (GSJ), Japan Agency for Marine-Earth Science and Technology (JAMSTEC), National Institute for Resources and Environment (NIRE), among others.

The Japan National Oil Corporation (JNOC) in February 2004 was absorbed into the newly established Japan Oil, Gas and Metals National Corporation (JOGMEC) with the mission of securing a stable supply of oil, natural gas, nonferrous metals and minerals to Japan, and controlling pollution caused by metal mining activities. The corporation 
provides financial assistance to support Japanese private companies' exploration, production and stockpiling activities in the fields of oil, natural gas and metals, and assists pollution control activities for metal mining in Japan. The corporation also collects, analyzes and disseminates information about the global energy industry and natural resources to companies in Japan ${ }^{27}$.

JOGMEC conducts a wide range of activities inside and outside Japan in the oil field. Some of these activities include support to the oil industry in several countries all over the world, including Kuwait, Saudi Arabia, and Iraq, among others. The corporation also occupies a leadership position in gas hydrate exploration ${ }^{27}$.

Several private companies are also involved in gas hydrates research, for example: Teikoku Oil Co., Ltd. (TOC) has been a frequent partner in several government funded research projects ${ }^{28}$. Another important private company involved in gas hydrate research is the Japan Production and Exploration Company (JAPEX). JAPEX is a leading Japanese upstream company engaged in oil and natural gas E\&P activities both in Japan and overseas. Its main operating areas are Hokkaido, Akita, Yamagata and Niigata in Japan, and Canada, Indonesia, China, the Philippines, Libya, and other world regions ${ }^{29}$.

JAPEX was founded in December 1955 as a special purpose company through a government initiative and has continued to explore and produce oil and natural gas in Japan and expand its activities overseas. JAPEX was established in April 1970 as a private company under the former Commercial Code. JAPEX listed on the First Section of the Tokyo Stock Exchange in December 2003. JAPEX has been actively involved in the development of gas hydrate technology, playing a central role in joint research carried out between1995 and1999 with Japan National Oil Corporation (JNOC) and a number of private-sector companies. Later JNOC changed its name to Japan Oil, Gas and Metals National Corporation (JOGMEC). In fiscal 1999, JAPEX became the first company in Japan to successfully drill and core a methane hydrate layer in domestic waters. In 2001, the company began full-scale joint research into possible uses for methane hydrate with a number of public and private agencies. The research carried out includes the start of drilling and survey activities off the east coast of Japan's Tokai region in January 2004, with JAPEX selected as the operator. The company plans to play a leadership role in research and development into methane hydrates in Japan ${ }^{29}$.

\section{Japan $R \& D$}

In 1997, the public and private sectors in Japan invested $\$ 90.3$ billion in R\&D. Japan is the second largest supporter of R\&D after the United States. A very large percentage (79.4\%) of all R\&D in Japan is supported by the private sector. The prolonged economic recession that has plagued the Japanese economy for most of the 1990s has significantly reduced the scale of the Japanese R\&D effort compared to what it would have been had the economy been more robust. The Japanese government has recently attempted to bring the economy out of this recession through the use of economic stimulus packages. These stimulus packages have contained significant new funding for $R \& D$, although it is 
apparent that much of the funding is going to $R \& D$ programs and $R \& D$ construction projects with very near term payoff and not to the support of longer term $R \& D^{30}$.

In 1998, the Japanese government devoted 13.7\% of all public R\&D funds to the support of energy R\&D. The priority accorded to energy R\&D in Japan is significantly higher than in any other industrialized nation. The Japanese energy R\&D program, which was funded at $\$ 2.5$ billion in 1997, is overwhelmingly focused on nuclear energy R\&D. Nuclear energy R\&D (fission and fusion) accounts for $75 \%$ of the total national energy R\&D budget. The fission energy R\&D effort has decreased nearly 24\% since 1996 as the government attempts to refocus this program in the face of growing public opposition to the Japanese government's efforts to expand the nuclear power program. Energy efficiency $\mathrm{R} \& \mathrm{D}$ ( $8 \%$ of the total national energy $\mathrm{R} \& \mathrm{D}$ budget) and renewable energy R\&D (3\%) receive relatively modest support from the Japanese government ${ }^{30}$.

In $199975 \%$ of the R\&D funding effort was dedicated to nuclear energy while only $8 \%$ of all R\&D was dedicated to energy efficiency and only $3 \%$ to renewable energy sources. A status of the energy R\&D research in Japan during the late 1990s is attached below $^{30}$.

In the early 2000s significant changes occurred. These changes were produced by the prolong recession affecting the Japanese economy during the 1990s. The focus on the energy R\&D effort went into supporting basic research in public universities and research centers through block-grants while most of the applied energy research was left to private industry. These changes in focus were also accompanied by reorganization of several governmental agencies. The ministry of International Trade and Industry (MITI) founded in 1951 was reorganized to the Ministry of Economy, Trade and Industry (METI). Several other organizations were reorganized and even closed $^{30}$.

\section{Gas Hydrate R\&D}

In the year 1997 the Japanese government invested \$4.1 - \$4.7 million ( $¥ 727$ - ¥827 million) in gas hydrates research. The Japanese government believes that economical develop of the methane hydrate accumulations known to exist in marine sediments around Japan would give Japan approximately 100 years gas consumption at current rates ${ }^{1}$. JNOC funded applied research relating to methane hydrate production, including the drilling of a test well in the Canadian permafrost region in the Mackenzie Delta in order to develop and validate proposed production methods. JNOC, in cooperation with the Geological Survey of Japan $(\mathrm{GSJ})^{31}$, was also responsible for identifying and mapping the methane hydrate resource off the Japanese coast ${ }^{32,33}$ NIRE $^{34}$, the GSJ, and the Hokkaido National Industrial Research Institute (which received its funding through the Sunshine Program ${ }^{35}$ ) was funding in 1997 most basic and laboratory-based methane hydrate research. NIRE's research was focused on laying the foundations for new mining methods for methane hydrates, including research on "a process control system of formation and dissociation of methane hydrates, fluid flow dynamics of dissociated gas and water in marine sediment, and disposal of $\mathrm{CO}_{2}$ by its substitution into methane hydrates." NIRE was also at the time funding research to determine the origins of 
methane hydrates and the environmental impacts that might be associated with mining methane hydrates ${ }^{35}$.

In order to advance into gas hydrates production METI established in the early 2000s an Advisory Committee for National Methane Hydrate Exploitation Program, led by Tokyo University Professor Emeritus Shoichi Tanaka. This committee has prepared a long-term research program entitled "National Methane Hydrate R\&D Program ${ }^{20}$." This program, presented in July 2001, is divided into three phases, extending over 16 years (2001-2016). The Research Consortium for Methane Hydrate Resources in Japan (also known as the MH21 Research Consortium) was established to undertake research in accordance with this $\operatorname{plan}^{20}$. More information on this program is provided below.

\section{International Cooperative Projects}

Japanese scientists have been involved in several international projects. There has been a strong Japanese presence in the exploration of the Canadian Arctic. Earlier research work by the Geological Survey of Canada and other organizations led to a much larger effort in drilling on the Mackenzie Delta of the first arctic research well specifically for gas hydrate research. The well was an effort by a consortium including the Japan National Oil Corporation (JNOC), the Geological Survey of Canada, and principal collaborators, the Japan Petroleum Exploration Company (JAPEX) and the U.S. Geological Survey ${ }^{24}$. A detailed description of these efforts is included on the description of the Canadian gas hydrates program.

The Kitami Institute of Technology (KIT, Japan) organized in 2003 a cooperative project, CHAOS (Hydro-Carbon Hydrate Accumulations in the Okhotsk Sea $)^{36}$. The participants were the All-Russia Research Institute for Geology and Mineral Resources of the World Ocean (Russia), V. I. Il'ichev Pacific Oceanographic Institute FEB RAS (Russia), Korea Polar research Institute (Korea), IFM-GEOMAR (Germany), Limnological Institute SB TAS (Russia), and Renard Center of Marine Geology (Belgium), besides KIT, with the aim of study natural gas hydrates deposits in the Okhotsk Sea ${ }^{22}$.

The Nankai trough was studied during the research cruises, 'legs', 31 and 87 of the Deep Sea Drilling Project (DSDP) ${ }^{37}$. Later Japan became a member of the Ocean Drilling Program (ODP). The program was funded by the US National Science Foundation and 22 international partners and was directed by the international Earth science community (JOIDES). Joint Oceanographic Institutions, Inc. (JOI) served as the Program Manager. Texas A\&M University, College of Geosciences was the Science Operator and Lamont-Doherty Earth Observatory of Columbia University provided Logging Services and administered the Site Survey Data Bank ${ }^{38}$. The program conducted 111 research cruises, called 'legs', from 1983 until 2003 ${ }^{38}$. Legs 131, 190 and 196 conducted exploration in the Nankai trough area".

During Leg 131 (March 1990), one site (Site 808) was drilled to study the interplay of the various parameters that influence structural evolution of accretionary prisms with 
special emphasis on hydrogeology. Gas hydrates samples were obtained from well $808^{40}$. Leg 190 (2000) was the first of a two-legs program designed to sample a transect of sites across the Nankai Trough accretionary prism (SW Japan) within a three-dimensional (3D) seismic survey. One additional site was drilled to the west of the main transect to compare along-strike variations in accretionary processes. The main logging effort of this program took place on Leg 196 in 2001 using logging-while-drilling (LWD) technology to collect further in situ physical properties data at most of the same sites ${ }^{41}$.

After 2003 Japan became a member of the Integrated Ocean Drilling Program (IODP). This program is an international research effort that explores the history and structure of the earth as recorded in seafloor sediments and rocks. IODP builds upon the earlier successes of the Deep Sea Drilling Project (DSDP) and the Ocean Drilling Program (ODP), which revolutionized our view of Earth history and global processes through ocean basin exploration. IODP represents the latest generation of these highly successful scientific ocean-drilling initiatives and seeks to greatly expand the reach of these previous programs by forming a collaborative union between the United States, Japan, and the European Union, each of whom will be responsible for providing drilling platforms appropriate for achieving the scientific objectives outlined in the IODP Initial Science Plan. Within the structure of the IODP, the United States is responsible for operating the riser-less drilling vessel JOIDES Resolution, Japan the riser drilling vessel Chikyu, and the European Union mission-specific platforms capable of drilling in environments unsuitable for either the riser-less or riser vessels ${ }^{42}$.

There have been other international research endeavors such as the geophysical survey of the Ontong Java Plateau (OJP) during February 1998 by scientists from Japan, the United States, Norway and Poland led by A. Taira aboard the University of Tokyo's R/V Hakuho Maru. The expedition had several objectives, the most interesting to ODP scientists involved to obtain seismic data to support proposed ODP drilling in the Indian and Pacific Oceans ${ }^{31}$.

French researchers used high-resolution 2-D seismic data that were collected on the eastern Nankai Trough slope, during the French-Japanese Seize program (SFJ) cruise in year 2000 and AVA analyses of the enigmatic reflectors to conclude that high amplitude anomalies above the BSR delineate the top of gas hydrate rich sediments. They also conclude that several tens $\%$ of the sediment porosity would be filled with gas hydrates between the BSR and a sharp boundary 30 to $60 \mathrm{~m}$ above ${ }^{23}$.

JOGMEC is a member of the Chevron lead Joint Industry Project (JIP) in association with the US DOE and several partners listed below ${ }^{43}$. Chevron formed a Joint Industry Project (JIP) to conduct research concerning natural gas hydrate deposits in the deepwater portion of the Gulf of Mexico. A proposal was submitted to NETL on April 24, 2001. Chevron was awarded the contract on the basis of the proposal entitled "Characterizing Natural Gas hydrates in the Deep Water Gulf of Mexico- Applications for Safe Exploration". The list below indicates the original participants and the tasks assignment for the members of the joint Industry project (JIP): 
Chevron Energy Technology Company

Schlumberger oilfield Services

Halliburton Energy Services

Conoco Phillips Inc.

Total

JOGMEC (Japan)

Reliance Industries ltd.

Statoil Hydro

TAMU

Korean national Oil Co (KNOC)

Minerals Management Service

Scripp Institute of Oceanography

Naval Research Lab

US Geological Survey

Georgia Tech.

AOA Geophysics

Aumann \& Associates

Rice University
JIP partner, overall project management, drilling and coring team leader.

JIP member, Technology transfer team leader

JIP member

JIP member, Hydrate

characterization team leader

JIP member

JIP member

JIP member

JIP member

JIP member

JIP member

non-cost JIP member, Seafloor

stability team leader

Science leader

Pre-cruise site geochemical and thermal investigation

Several contributions to the science program

Pre-cruise lab. Studies, development of new ship-based sampling equipment

contribution to seismic evaluation and field selection and characterization pressure coring tool evaluation and design

Geologic modeling

More information on the series of projects undertaken by this global research effort is included in the corporate activities section.

Multidisciplinary field investigations were carried out in Okhotsk Sea by $R / V$ Akademik M.A. Lavrentyev (LV) of the Russian Academy of Sciences (RAS) in May 2006, supported by funding agencies from Korea, Russia, Japan and China. Geophysical data including echo-sounder, bottom profile, side-scan-sonar, and gravity core sample were obtained to understand the characteristics and formation mechanism of shallow gas 
hydrates. Based on the geophysical data, it was found that the methane flare detected by echo-sounder was the evidence of free gas in the sediment, while the dome structure detected by side-scan sonar and bottom profile was the root of gas venting. Gas hydrate retrieved from cores on top of the dome structure was found as thin laminations or lenses with thickness varying from a few millimeters to $3 \mathrm{~cm}$. Gas hydrate content in hydratebearing intervals visually amounted to $5 \%$ to $30 \%$ of the sediment volume ${ }^{44}$.

Recently, production tests have been conducted at the Mallik site in the Mackenzie Delta, Canadian Artic. Researchers have successfully extracted methane gas from frozen gas hydrates found beneath hundreds of meters of permafrost $\mathrm{t}^{20}$. The project was jointly funded by the governments of Canada and Japan. Natural Resources Canada and the Japan Oil, Gas and Metals National Corporation worked in partnership with help from the Aurora Research Institute in Inuvik (Canada) acting as the operator for the project ${ }^{45}$.

Following the work done in 2002, Japanese and Canadian researchers united in the town of Inuvik, to start a new phase of gas hydrate research. This time, the goal was to undertake a longer test and advance new research and development studies utilizing a simple depressurization technique. The two-winter research program was successfully completed in April 2008 $8^{46}$.

The Japanese and Canadian parts agreed to adopt a simple depressurization technique as the gas hydrate production method to simplify the operational conditions of the test and to minimize unknown variables. The field scale verification of the technique was defined as the prime objective of the project ${ }^{47}$. In January 2007, an ice road was built on the Mackenzie River and Beaufort Sea to connect Inuvik with the Mallik site, and allow mobilization of drilling rigs and other equipment. The project was carried out after more than a year of planning by a team of scientists and engineers who designed the gas production procedure and necessary downhole and surface equipment for the test.

Field operations during the first year winter (2007) focused on installing infrastructure and undertaking a short production test. A well drilled for a 1998 research program (Japex/JNOC/GSC Mallik 2L-38) was modified to establish a production test well by reaming, casing, and cementing. The production test operation started on April 2. The test zone, a $12 \mathrm{~m}$-thick interval near the bottom of the gas hydrate occurrence zone (GHOZ), was selected based on the logging data. Pressure and temperature conditions of the zone were considered most suitable for the depressurization method, with petrophysical conditions including fairly high gas hydrate saturation and relatively high permeabilities. An electrical submersible pump (ESP) was set below the perforation zone to depressurize the formation by dropping the water level of the well. The well was designed to enable all produced water to be injected into aquifers below the $\mathrm{GHOZ}^{46}$.

Sand production (flow of formation sand to the borehole mixed with fluid) prevented continuous pumping, and the operation was terminated 60 hours after the start of pumping. However, during the most successful 12.5 hours of the test, at least $830 \mathrm{~m}^{3}$ of gas were produced and accumulated in the borehole. 
In winter 2008 field activities were undertaken to achieve longer term gas hydrate production by implementing countermeasures to overcome the problems encountered in 2007. After ice road and site construction, the Mallik 2L-38 production test well was reentered, and a modified pumping system was run into the hole including sand control devices. The pump operation started in the afternoon of March 10 and continued until the preset test termination time of 12 noon on March 16. Six days of continuous pump operation established stable pressure conditions at the bottom of the hole. Stable gas flow was measured at the surface with a sustained gas flare from the hydrate dissociated gas. Pressure, temperature, and gas and liquid flow rate data were measured at the bottom of the hole and at the surface. Gas, liquid, and solid samples were collected. After the test, the production well was abandoned and all equipment was demobilized by early April ${ }^{46}$.

The 2008 testing program at Mallik confirmed that continuous gas flow ranging from 2000 to $4000 \mathrm{~m}^{3} /$ day was maintained throughout the course of the six-day (139-hour) test. Cumulative gas production volume was approximately $13,000 \mathrm{~m}^{3}$. Initial data confirmed that the depressurization method is the correct approach. Japanese and Canadian research teams will analyze the data and publish scientific and technical papers internationally. The gas rate prediction by the MH21-HYDRES gas hydrate reservoir simulation $^{48}$ matches well with the observed values. By analyzing the data of the production test it is expected to make additional improvements in the model.

In Lake Baikal shallow fresh water gas hydrates have already been identified in six mud volcano/seep structures through joint Russian, Japanese and Belgian research. These mud volcano/seep structures are found at different water depths (from $1380 \mathrm{~m}$ to as shallow as $440 \mathrm{~m}$ ) and contain shallow hydrates of both structure I and II. Bottom Simulating Reflectors (BSRs), indicative for the presence of deep-seated hydrates, has been observed on nearby seismic profiles ${ }^{49}$.

A production test of shallow gas hydrate in Lake Baikal is planed in cooperation with Japanese and Russian parties. The aim of this project is to develop technologies for recovering gas hydrate from the near surface sediments in the bottom of Lake Baikal, with the goal of establishing environmentally friendly and economical natural gas production technologies from gas hydrate layers 49 .

On June 6, 2008, US Secretary of Energy Samuel Bodman and Japanese Minister of Economy, Trade and Industry, Akira Amari, signed a Statement of Intent for cooperation in methane hydrate research and development. Japan has an active methane hydrate $\mathrm{R} \& \mathrm{D}$ program that has resulted in the discovery of large offshore hydrate deposits and successful short-term production testing in the Canadian $\operatorname{arctic}^{50}$.

\section{Japan's National Methane Hydrate R\&D Program}

Methane hydrate is currently being eagerly examined as a next-generation energy resource to replace oil and natural gas. It is estimated that the methane hydrate reserves around Japan, a nation otherwise poor in energy resources, would be sufficient to last over 100 years, based on present levels of natural gas consumption. To develop this new, 
unfamiliar resource, the Advisory Committee for National Methane Hydrate Exploitation Program, an investigative committee established within the Ministry of Economy, Trade and Industry and led by Tokyo University Professor Emeritus Shoichi Tanaka, has prepared Japan's National Methane Hydrate R\&D Program.

The Research Consortium for Methane Hydrate Resources in Japan (also known as the MH21 Research Consortium) was established to undertake research in accordance with this plan.

The Japan's National Methane Hydrate R\&D Program is intended to promote technical development for economical drilling, production and recovery of methane hydrate, and to facilitate its utilization and contribution to the long-term stable energy supply. The project defines methane hydrate as a future energy resource that is expected to exist in large amounts offshore around Japan.

The goals outlined in the "Japan's National Methane Hydrate R\&D Program are:

1. Understand the conditions and features of methane hydrate existing offshore around Japan.

2. Estimate the amount of methane gas in the hydrated area.

3. Select methane hydrate resource fields from the potential sea areas and study their economic feasibility.

4. Implement methane hydrate production tests in the selected resource fields.

5. Develop technologies for commercial production.

6. Establish the exploitation system considering environmental preservation.

Japan's National Methane Hydrate R\&D Program is divided into three phases, extending over 16 years. These phases are:

\section{Phase I (fiscal 2001-2008)}

Development of basic research technologies (survey techniques, fundamental physical properties, dissociation/generation technology, etc.) to:

- Optimize methane hydrate research technologies.

- Identify potential methane hydrate fields in sea areas and evaluate its resources.

- Select methane hydrate resource field for offshore production test in Phase II.

- Through on-shore production test, to verify the technology that allows dissociating methane hydrate and recovering methane gas at wellhead.

\section{Phase II (fiscal 2009-2011)}

Development of basic research technologies (production technologies, environmental impact assessment, etc.) to:

- Evaluate methane hydrate resources in the selected hydrate fields. 
- Implement offshore production test in the sea off Japan and verify production techniques.

\section{Phase III (fiscal 2012-2016)}

Develop the technologies for commercial production and evaluate economic feasibility, environmental impact, etc.

The MH21 Research Consortium was established to oversee the completion of Phase I of the Basic Policy. Led by the Project Leader Shoichi Tanaka, Tokyo University Professor Emeritus, MH21 is organized into three main groups: the Japan Oil, Gas and Metals National Corporation (JOGMEC), the National Institute of Advanced Industrial Science and Technology (AIST), and the Engineering Advancement Association of Japan (ENAA). A Steering Committee was established to oversee the operation of the three groups.

The initial activities of this research plan included the $1^{\text {st }}$ on-shore production test executed at the Mallik field in the Canadian Arctic in 2001-2002 funded by a consortium from Canada, USA, Germany, India and Japan. Methane gas was successfully produced by the hot fluid circulation method producing methane hydrate dissociation underneath the permafrost zone. It also tested depressurized methods for methane hydrates dissociation $^{51}$.

\section{Nankai Trough}

The Nankai Trough is a submarine trough located south of Japan's island of Honshu, extending approximately $900 \mathrm{~km}$ offshore. The Nankai Trough limits a subduction zone caused by movement of the Philippine Sea Plate beneath Japan, a part of the Eurasian plate $^{52}$. The Nankai Trough is the topographic expression of the subduction boundary between the Shikoku Basin and the Southwest Japan Arc (Fig. 1). The Shikoku Basin is part of the Philippine Sea plate, which is moving to the northwest under Japan at a rate of $2-4 \mathrm{~cm} / \mathrm{yr}^{41}$, approximately normal to the plate margin. Active sediment accretion is presently taking place at the Nankai Trough. The record of accretion extends landward to Shikoku Island, where older accretionary prism rocks are exposed. This plate boundary would be an oceanic trench, except for a high flux of sediments that fills the trench. Within the Nankai Trough there is a large amount of deformed trench sediments ${ }^{53}$, making one of Earth's best examples of accretionary prism.

The Nankai trough has been studied by several marine research expeditions called 'legs' during a long period of time. These studies have produced a big amount of scientific data. International expeditions or 'legs' 31 and 87 of the Deep Sea Drilling Project (DSDP) ${ }^{37}$, Legs 131, 190 and 196 of the Ocean Drilling Program (ODP) ${ }^{38}$, and the 2004 multi-well exploration campaign organized by the MH21 Research Consortium $^{54}$.

Abundant presence of gas hydrates has been inferred from Bottom Simulated Reflector (BSR) analysis ${ }^{55,56}$ and determined by drilling ${ }^{57}$. It has been estimated that convergent margins may contain up to two-thirds of the total gas hydrate volume on the 
earth $^{58}$. The Nankai Trough has been described as containing a large amount of gas hydrates and is one of the best studied sites of gas hydrate formations ${ }^{59,60}$.

BSR signals have been widely studied offshore Japan by seismic survey indicating that the existence of large amounts of methane hydrates underneath the seafloor in the area $^{56}$. METI organized in 1995 a 5 years research plan to study the area. The resultant research program 'Nankai Trough' led to the drilling in the area of the first exploratory wells for methane hydrates in Japan ${ }^{57}$. The wells drilled at a water depth of $945 \mathrm{~m}$ established the presence of hydrate bearing formations at a depth range from 1135 to $1213 \mathrm{~m}$. Analyses of the samples taken during the research program produced many scientific data that proved without doubt the presence of a big accumulation of gas hydrates in the ocean floor. Core samples were recovered showing that methane hydrates fill in the porous space in sandy sediments ${ }^{57}$.

Building on the information produced by the first 5 years research plan METI decided in 2004 to conduct a multi-well exploration campaign in the Nankai Trough. It was organized by the Japan Oil Gas and Metals National Corporation (JOGMEC) in collaboration with Japan Petroleum Exploration Co. Ltd. (JAPEX) and Teikoku Oil Co. Ltd. (TOC) as drilling operators. All scheduled activities were performed by the deepwater research vessel 'JOIDES Resolution' operated by Transocean. Thirty wells were drilled mainly for geological research purposes while 2 wells were drilled for engineering purposes during this campaign ${ }^{53}$. The purpose of the experiments was to obtain engineering data and to verify technologies which could use in the future for production. The following experiments were carried out, 1) Testing of drilling fluids for borehole stability; 2) Monitoring of downhole pressures and temperatures during drilling; 3) Cementing; 4) Formation/Fracture pressure measurements; 5) Testing horizontal drilling of unconsolidated formations and hydrate layers in shallow sediments underneath seabed. This experimental program was carried out by Japan Drilling Co. Ltd. (JDC) under contract with JOGMEC for the planning and analysis of the field data, and by JAPEX for operation ${ }^{61}$.

Field results confirmed the stability of the selected drilling fluids. The especially designed slurry cement covered up successfully the hydrate formations. Useful pressure data were obtained at various points including hydrate formations by using a Cased Hole Dynamics Tester (CHDT) technique. A horizontal well was executed according to plan. The well path extended by $300 \mathrm{~m}$ across gas hydrate layers including a horizontal section of $100 \mathrm{~m}$ in length at $340 \mathrm{~m}$ below seabed ${ }^{61}$.

\section{CANADA}

\section{Introduction}

Field studies of natural gas hydrates have been carried out in Canada for many years by the Geological Survey of Canada and by a number of universities. The two largest field programs are: 
- Arctic permafrost-related hydrate studies, including the Mallik research drilling on the Mackenzie Delta and

- Geophysical studies and ODP drilling of marine gas hydrate beneath the continental slope off Canada's west coast.

\section{Research on the Canadian Arctic}

The Geological Survey of Canada and several universities have carried out studies of gas hydrate in the arctic for many years with application both to hazard in conventional exploration and for its role in climate change. Assessments of gas hydrate occurrence in the Mackenzie Delta-Beaufort Sea region have been made mainly on the basis of data obtained from hydrocarbon exploration wells. Indirect evidence includes well-log responses, steady buildup of shut-in pressure during production tests, and gas flows during drilling. Smith and Judge ${ }^{62}$ (1995) showed that $17 \%$ of 145 onshore wells in the Mackenzie Delta area showed evidence of gas hydrates. All of the occurrences were in the clastic sedimentary rocks of the Kugmallit, Mackenzie Bay, and Iperk sequences. Two occurrences were associated with ice-bearing permafrost; the remainder was located beneath the permafrost interval. The frequency of gas hydrate presence in offshore wells was significant, $63 \%$ of 55 wells. Smith and Judge (1995) estimated that the Mackenzie Delta-Beaufort Sea region might contain 16 trillion $\mathrm{m}^{3}$ of natural gas in hydrate form ${ }^{62}$.

The earlier arctic hydrate work led to a much larger effort in drilling on the Mackenzie Delta of the first arctic research well specifically for gas hydrate research. The well was an effort by a consortium including the Japan National Oil Corporation (JNOC), the Geological Survey of Canada, and principal collaborators, the Japan Petroleum Exploration Company (JAPEX) and the U.S. Geological Survey. The research well (JAPEX/JNOC/GSC Mallik 2L-38) was drilled to a depth of $1150 \mathrm{~m}$ on the north coast of the Mackenzie Delta near the site of an existing industry exploration well. Many of the results were published in a series of articles in the Geological Survey of Canada (GSC) Bulletin 544 (Dallimore et al. ${ }^{24}$, 1999). Scientific operations included permafrost and gas-hydrate bearing core samples, downhole geophysical logging, and in-hole vertical and offset seismic profile survey (VSP). Laboratory studies and modeling included, sedimentology, biostratigraphy, physical/petrophysical properties, pore-water and gas geochemistry, geophysics, and reservoir characteristics of the Mallik field gas hydrate accumulation ${ }^{24}$. The well delineated the most concentrated gas hydrate deposit presently identified, and recovered significant amounts of hydrate. The Mallik hydrate layers exceed $110 \mathrm{~m}$ in thickness, in some parts having $80 \%$ pore saturation by hydrate. The total amount of in-situ gas within the Mallik structure is estimated to be approximately 100 billion $\mathrm{m}^{3}$ (Hyndman and Dallimore ${ }^{63}$ ).

Three 1,200-m-deep wells - a main production research well and two nearby scientific observation wells - were drilled in 2002 in the Mackenzie Delta region of the Northwest Territories, Canada, to explore the presence of sub-permafrost gas hydrate ${ }^{63}$. The Mallik 2002 Gas Hydrate Production Research Well Program was one of the most 
complex, expensive, and daring undertakings to explore natural-gas hydrate in the natural setting.

The drilling project, involving more than 60 scientists and engineers and 250 support staff from six countries, overcame huge logistical problems compounded by the drill site's extremely remote location and harsh winter conditions, including temperatures below $-40^{\circ} \mathrm{C}$. The drill holes, spaced $40 \mathrm{~m}$ apart, were located in the Mallik gas-hydrate field next to the Beaufort Sea on the northern part of Richards Island, and were near the Mallik 2L-38 well drilled in 1998. All major equipment was delivered by way of a project ice road constructed on the frozen Mackenzie River.

Overall scientific leadership and responsibility were provided by Scott Dallimore (Geological Survey of Canada, Sidney, British Columbia), and the principal investigators were Tim Collett (USGS Energy Team, Denver, CO), Takashi Uchida (Japan Petroleum Exploration Co., Chiba, Japan), and Michael Weber (GeoForschungsZentrum, Potsdam, Germany). The Japan Petroleum Exploration Co. coordinated drilling activities. Other organizations involved in the project included Canada's University of Ottawa and University of Alberta; the United States' Department of Energy (DOE), Idaho National Environmental and Engineering Laboratory, Lamont-Doherty Earth Observatory, Pacific Northwest National Laboratory (PNNL), and Lawrence Berkeley National Laboratory; Japan's University of Tokyo and Japan National Oil Corp.; and India's Oil and Natural Gas Corp ${ }^{64}$.

The 2002 completed Mallik project consisted of several different phases. Drilling of the first observation well began on Christmas Day. One after the other, the two observation wells were drilled and instrumented with fiber-optic temperature sensors; then the main well was begun. The 640-m-deep permafrost section in the main well was drilled and cased before the start of continuous coring, which completely penetrated the gas-hydrate section between about $890-\mathrm{m}$ and 1,150-m depth. Because recovery of sediment cores containing gas hydrate was extremely good, more than 50 pressure vessels and four liquid-nitrogen dewar flasks were filled to capacity. Other aspects of the project consisted of well logging, downhole temperature profiling, microbiologic studies, seismic cross hole tomography (yielded information about sediment density and elastic properties), and the first intentional production tests of a gas-hydrate reservoir involving both pressure draw down and thermal stimulation. These last tests were conducted to determine the relation between pressure reduction and dissociation of in place gas hydrate, and to measure gas release for a given input of thermal energy.

Bill Winters (Woods Hole Field Center) was responsible for determining the physical properties of cored sediment and making infrared temperature measurements of freshly obtained sediment sections at the drill site. At the Inuvik Research Center ( 3 to 4 hours south of the drill site by ice road), Bill recorded time-lapse infrared imaging of dissociating gas hydrate, using a custom-made system supplied by Phil Long of the Pacific Northwest National Laboratory. 
The infrared temperature measurements were part of a pilot program involving Frank Rack of Joint Oceanographic Institutions (JOI) and Bill Gwilliam (DOE).

Gas-hydrate sediment sections were preserved in pressurized vessels for testing in the Gas Hydrate and Sediment Test Laboratory Instrument (GHASTLI) located at the Woods Hole Field Center. Other members of the Woods Hole gas-hydrate group include Debbie Hutchinson, Bill Dillon, Bill Waite, and Dave Mason.

Many of the samples were analyzed by Tom Lorenson and Keith Kvenvolden (USGS, Menlo Park). Steve Kirby, Laura Stern, Susan Circone, and John Pinkston (USGS, Menlo Park) used a scanning electron microscope to perform fabric analyses on the mixtures of gas hydrate and sediment, and they conducted dissociation tests on samples preserved in liquid nitrogen. Tom Mroz (DOE) and Pete McGrail (PNNL) determined the properties and dissociation characteristics of preserved sediment samples containing gas hydrate ${ }^{64}$.

Gas hydrates cores and associated sediments were obtained from a depth interval between 880-1150 meters. These cores have been the subject of intensive examination by members of the Mallik Partnership, including scientists and engineers enabled by the International Continental Drilling Program. Detailed information on the geology, geochemistry, geotechnical and microbiological properties of gas hydrate bearing sediments was completed by an extensive research geophysics program, which included both surface, and downhole studies. This body of scientific data plus a complementary production test program provided the world's most detailed scientific and engineering data set describing the occurrence and production characteristics of gas hydrates ${ }^{65}$. A brief description of the studies conducted is shown below.

Over $150 \mathrm{~m}$ of high quality gas hydrate cores were collected during the Mallik program allowing for a wide variety of studies that ranged from assessing the macroscopic to microscopic properties of the reservoir sediments. New work included investigations of the kinetics of gas hydrate dissociation from the solid to the gaseous form, studies of the petrophysical properties, investigations of the molecular chemistry and geotechnical properties such as compressive strengths and stress regime.

A wide range of geophysical studies was carried out to quantify gas hydrate distribution. A key aspect of the program was to test new geophysical tools. Fiber optics instrumentation documented the geothermal regime with meter-scale precision. Surface, downhole, cross-hole seismic and advanced well log studies were also carried out. Downhole geophysical measurements allowed for direct estimates of in-situ permeability, gas hydrate content and investigations of the occurrence of natural fractures.

One of the most important aspects of the project was the production study. Due to logistics and cost constraints a decision was taken by the partners to conduct short-term carefully controlled production experiments rather than long term production testing. The response of gas hydrates to heating and depressurization was evaluated with careful attention to accurately measure both input conditions and reservoir responses. The overall goal was to combine the science and production program to allow for calibration and 
refinement of reservoir simulation models capable of prediction long-term reservoir response $^{65}$.

\section{Depressurization Experiments}

The Mallik 2002 production research well program pressure draw down experiments were designed to study the response of gas hydrate to a reduction in formation pressure conditions. The results of three short duration gas hydrate tests demonstrate that gas can be produced from gas hydrates with different concentrations and characteristics, exclusively through pressure stimulation. The data supports the interpretation that gas hydrates are much more permeable and conducive to flow from pressure stimulation than previously thought. In one test the gas production rates were substantially enhanced by artificially fracturing the reservoir ${ }^{65}$.

\section{Thermal Heating Experiments}

The Mallik 2002 production research well program thermal heating experiments were designed to destabilize gas hydrates by thermal stimulation. A five-day experiment was undertaken within a 17-m-thick section of highly concentrated gas-hydrate-bearing strata. Gas was continuously produced throughout the test at varying rates with maximum flow rate reaching 1500 cubic meters per day. The total gas flowed was small reflecting that the test was a controlled production experiment rather than a long duration test well. A decrease in production rate at 52 hours into the test is interpreted as a formation event, which may be indicative of sudden loss of produced gas. Several lines of evidence suggested that natural and enhanced fractures may have been conduits for gas transmission with reservoir storage away from the well ${ }^{65}$.

The Geological Survey of Canada published the combined results of this research program in $2005^{66}$. The publication, GSC Bulletin 585, includes the 63 technical research papers and accompanying databases related to this study. Important new work and insight are presented on gas hydrate production testing. New studies are reported on in-situ physical and geophysical properties of gas hydrate, with complementary studies on an extensive coring program. New appraisals are presented on the relevance of gas hydrate to energy, climate, and geo-hazard research ${ }^{66}$.

In 2007 a new research effort at the Mallik site in the Mackenzie Delta successfully extracted methane gas from frozen gas hydrates found beneath hundreds of meters of permafrost $^{45}$. The project was jointly funded by the governments of Canada and Japan. Natural Resources Canada and the Japan Oil, Gas and Metals National Corporation worked in partnership with help from the Aurora Research Institute in Inuvik (Canada) acting as the operator for the project ${ }^{46}$.

Five years after the success of the world's first gas production from a methane hydrate reservoir at the JAPEX/GSC/JNOC et al. Mallik 5L-38 research well in the Mackenzie Delta, Northwest Territories, Canada, Japanese and Canadian researchers reunited in the town of Inuvik. The goal was to undertake a longer test and advance new 
research and development studies utilizing a simple depressurization technique. The twowinter research program was successfully completed in April $2008^{47}$.

\section{Research Offshore Western Canada}

Marine gas hydrate was first discovered beneath the continental slope off the west coast in conventional marine multi-channel seismic data acquired as part of the Geological Survey of Canada's Frontier Geoscience Program. This program involved surveys of the resources in the 200-mile zone off Canada's west coast following the Law of the Sea convention. Several additional multichannel surveys were acquired as part of a site survey for drilling by the international Ocean Drilling Program (ODP). A successful proposal to ODP resulted in two closely spaced shallow research wells into the mid continental slope off Vancouver Island on (ODP Sites 889 and 890) and a reference well in the adjacent deep sea Cascadia Basin ${ }^{67}$.

There is now a very comprehensive geophysical data base from surveys, studies and sampling in the area with work by the Geological Survey of Canada, University of Victoria, University of Toronto, Dalhousie University, Cambridge University U.K., University of Bremen Germany, Scripps Inst. Oceanography California, the U.S. Navy Research Laboratory, and numerous others though the Ocean Drilling Program. The work includes numerous seismic reflection surveys with a wide variety of systems, electrical profiling, thermal studies, seafloor core sampling, and remotely operated submersible (ROV) studies ${ }^{68}$. Most information has come from the seismic surveys, including mapping the area of the BSR, determining the depth distribution of hydrate and underlying free gas, and the geological controls of hydrate formation.

On this margin there is a large clastic accretionary sedimentary prism (i.e., active fold and thrust belt), the most common environment for high concentrations of marine gas hydrates. BSRs are evident beneath about half of the mid-continental. Special seismic studies include BSR reflection coefficients, the frequency dependence of the BSR amplitude, BSR amplitude-versus-offset (AVO), and full waveform inversions. Large increase in amplitudes and phase change at far offsets were found. This behavior may represent turning or diving rays in the high-velocity hydrate rather than normal interface AVO behavior ${ }^{68}$.

Additional information on hydrate concentration is provided by electrical resistivity profiling, and measurements of seafloor compliance. Detailed heat flow surveys have mapped the thermal regime that controls the depth to which gas hydrate is stable. ODP downhole geophysical logs and core analyses have constrained the concentrations of hydrate and free gas at the drill sites, and provided calibration of the regional geophysical data. In the region of the ODP site, the estimated concentration of hydrate from both geophysical and borehole data is $20-30 \%$ of the pore space (10-15\% of total volume) over $100 \mathrm{~m}$ above the BSR, with an underlying 10-20 m layer of less than $1 \%$ free gas. In addition, seismic studies have mapped a number of vent structures that may carry upward migrating gas and associated gas hydrate ${ }^{63}$. 
RUSSIA

\section{Introduction}

The work done in Russia and the former Soviet Union is the most important from the historical point of view. There has been a significant downturn in research after the demise of the former Soviet Union, but there has been some recovery in recent years.

Russia has abundant sediments of gas hydrates both in marine shelf sediments and on-shore regions beneath permafrost. The presence of gas hydrates in offshore continental margins has been inferred mainly from anomalous seismic reflectors that coincide with the predicted phase boundary at the base of the gas-hydrate stability zone. This reflector is commonly called a bottom-simulating reflector or BSR. Gas hydrates have been recovered in gravity cores within $10 \mathrm{~m}$ of the sea floor in sediment of the Black Sea, the Caspian Sea, the Bering Sea, and the Sea of Okhotsk ${ }^{69}$.

At the same time fresh water gas hydrates have found in Lake Baikal. Lake Baikal contains about $20 \%$ of the world's fresh water and presents a rare occurrence of fresh water gas hydrates. Massive Structure I and Structure II hydrates have been found adjacent to each other just beneath the lake bed ${ }^{70}$.

Onshore gas hydrates are believed to be present in the West Siberian Basin and are believed to occur in other permafrost areas of northern Russia, including the TimanPechora province, the eastern Siberian Craton, and the northeastern Siberia and Kamchatka areas ${ }^{69}$.

\section{Historical Perspective}

The Markhinskaya well drilled in 1963 in Yakutiya to a depth of $1800 \mathrm{~m}$ revealed a section of rock at $0{ }^{\circ} \mathrm{C}$ temperature at the $1450 \mathrm{~m}$ depth, with permafrost ending at approximately $1200 \mathrm{~m}$ depth. Comparison of the conditions of that section of rock with hydrate formation conditions allowed scientists to formulate the possibility of the existence of gas-hydrate accumulations in the cooled layers (Makogon ${ }^{71}$, 1965). This concept, which was received with serious doubt by many experts, needed experimental confirmation. Hydrates of natural gas were formed in a laboratory in 1966 in porous media and in real core samples at the Gubkin Oil Institute in Moscow (Makogon ${ }^{72}, 1966$ ). The results, which compellingly showed the possibility of formation and stable existence of naturally occurring gas-hydrates in rock layers, were recorded as the scientific discovery of natural gas-hydrates. After a comprehensive international examination, the discovery of natural hydrates was recorded in the USSR State Register of scientific discoveries (Moscow, 1969) as No 75 with the following formulation: "Experimentally established was the previously unknown property of natural gases to form deposit in the solid gas-hydrate state in the earth's crust at specific thermodynamic conditions" (Moscow, 1969).

Soon thereafter, a group of young geologists named Sapir, Ben'yaminovich and Beznosikov found the first gas-hydrate deposit in the Messoyakha field in the Transarctic, on the eastern border of West Siberia (Makogon et $\mathrm{al}^{73}, 1970$ and Makogon et al. ${ }^{74}, 1971$ ). Comprehensive geophysical and thermodynamic studies performed in the 
Messoyakha wells showed that gas in the hydrated state existed in the upper part of the deposit (Bernosikov ${ }^{75}, 1970$ and Ben'aminovich et al. ${ }^{76}, 1972$ ). The underlying part of the deposit contained gas in a free state. The Messoyakha field, with original reserves of about 30 billion $\mathrm{m}^{3}$, was dwarfed by the giant Urengoy, Yamburg and Medvezhye fields in Siberia. However, the Messoyakha production of gas from hydrates was a catalyst in the growth of studies of natural gas-hydrates in the world. The field provided gas to an important Norilsk steel mill in the Transarctic and allowed the steel mill to replace costly imported coal with clean, cheap natural gas. The Messoyakha field was confirmation of the presence of gas-hydrate deposits and the possibility of their commercial development $^{77}$.

This field was the first production facility in the world. It produced continuously from 1970 to 1978, and intermittently thereafter, primarily in summer to accommodate the local industrial demand ${ }^{78}$. The work done on this field has given a lot of experience to the Russian scientists. Former Soviet scientists have either emigrated abroad or started several renowned research groups such as, the Novosirssk research group ${ }^{79}$ and the St. Petersburg ocean research group.

Among the various techniques for production of natural gas from in-situ gas hydrates, the most economically promising method is considered to be the depressurization scheme. The Messoyakha gas field in the northern part of the West Siberian Basin is often used as an example of a hydrocarbon accumulation from which gas has been produced from in-situ natural gas hydrates. Production data and other pertinent geologic information have been used to document the presence of gas hydrates within the upper part of the Messoyakha field ${ }^{69}$. It has also been suggested that the production history of the Messoyakha field demonstrates that gas hydrates are an immediate producible source of natural gas and that production can be started and maintained by conventional methods. Long-term production from the gas-hydrate part of the Messoyakha field has been achieved by the simple depressurization scheme. As production began from the lower free-gas portion of the Messoyakha field in 1969, the measured reservoir-pressures followed predicted decline relations; however, by 1971 the reservoir pressures began to deviate from expected values. This deviation has been attributed to the liberation of freegas from dissociating gas hydrates. Throughout the production history of the Messoyakha field it is estimated that about 36 percent (about 183 billion cubic feet) of the gas withdrawn from the field has come from the gas hydrates ${ }^{69}$. Recently, however, several studies suggest that gas hydrates may not be significantly contributing to gas production in the Messoyakha field ${ }^{80}$.

\section{International Activities}

\section{Gas Hydrate-Bearing Sediments Offshore Sakhalin}

The CHAOS (Hydro-Carbon Hydrate Accumulations in the Okhotsk Sea) cooperative project organized by Kitami Institute of Technology (KIT, Japan), All-Russia Research Institute for Geology and Mineral Resources of the World Ocean (Russia), V. I. Il'ichev Pacific Oceanological Institute FEB RAS (Russia), Korea Polar Research Institute 
(Korea), IFM-GEOMAR (Germany), Limnological Institute SB RAS (Russia) and Renard Centre of Marine Geology (Belgium) with the aim of the natural gas hydrate study at the Okhotsk Sea was conducted in 2003. The core sampling areas were located offshore Sakhalin Island. The gas hydrate-bearing and gas hydrate free marine sediments were retrieved from the bottom of the Okhotsk Sea at water depths between 830 and 960 $\mathrm{m}$ by using gravity- and hydro- corers ${ }^{81}$.

\section{Free Gas in Gas Hydrate Stability Zone-Data from Okhotsk Sea}

Multidisciplinary field investigations were carried out in Okhotsk Sea by $\mathrm{R} / \mathrm{V}$ Akademik M.A. Lavrentyev (LV) of the Russian Academy of Sciences (RAS) in May 2006, supported by funding agencies from Korea, Russia, Japan and China. Geophysical data including echo-sounder, bottom profile, side-scan-sonar, and gravity core sample were obtained aimed to understand the characteristics and formation mechanism of shallow gas hydrates. Based on the geophysical data, we found that the methane flare detected by echo-sounder was the evidence of free gas in the sediment, while the dome structure detected by side-scan sonar and bottom profile was the root of gas venting. Gas hydrate retrieved from cores on top of the dome structure was found as thin laminations or lenses with thickness varying from a few millimeters to $3 \mathrm{~cm}$. Gas hydrate content in hydrate-bearing intervals visually amounted to $5 \%$ to $30 \%$ of the sediment volume. It has been proposed that not all the amount of gas found in the sediment core was from gas hydrate decomposition. During the gravity core lifting process, free gases may exist in the gas hydrate stability zone, and tectonic structures like dome structures in this research were found to be free of gas in the central zone. Gas hydrate formed only when gases over-saturated in this gas central zone, away from these structures, gas hydrate could not form due to low gas concentration ${ }^{82}$.

\section{Russia-Japan}

In Lake Baikal shallow gas hydrates have already been identified in six mud volcano/seep structures through joint Russian, Japanese and Belgian research. These mud volcano/seep structures are found at different water depths (from $1380 \mathrm{~m}$ to as shallow as $440 \mathrm{~m}$ ) and contain shallow hydrates of both structure I and II. Bottom Simulating Reflectors (BSRs), indicative for the presence of deep-seated hydrates, has been observed on nearby seismic profiles ${ }^{49}$.

A production test of shallow gas hydrate in Lake Baikal is planed in cooperation with Japanese and Russian parties. The aim of this project is to develop technologies for recovering gas hydrate from the near surface sediments in the bottom of Lake Baikal, with the goal of establishing environmentally friendly and economical natural gas production technologies from gas hydrate layers. To produce gas from hydrate safely and without damaging the environment it is needed to address many wide-ranging environmental issues. One of them is to assess sediment deformation during gas production. Gas hydrate acts as a binding agent that holds together the soil grains that make up the strata. It has been suggested that production may lead to settlement or landslides on the bottom of lake, as the strata becomes unstable following removal of this 
binding agent. The high quality strength parameters of hydrates bearing sediments are essential for a success of the production test of shallow gas hydrate. Cone penetration tests (CPTs) were conducted to estimate the strength of sediments under in-situ stress condition at the bottom of Lake Baikal. A new CPT probe for deep water (maximum depth 2,000m) has been developed. The results of CPTs around the mud volcano structures indicated that the cone tip resistance in hydrate bearing sediments strongly depends on the textures of hydrate in sediments, and that the ratio of CPT tip resistance to the shear strength obtained from the vane shear tests on core samples is $12^{49}$.

\section{Russia-India}

India and Russia have been successfully executing for more than twenty years probably one of the largest mutual cooperation programs in science and technology between any two countries. The dimensions of research cover the widest possible spectrum $^{83}$. The Science \& Technology interaction between India and Russia is conducted through two types of programs:

\section{(i) Programs Based on Inter-Governmental Bilateral Agreements:}

These include the Integrated Long-Term Program of Cooperation (ILTP), the Working Group on Science \& Technology, and the Academy Exchange Program.

(ii) Programs Based on Agreements between Governmental Agencies:

These programs are based on Protocols, Memoranda of Intent (MoUs), and Agreements between Russian and Indian agencies ${ }^{83}$.

The agreement on the Integrated Long-Term Program of Cooperation (ILTP) was signed on July 3, 1987 by H. E. Mr. Mikhail Gorbachev, the then President of the erstwhile Soviet Union and H. E. Mr. Rajiv Gandhi, the then Prime Minister of India. It has been renewed for another 10 years on $3^{\text {rd }}$ October, 2000. It is the largest bilateral Science \& Technology program that India has entered into with any country. The ILTP is coordinated by the Department of Science \& Technology on the Indian side and by the Russian Academy of Sciences on the Russian side. Continuous dialogue and interaction between Indian and Russian scientists results in identification and implementation of joint projects in the areas of mutual interest. In its first 16 years of implementation, the ILTP is credited with about 3000 exchange visits, 300 completed joint research projects and establishment of 6 joint research centers in important areas of science. Currently, about 150 joint research projects are being implemented and one joint center in the areas of Biomedical Instrumentation is under execution. ILTP comprises cooperation in 11 thrust areas related to frontiers of S\&T, namely: Biotechnology and Immunology; Materials Science \& Technology: Laser Science \& Technology: Catalysis: Space Science \& Technology: Accelerators \& their Applications: Hydrology; Computer \& electronics; Biomedical Science \& Technology; Oceanology \& Oceanic Resources and Engineering Sciences; and seven select areas of basis research in science, namely: Mathematics; Applied Mechanics; Earth Sciences; Physics \& Astrophysics; Ecology and Environmental Protection; Chemical Sciences and Life Sciences ${ }^{84}$. 
Under this program six joint Indo- Russian centers have been established to pursue the agreed upon research work. In the area of gas hydrates the Indo-Russian Center for Gas Hydrates is the latest addition to the list of Centers of excellence created under ILTP. The agreement for establishment of this Centre was formally concluded during the visit of Indian Prime Minister, A. B. Vajpayee, to Russia in November 2003 between the department of Science \& Technology on the Indian side and the Russian Academy of Sciences on the Russian side. The Centre was inaugurated at National Institute of Ocean Technology, Chennai on $12^{\text {th }}$ March $2004^{84}$.

\section{Russia-Spain}

A study was carried out as a part of the joint Dutch-Russian NWO/RFBR DutchRussian cooperative project (047.017.003) between the Royal NIOZ and the UNESCO/MSU Center for Marine Geology and Geophysics entitled "Evolution and Ecology of Cold Seep Structures in the Gulf of Cadiz".

The gas hydrate formation in the Gulf of Cadiz depend on the following: temperature of the near bottom water that varied from 12 (near Gibraltar and shelf) to 2-4 degree $C$ (at the deep water areas) due to climate, shallow-water environment of the shelf water areas, and due to the influence of the warm Mediterranean outflow or cold Atlantic waters. Both gas hydrates of structures I and II are present in the Gulf of Cadiz. This fact implies different PT conditions necessary for the hydrate formation; all known to be found in the Gulf of Cadiz. Gas hydrate occurrences are associated with mud volcanism suggesting a specific mechanism for gas hydrate formation, and definition of size and shape of the gas hydrate accumulations. The gas hydrate accumulation occurs at the water depth defining PT conditions which are close to the stability boundary (GHSZ) for the methane hydrate formation under the temperature of the bottom water of about 11 degree $C$. Thus, the upper boundary of the GHSZ is limited by the 800-900 $\mathrm{m}$ depth level (for the structure II gas hydrates ${ }^{85}$ ).

For the formation of structure I hydrate the water depth must be greater. The lower GHSZ boundary is outlined by the continental slop line. The deepest gas hydrate accumulation associated with the Porto mud volcano occurs at water depth of about 4000 m.

In the Gulf of Cadiz about 20 mud volcanoes are known within the limits of the GHSZ, nine from them are proved to be gas hydrate-bearing. In fact the number of the mud volcanoes situated within the limits of the GHSZ should be at least several times more. The size of the gas hydrate accumulations corresponds to the size of mud volcanoes which can be approximated by circles with diameters varying from 1.5 to 4 $\mathrm{km}$. Total gas amount captured by hydrates at these accumulations is estimated as much as $2.810^{10}$ cubic meters of gas. It should be noted, that the resource potential of gas hydrates for the Gulf of Cadiz could be greater because the number of discovered mud volcanoes is increasing year after year ${ }^{85}$. 


\section{Geographical Areas of Interest}

\section{West Siberia}

First indications about relic hydrates existence in permafrost of West Siberia (Yamburg gas field area) have been documented at the end of eighties - beginning of nineties during the 20 th century ${ }^{86,87}$. Clear indications were found due to gas leaks from permafrost drill cores from depths less than $150 \mathrm{~m}$ when thawing in kerosene or warm water. Drill cores were represented by fine-grained sand and had very small empty space in pores for free gas. The volume of gas liberated when thawing was many times over this space volume. The same situation was found later in drill cores recovered from depth $119 \mathrm{~m}$ at the well $92 \mathrm{GSC}$ Taglu at the North of Canada ${ }^{88}$. In this location it was also assumed the presence of relic (metastable) gas hydrates.

The most advanced studies of relic gas hydrates have been conducted at Bovanenkovo gas field area in Yamal peninsula at the North of West Siberia ${ }^{86,87}$. These studies included well drilling, permafrost cores recovery, permafrost gas liberations study (at wells), and hydrate content of drill cores measurement (in laboratory). Gas hydrates were found only in some of the drill cores selected for study. Other cores did not contained hydrates at all. The cores containing gas hydrates presented volumes $0.5-3 \%$ of pore space volume according to the volume of gas liberated during the sample thawing in water. The most interesting observation was that hydrate containing sediments often neighbored with intra-permafrost gas-bearing layers. Gas flow rates at wells reached more than 10,000 $\mathrm{m}^{3} /$ day from depth 60-120 m. Gas analysis showed microbial genesis of methane in hydrates and in free gas liberations from permafrost. These data led to the assumption that free gas accumulations could be in particular the result of gradual decomposition of intra-permafrost relic (metastable) gas hydrates.

According to isotopic and chemical analysis, the gas pesent in permafrost in Bovanenkovo gas field area is completely different from the gas of the upper productive reservoir. The same situation is found at the Yamburg gas field. This means, that gas hydrate and free gas accumulations within permafrost interval can have their own mechanism of gas generation, accumulation and conservation. Probably, microbial gas was generated before the freezing of the section and was partially dissolved in pore waters. Freezing of the geologic section could concentrate the gas under a freezing front and in certain situations results in local hydrate formation. Formed hydrates then became metastable and this process is accompanied by free gas accumulation in neighboring permeable layers. We can not evaluate precisely total gas resources of intra-permafrost relic gas hydrates and free gas accumulations at Yamal peninsula, but according to first estimations, specific density of these resources at Bovanenkovo gas field area in the interval $60-120 \mathrm{~m}$ should be no less than $100,000 \mathrm{~m}^{3} / \mathrm{km}^{2}$. This value was calculated by measurement of the total volume of gas

Other target of studies is drill cores recovery from the lower part of permafrost, from sediments situated in the conventional HSZ. This part of West Siberia is characterized by deep cryolithozone - about 400-450 m and has a considerable HSZ - about $400 \mathrm{~m}$. The 
upper part of HSZ in a depth interval of 250-350 $\mathrm{m}$ is situated in the permafrost zone. In the same depth interval there is a regionally spread sandy layer, generating weak gas leaks when wells are drilled through warm drill mud. This layer has not been studied for gas yet and there are no drill cores from this area. So its testing for gas hydrates could be of interest ${ }^{89}$.

\section{Bering Sea}

Cold war era acoustic research may have stumbled across vast quantities of methane trapped under 12,000 feet of water. The remote Bering Sea seems an unlikely location for a major natural gas natural province. Yet the region may hold thousands of trillions of cubic feet of gas resources ${ }^{90}$.

Senior Research Geologist David Scholl has described what appear to be massive methane hydrate bodies peppering the south-central Bering Sea subsurface in a region that straddles the divide between the U.S. and Russian economic zones. The hydrates occur in a flat area of the abyssal plain, comparable in size to Nevada and Utah combined, Scholl said.

The hydrate bodies appear as strange looking features in seismic data collected during the Cold War. The scientists engaged in the Cold War era research observed many strange-looking anomalies in the deep Bering Sea seismic sections. In profile, these anomalies looked like giant mushrooms, with the heads of the mushrooms typically about 1,200 feet below the seafloor and about 3 miles across. The stalks of the mushrooms would extend vertically downwards for several thousand feet to basement rocks that lie underneath the sediments that blanket the seafloor. Typical water depths in the region where the structures were found are around 3,800 meters (12,500 feet).

Scholl explained that because no seismic line crossed the same structure twice, it was impossible to say whether in plain view a structure was circular or of a more elongated form. The structures showed up on seismic profiles in part because they contained areas of heightened seismic signal amplitude, and in part because within the structures the reflections of rock strata would be deflected out of the horizontal.

In the head of the mushroom seismic reflections from otherwise horizontal rock strata would be deflected upwards, a phenomenon that geophysicists term "pull up," while in the stalks the reflections would bend down, a phenomenon known as "push down." Pull up is caused by material with relatively high sound velocity - the reflections of the seismic sound reach the surface seismic receivers more quickly than normal, thus making the reflections appear closer to the surface. Push down is the opposite effect, where a relatively low sound velocity slows down the seismic signals.

The scientists termed the Bering Sea structures VAMP structures, an abbreviation for velocity and amplitude anomaly. After the physics of methane hydrates became known in the early 1970s it became evident that the VAMP structures related to gas hydrates in the subsurface.

The hydrate has a relatively high sound velocity that would account for the pull-up effect in the head of the VAMP. Methane reduces the sound velocity, so that the push 
down in the mushroom stalk provides evidence of a gas chimney. Gas in the chimney would bubble upwards from deep within the seafloor rock strata and feed the hydrate accumulating in the head of the mushroom.

The push down effect in the stalks of the VAMP mushrooms increases with depth, presumably because of the cumulative velocity effect of sound passing to deeper and deeper levels through gas in the gas chimneys. This fact shows that the gas is flowing from great depth within the chimneys and, thus, indicates that the gas is thermogenic, i.e., forms from the heating of organic material, as distinct from biogenic gas that results from bacterial decomposition of the material.

And there's a plausible geologic explanation for a gas hydrate kitchen under the deep Bering Sea. The seismic sections show that near-horizontal sedimentary strata, anywhere from about 3,000 feet to 30,000 feet thick, blanket a pre-existing, mountainous rock basement with immense troughs and ridges. The VAMP structures tend to occur over the higher points in that basement.

Some drilling done in association with the acoustic survey work found that the sedimentary strata consist of two distinct sequences. The younger and shallower of these sequences consists of rocks called turbidites that are typically laid down from sediment flows in deep water. The Bering Sea turbidites started to form about 2.5 million years ago, Scholl said. Under the turbidites lies an older sequence of mudstones containing huge quantities of diatom remains - diatoms are tiny algae with silica cell walls. The older sequence of strata appears to extend back into the Miocene epoch that began around 26 million years ago.

The existence of diatoms in the mudstones indicates that in the geologic past the Bering Sea was organically productive, just as it is at present. And organic material from buried diatoms and other organisms would feed thermogenic gas production in the region.

Some simple calculations show that the Bering Sea VAMP structures may contain vast amounts of methane. Assuming that the structures are circular and assuming a minimum gas concentration in the chimneys, a typical vamp might contain anywhere from 0.5 trillion cubic feet to 1 tcf of methane ${ }^{90}$.

\section{Laptev Sea}

The Arctic Ocean is a vulnerable environment with unique ecosystems that are adapted to harsh conditions. Enormous stores of methane gas $\left(\mathrm{CH}_{4}\right)$, referred to commonly as the "Arctic Carbon Hyper Pool", are present in the Arctic Ocean sediments. These stores include three basic reservoirs of methane: methane trapped within seabed permafrost (sediments with a 2-year mean temperature below $0^{\circ} \mathrm{C}$ ), methane stored in a form of gas hydrate deposit beneath the permafrost, and thermogenic methane (free gas) that comes upward from deep within the earth. The amount of methane within seabed permafrost is unknown but it is presumed to be significant. Gas hydrate deposits beneath the Siberian Arctic shelf are predicted to contain about 60 Giga-tons or Gts $\left(1 \mathrm{Gt}=10^{15} \mathrm{~g}\right)$ 
of $\mathrm{C}-\mathrm{CH} 4$ (carbon within the methane deposits); the amount of free gas underlying the gas hydrates is likely to be one half to two thirds the amount of gas stored in gas hydrate.

This "mega-pool" of methane substantially exceeds the atmospheric methane reservoir of $3.6 \mathrm{Gt}$. The release of a very small fraction of the methane currently sequestered in Siberian Arctic shelf $\left(\sim 1 \%\right.$ or $1 \mathrm{Gt}$ of $\left.\mathrm{CH}_{4}\right)$ would raise the current atmospheric concentrations by almost $30 \%$, which is similar to the increase in atmospheric methane observed during the $20^{\text {th }}$ century (IPCC, 2001) $)^{91}$.

\section{Gas Hydrates Research in the Black Sea}

A research cruise (RV Meteor Cruise 72) was conducted in the Black Sea from March 17 to April 23, 2007 to study the distribution of methane and gas hydrates in marine sediments. Multinational institutions participated in the study from: the Research Center Ocean Margins (RCOM), University Bremen, Germany; Leibniz-Institut für Meereswissenschaften (IFM-GEOMAR), Kiel, Germany; Alfred-Wegener-Institute for Polar and Marine Research, (AWI) Germany; Faculty of Geography, Seismometrical Laboratory; Tbilissi State University (TSU), Tbilissi, Georgia; A. O. Kovalevsky Institute of Biology of the Southern Seas (IBSS), Ukrainian Academy of Sciences, Sevastopol, Ukraine; UNESCO Center for Marine Geosciences; Moscow State University (MSU), Moscow, Russia; Turkiye Petrolleri A.O. (TPAO), Ankara, Turkey; Institute of Marine Sciences (IMST); and Dokuz Eylül University (DEU), Izmir, Turkey ${ }^{92}$.

The expedition was the third leg of cruise 72 of RV METEOR. Due to logistic reasons this leg 3 was split in two sub-legs $3 \mathrm{a}$ and $3 \mathrm{~b}$ with a port call in Trabzon between the two sub-legs. The investigations of leg 3 were part of the BMBF collaborative project METRO, which is funded within the subject area "Methane in the geo-biosystem" as part of the special program "Geotechnologies". METRO is also embedded in the GermanRussian agreement on "Cooperations on the realm of marine and polar research". The distribution and the dynamics of methane and gas hydrates at active fluid emission sites as well as in areas without seepage have been investigated. Near-surface marine gas hydrates in particular are of relevance for climate studies, stabilities of sediments and biogeochemical processes. They were explored by various high-resolution geophysical, geochemical and geological methods. Different geological structures characterized by active gas and oil seepage, near-surface gas hydrate deposits, and mud volcanoes in various areas of the eastern Black Sea in Ukraine, Turkey and Georgia have been studied $^{92}$.

\section{Lake Baikal}

In 1997 an underwater borehole was drilled in the South part of Lake Baikal (water depth, 1,433 m; borehole depth, $225 \mathrm{~m}$; the temperature at these depths is about $10^{\circ} \mathrm{C}$ ). Samples of sediments containing methane hydrate were collected at depths 121 and 161 $\mathrm{m}$ below bottom. At present, this is the only example of the existence of gas hydrates in a fresh-water basin under non-permafrost conditions ${ }^{70}$.

The Limnological Institute in Irkutsk (Siberian Branch of the Russian Academy of Sciences) organized a four-day international Conference on Gas Hydrates from $3^{\text {rd }}-8^{\text {th }}$ 
September, 2007, in the small lakeside settlement of Listvyanka. The meeting focused on many aspects of gas hydrate research but with a particular emphasis on gas hydrate occurrences in Lake Baikal. This lake contains about $20 \%$ of the world's fresh water and presents a rare occurrence of fresh water gas hydrates. Massive Structure I and Structure II hydrates have been found adjacent to each other just beneath the lake bed. On the last day of the conference, the G. U. Vereshchagin sailing from Listvyanka recovered, from a water depth of 1300 meters, a 1.5 meter long gravity core from a previously sampled "mud-volcano-like" feature (guided by a strategically placed handheld GPS hanging out of the bridge window). When the core was split open, abundant, thick, dipping gas hydrate layers were revealed ${ }^{70}$.

\section{Who Work On Gas Hydrates in Russia}

There are four main gas hydrate research groups in Russia. Each group has its specific history and scientific direction:

- Institute of Inorganic Chemistry of the Siberian Branch of Russian Academy of Sciences (IICh SB RAS, Novosibirsk). This group was lead by Prof.Yuri Dyadin DIED 28 January, 2002 and Dr.Vladimir Belosludov (bel@casper.che.nsk.su/ It is the oldest Russian gas hydrate group still in action in Russia. Their fields of interest are: molecular dynamics of clathrate compounds, phase equilibria, hydrates at high pressures (up to $4000 \mathrm{MPa}$ ), hydrate structures and fundamental properties of clathrate hydrates.

- All-Russian Institute of the World Ocean Geology and Mineral Resources (VNIIOkeanGeologia, Sankt-Peterburg). This group was leaded by Dr.Gabriel Ginsburg - DIED 5 May, 1999 and Dr.Valeri Soloviev- DIED 19 September, 2005. Now it is headless. A part of the gas hydrate research activity is continued by Dr. Leonid Mazurenko (leonidius@yandex.ru). This was the most well-known Russian research group on marine gas hydrates. Their fields of interest were: origin and geology of marine hydrates, properties of hydrate-containing sediments, geophysic and geochemical exploration, resource assessment. They have conducted a special study on Messoyakha gas field in West Siberia which showed abundance of hydratecontaining sediments.

- Institute of the Earth Cryosphere of the Siberian Brunch of Russian Academy of Sciences (IEC SB RAS, Tyumen). This group led by Dr.Anatoly Nesterov (nesterov@ikz.ru) is the most advanced in kinetic studies of gas hydrates with surfactants and mineral adds. Their fields of interest are: phase equilibria of gas hydrates with different solutions, hydrates within permafrost, hydrate kinetics.

- Moscow Gas Hydrate Group from the Research Institute of Natural Gases and Gas Technologies (VNIIGAZ, Moscow) and Moscow State University (MSU, Moscow). This group led by Dr.Vladimir Istomin (istomin@gol.ru), Dr.Vladimir Yakushev (vyakushev@hotmail.com) (both-VNIIGAZ) and Dr.Evgeny Chuvilin (chuvilin@geol.msu.ru) (MSU) conducts a wide range of gas hydrate studies - from fundamental properties to field drill samples recovery and study. Practically all 
aspects of gas hydrate study are included into their field of interest, but their main studies are on thermodynamic equilibria, experimental equipment design and manufacturing, hydrate-containing sediments experimental study, and industrial applications of gas hydrates.

Experimental studies have been conducted in the Geocryology Department of MSU since 1986 together with Dr. V.S. Yakushev and Dr. V.A. Istomin (VNIIGAZ) within the objectives of the "Moscow Gas Hydrate Group". The first experiments were devoted to gas hydrate formation under cooling and freezing of methane-saturated water. Based on the experimental investigation the self- preservation phenomenon of gas hydrate at temperature below $0{ }^{\circ} \mathrm{C}$ was discovered and described in 1988. It allowed to explain the existence of gas hydrates under pressured below equilibrium and to identify the gas hydrate as a new component of frozen sediments. Follow-up experimental investigations were directed on the study of gas hydrate formation in different types of sediments ${ }^{93}$.

\section{SOUTH KOREA}

\section{Introduction}

South Korea is ranked $10^{\text {th }}$ in the world in terms of GDP. The ratio of R\&D investment is among the highest in the world, hitting nearly 3\% of GDP in 2007. Korea recovered dramatically from the 1997 financial crisis and once again has a strong economy, with shipbuilding, construction, flat panel displays and wireless communications at the fore ${ }^{79}$.

In order to sustain growth South Korea must continue to enhance its knowledge-based industries. To this end the government continues to support applied research while at the same time is now putting more emphasis than before on fundamental sciences ${ }^{94}$.

South Korea is moving into big science. It is a member of the ITER consortium and has formulated a National Fusion Energy Development Plan (for the period 2006-2035). South Korea is also constructing its own rocket launch facility on the south coast of the peninsula to support its growing space program. Corporate investment accounts for about two-thirds of R\&D expenditure. Unsurprisingly much of this $R \& D$ is on the applied side and the investment comes mostly from the large Korean conglomerates (Chaebol) such as Samsung, LG and Hyundai. There are around thirty government research institutes. Many of these are clustered in Daedeok Science Town, close to Daejon, about $160 \mathrm{~km}$ south of Seoul. Since the 1970s this area has been deliberately developed as a center for R\&D and has become synonymous as South Korea's research base. The town currently houses a total of 242 of research centers and venture start-ups hiring roughly 24,000 employees, 6,236 of whom are PhDs. The cluster is roughly divided into four main sectors: information technology, biotechnology, radiation technology and nanotechnology. A total investment of 18.4 trillion won was made from 1973 to 2004.

\section{Organization of Public Science \& Technology in South Korea}


* Fiscal Year: January - December

March: General budget and fiscal policy guidelines by the President

May: request Budget to NSTC

June: NSTC pre-coordinates Budget

July: NSTC submits budget to MPB

September: President submits budget to the National Assembly

October: Budget approved by the National Assembly

The organization chart shows the core structure of the science, technology and innovation (STI) system in South Korea. As various ministries implement STI policies in their own areas, coordination is crucial. Three organizations carry out this coordinating mission in different ways: the National Science and Technology Council (NSTC), the Presidential Advisory Council for Science and Technology (PACST), and the Ministry of Planning and Budget (MPB). The main function of NSTC is short-term and long-term science and technology policy coordination, while its member ministries are in charge of implementation.

The role of PACST is to recommend long-term science and technology innovation strategies to the President. The South Korean R\&D budget was around $\$ 7.6$ billion in 2004. The most important relevant government agency is the Ministry of Science and Technology (MOST). MOST accounted for slightly under a quarter of this budget. Following reorganization in 2004, MOST now provides central direction, leadership, and coordination of all science and technology activities in South Korea.

In November 2004 MOST established an Office of Science and Technology Innovation (OSTI) to act as an administrative body of the National S\&T Council. OSTI is responsible for the overall management and co-ordination of S\&T policies, national $R \& D$ projects, industry and human resource policies related to science and innovation. It is headed by the Vice Minister of Science and Technology Innovation.

South Korean scientists apply for research grants through their universities and institutes to one of R\&D management institutes. The Korea Science Engineering Foundation (KOSEF), which is fully funded by MOST, holds a significant amount of the grant programs.

Three groups in South Korea undertake R\&D: the private sector, government research institutes and universities. South Korea's government and industrial R\&D expenditure in 2004 was officially announced U\$S 19.3 billion, showing an increase of $17 \%$ from the previous year. The R\&D expenditure as a percentage of GDP is $2.85 \%$ in 2004. Ministry of S\&T unveiled the government R\&D budget in 2005, US\$ 7.6 billion with an annual average of 10\% from 1998 .

Although South Korean universities have $78 \%$ of the country's PhD-qualified researchers, research conditions in universities are not as good as outside. This is due in part to lack of funds, inadequate research equipment and other facility issues. In 2004 only $9.9 \%$ of national R\&D expenditure was allocated to universities, whereas the figure 
for Government Research Institutes was $13.4 \%$ and for industry $76.7 \%$. The result is that the South Korean university effort generally has to rely on strong individual performances. The government recognized this, and planed to increase expenditure on basic research to $25 \%$ of the total government R\&D budget by the year $2007^{94}$.

\begin{tabular}{|c|l|l|l||}
\hline & 2001 & 2003 & 2004 \\
\hline \hline GDP, (US \$billion) & 482 & 608 & 681 \\
\hline R\&D expenditure, (US \$ billion) & 12 & 16 & 19.3 \\
\hline R\&D Expenditures/GDP (\%) & 2.59 & 2.53 & 2.85 \\
\hline Public:Private R\&D ratio & $26: 74$ & $25: 75$ & $24.5: 75$ \\
\hline Basic:applied:development ratios & $13: 25: 62$ & $14: 21: 65$ & $15: 21: 63$ \\
\hline Research workers & 136,337 & 151,254 & 156,220 \\
\hline $\begin{array}{c}\text { Number of overseas patents } \\
\text { (Growth rate, \%) }\end{array}$ & $2,318(53.1)$ & $2,947(15.5)$ & $3,554(17 \%)$ \\
\hline $\begin{array}{c}\text { Number of SCI publications } \\
\text { (Growth rate, \%) }\end{array}$ & $14,878(19.0)$ & $18,635(17.4)$ & $19,279(3 \%)$ \\
\hline \hline
\end{tabular}

The best South Korean research universities include:

1. POSTECH (Pohang Institute of Science and Technology) which was founded by an endowment of U\$S 200million from the Pohang Iron and Steel Company in 1987. The university is home to the Pohang Accelerator Laboratory (PAL) - the only synchrotron light accelerator in Korea;

2. The South Korean Advanced Institute for Science and Technology (KAIST) - a research-oriented science and engineering university established in 1971;

3. Seoul National University - regarded as South Korea's most prestigious institution. SNU's research support is greater than any other university in Korea.

\section{South Korean Organizations Involved in Gas Hydrate Research}

The Korea National Oil Corporation (KNOC) has played a leading role in the country's drive toward energy self-sufficiency over the past three decades. South Korea's state-run oil company is making its utmost efforts to be reborn as one of the world's top 50 petroleum enterprises by 2015 based on its tangible achievements in Asia and the rest of the globe in recent years. Established in 1979 for the country's drive toward energy self-sufficiency, the Korea National Oil Corporation (KNOC) pulled South Korea up to the rank of the world's 95 th oil-producing country by succeeding in the development of the Donghae-1 gas field in $2004^{95}$. 
One of the firm's proudest achievements was the development of the Donghae-1 gas field. Located on South Korea's continental shelf, the discovery was a major step toward turning the country into an oil producer. KNOC also has an interest in 32 blocks in 15 different countries. It has been active in securing oil reserves in anticipation of future energy crises, operating storage facilities with a capacity of 116 million barrels.

In order to stabilize the country's petroleum supplies, the KNOC is currently participating in a number of overseas oilfield development projects that will contribute to the government's objective of attaining a domestic crude oil production self-supply ratio of 18 percent by the year 2013. Its ultimate goal is to become a world-class petroleum development company producing 300,000 barrels of petroleum on a daily basis by 2013 . KNOC executives and employees believed this goal could be achieved by expanding the company's exploration and production activities through the diversification including oil sands, GTL (gas-to-liquid) and gas hydrates operations, and strategic alliances with other oil producing countries. As of 2006, the KNOC is taking part in 32 exploration and production projects in 15 different countries. Six of these activities involve production, four are for development and 22 are earmarked for exploration. The company has exclusive rights to reserves of 275 million barrels out of the 738 million secured by Korean petroleum operators (as of 2005). Meanwhile, its six oil fields are producing approximately 40,000 barrels of crude per day ${ }^{95}$.

South Korea currently relies on imported liquefied natural gas (LNG) for most of its natural gas, though it began producing a small quantity of natural gas from one offshore field in early 2004. Imports of LNG began in 1986, after the founding of the state-owned monopoly LNG importer Korea Gas Company (KOGAS). . KOGAS was established by the Korean government in 1983. Since its founding, it has now grown to become one of the world's largest LNG importer. As the nation's sole LNG provider, it is fully committed to providing clean, safe, and convenient energy to its people. In keeping with this promise, KOGAS now operates three LNG terminals and a nationwide pipeline network spanning $2739 \mathrm{~km}$ ensuring a stable supply for the nation. South Korea currently gets most of its LNG from Qatar, Indonesia, Malaysia, and Oman, with smaller volumes coming from Brunei, and Australia, and occasional spot cargoes from elsewhere. The supplies from Qatar, which is now the largest exporter of LNG to South Korea, began in August 1999 under a contract with Qatar's new Ras Laffan LNG (Ras Gas) venture. The first shipment of Omani LNG was loaded in April 2000. In 2003, natural gas comprised around 11 percent of South Korea's energy consumption. South Korea is the second largest importer of LNG worldwide, importing 1,049 billion cubic feet (Bcf) of LNG in 2004. Imports of LNG grew by nearly 17 percent in 2004, continuing a pattern of rapid growth which has been interrupted only once, during the Asian financial crisis of 199798. South Korean natural gas demand is split almost evenly between the electricity sector and the residential heating sector, with a smaller amount consumed in petrochemical plants $^{96}$.

Korea Institute of Geoscience and Mineral Resources (KIGAM) was established in 1918, and its central roles are in comprehensive mineral exploration and energy 
development as the government supported research institute. For the last century, KIGAM strives to achieve superior core technology, which mobilizes national competitiveness and endless productivity. KIGAM accomplishes national projects to enhance the quality of South Korean daily lives by improving safety levels, educating about natural disasters, and developing new materials and energy sources. KIGAM covers various fields of geological research in nationwide and overseas such as gas hydrate, mineral exploration, groundwater flow research, usage of underground space, and efficient utilization of national territory. More so, KIGAM endeavors to develop the prominent unchallenged technologies in geological disasters such as earthquakes and landslides, as well as global climate change, mitigation on $\mathrm{CO}_{2}$ geological storage, mineral carbonation, and waste disposal ${ }^{97}$.

\section{South Korean Gas Hydrate Research Program}

South Korea depends heavily on liquefied natural gas (LNG) imports for its energy needs. Recently, several countries have conducted projects to explore and develop natural gas hydrates in Korea. A five-year national research project was initiated in 2000 . As part of this project, a seismic survey was performed in the East Sea of Korea to quantify the potential magnitude and distribution of natural gas hydrates. Multi-channel seismic data and core samples have been measured in the survey area. Analysis of seismic data showed clear bottom simulating reflectors (BSRs), seismic blank zones (or wipe-out zones) with velocity pull-up structure, and pockmarks. Results of this geological survey have been published in literature ${ }^{98}$. Co-Authors include South Korean scientists from the Research \& Development Division, Korea Gas Corporation and the Korea Institute of Geoscience and Mineral Resources, in cooperation with Drs. Riedel and Hyndman from the Pacific Geoscience Center, Geological Survey of Canada ${ }^{98}$.

Potentially reducing South Korea's future large demand for LNG, the country has discovered about 600 million metric tons of gas hydrates off its east coast and hopes to begin commercial production from the deposit by 2015, government officials reported June $25,2007^{6}$. Engineers obtained chunks of gas hydrate from a deposit about 135 kilometers (85 miles) northeast of the southeastern industrial city of Pohang, not far from the Dongha gas field, an official at the Ministry of Commerce Industry and Energy said. The ministry estimated that the deposit contains about 600 million metric tons and could meet the country's gas needs for about 30 years ${ }^{99}$.

The government of South Korea started in 2005 a 10-year national project to develop natural gas hydrate in Korea's East Sea. In July 2005, a gas hydrate development team was formed that includes state-owned Korea National Oil Corporation (KNOC), Korea Gas Corporation (KOGAS) and the Korea Institute of Geosciences and Mineral Resources (KIGAM). The project is managed by the Gas Hydrate R\&D Organization (GHDO) and funded through the Ministry of Commerce, Industry and Energy (MOCIE). The team has been conducting surveys in the East Sea ${ }^{100}$.

The aforementioned discovery was the first since the project was launched. The country has earmarked Won 225.7 billion (\$243.5 million) for the project through 2014 . 
The endeavor is a three-stage gas hydrate project that runs from 2005 to 2014. In the first stage that ended in 2008, 66.7 billion won were spent. After a series of surveys in the East Sea in 2005-2006, Korean engineers picked 14 locations for drilling ${ }^{100}$.

A deep drilling and coring expedition to test the full extent of the gas hydrate stability zone at five locations got underway in late September 2007. GHDO's three-phase, 10 year program is designed to conduct a production test and confirm a viable production method by 2015. The motivation for this aggressive R\&D program is clear: South Korea is the world's second largest LNG buyer after Japan and relies on imports to meet its demand. In 2006 the country imported more than 25 million metric tons of LNG. A commercial capability to produce natural gas from hydrates in the East Sea could dramatically alter that situation. However, the area rich in gas hydrates is also claimed by Japan and is the matter of diplomatic conflict between the two countries ${ }^{101}$.

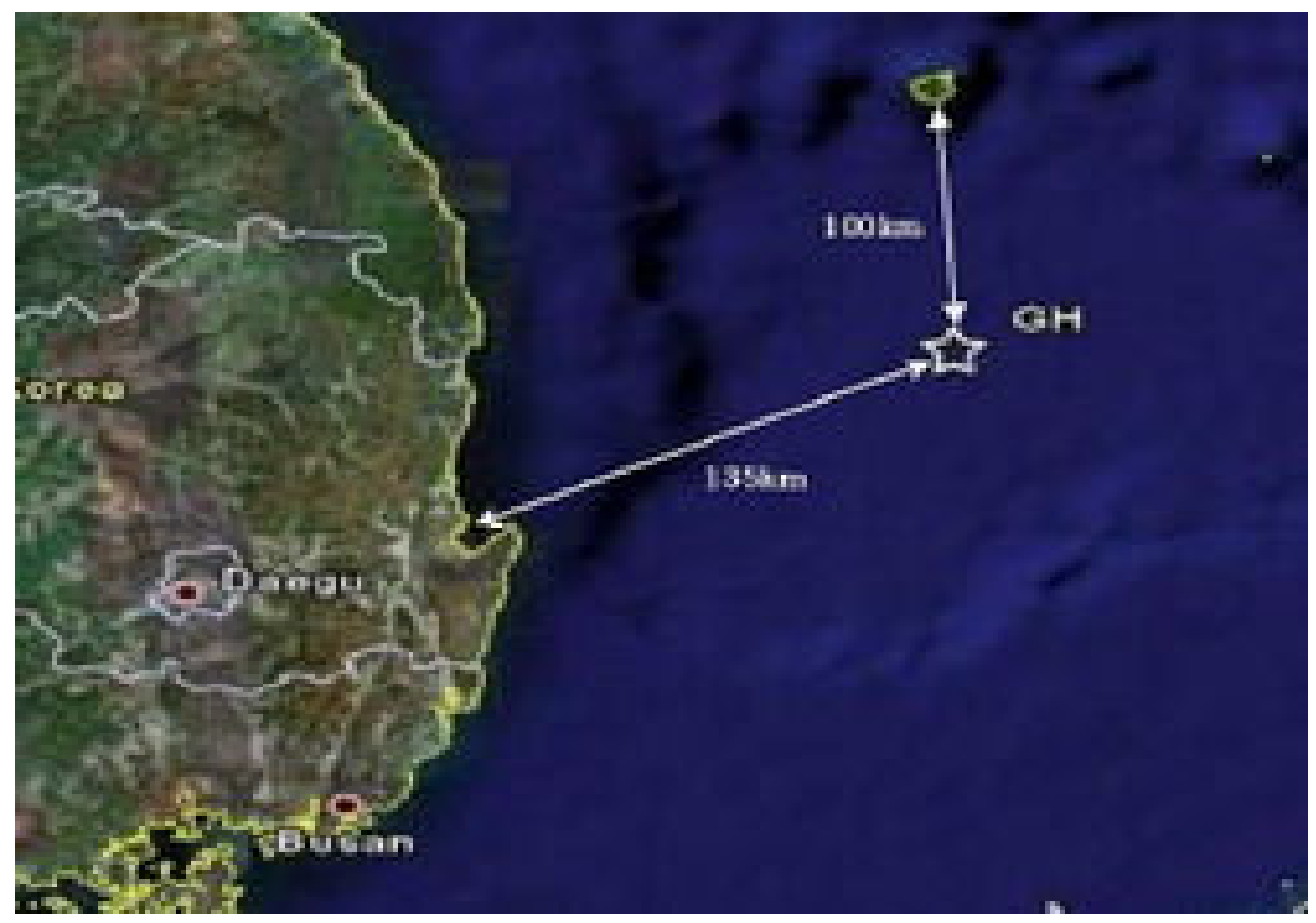

Fig. 2. Site location of Korean gas hydrate finding (Sea of Japan, Ref. 99).

South Korea conducted during November 2007 the first large-scale gas hydrate exploration and drilling expedition in the East Sea: Ulleung Basin Gas Hydrate Expedition 1 (UBGH1), which successfully explored and recovered gas-hydrate-bearing sediments at three different locations in the Ulleung Basin. Expedition UBGH1 sailed 57 days in two legs aboard the multipurpose offshore support vessel REM Etive, which had been converted to a drilling ship by Fugro Seacore using the heave-compensated R100 portable drill rig $^{102}$.

The Korea National Oil Corporation (KNOC) and Korea Gas Corporation (KOGAS) contracted Fugro to supply drilling, wireline logging, coring and associated services for Expedition UBGH1, while other companies including Schlumberger and Geotek 
provided Logging While Drilling (LWD) and core analysis services respectively. The project was directed by the Korea Gas Hydrate R\&D Organization and the Korea Institute of Geoscience and Mineral Resources (KIGAM). Leg 1 of the expedition investigated five "type" locations in the Ulleung Basin, which were selected as representative of the conditions on the basin based on pre-expedition 3-D seismic evaluations. Each of these sites was logged using the Schlumberger LWD suite of tools; in addition, 14 surface cores as well as many hours of camera surveys were collected using the REM Etive's remotely operated vehicles. The LWD data were used to select the three "type" locations most likely to contain gas hydrate for subsequent drilling and sampling on Leg 2. The second Leg lasted five weeks and entailed the drilling and coring of the three sites, where significant gas-hydrate-bearing reservoirs were documented up to 150 meters below the seafloor and at water depths between 1800 to 2100 meters. During UBGH1 Leg 2, a total of 38 conventional cores were recovered and 15 successful pressure cores were taken ( $75 \%$ success rate). Conventional and pressure cores were recovered downhole using several wireline coring tools.

The sediments from the three locations drilled and cored during UBGH1 were all deposited in sea-level controlled slope/basin environments; the finer sediments were a mix of terrigenous and pelagic materials, with coarser materials deposited by debris flows or turbidity currents. The dominant sediments were siliceous and calcareous clays; however, coarser-grained sand and silt beds, centimeters to meters thick, were also present. Gas hydrates were detected at all three sites in both the clay matrix, as veins and layers, and as pore-filling material within the silty/sandy layers. At one site, a 130-meterthick gas-hydrate-bearing sedimentary heterogeneous layer of sands and clays was discovered. This layer is one of the thickest gas- hydrate-bearing intervals to be documented worldwide. Another 100-meter- thick gas-hydrate-bearing layer was also discovered at another location. Methane was the predominant gas within core voids as well as in gas hydrate at all three sites; ethane was $0.3 \%$ or less in most gas samples. Quantification of gas hydrate from porewater freshening analysis showed that gashydrate-bearing sand layers contained an average of $30 \%$ gas hydrate by pore volume. The highest gas hydrate saturation from analysis of pressure cores, which average over a one-meter interval, was $23 \%$ gas hydrate by pore volume. While the overall magnitude of the electrical resistivity logs correlated loosely with the overall average gas hydrate saturation for the different sites, there was no obvious quantitative relationship between the two data sets ${ }^{102}$.

\section{International Cooperative Research Projects}

The renewed interest on gas hydrates exploitation has led to participation of South Korean scientists in several international joint projects ${ }^{98,103}$. At the same time several cooperative projects have been agreed upon with other countries ${ }^{103,104}$.

India and Korea signed in 2005 six memoranda of understanding (MoUs) for cooperation in the hydrocarbon sector. A MOU on Gas Hydrate related technical collaboration was signed between Director General of Hydrocarbons, Ministry of Petroleum \& Natural Gas Shri V. K. Sibal and Director GHDO of Korea, Mr. Kem Pil 
Park. The MoU was signed for collaboration between the two countries for R\&D in the field of gas hydrates, which is a large unconventional resource of energy of future. The most important field of R\&D is to establish a commercial technology to produce gas from gas hydrates, which so far does not exist anywhere in the world ${ }^{103}$.

On April 18, 2008, US Energy Secretary Samuel Bodman and South Korea Minister Lee Youn-Ho signed a Statement of Intent to exchange information on gas hydrate topics and technologies. South Korea is looking to gas hydrates as a future energy source and hopes to take part in U.S. pilot testing early $2009^{104}$.

\section{INDIA}

\section{Introduction}

It has been estimated than India has around 2,000 trillion cubic feet of prognostic reserves of gas hydrates off the country's east coast, directorate-general of Hydrocarbons (DGH) reported ${ }^{105}$. "Even if $10 \%$ of these reserves are recoverable, that is a huge potential waiting to be tapped," DGH director-general V. K. Sibal said at the International Conference on Gas Hydrates at Noida, on the outskirts of the national capital. Sibal said sizable reserves of good quality gas hydrates in KG basin have been found during test drilling. "We have the thickest gas hydrates in the world." "Till now, we have drilled at 20 sites and 11, all of them on off east coast, have given us gas hydrate," He added that the government's National Gas Hydrate Program in its second phase will conduct surveys to map the hydrate pools ${ }^{105}$.

Gas hydrates have been found in Krishna Godavari, North East Coast, Mahanadi and Andaman basin, he said. If mined and brought to atmospheric conditions, they will produce 160 times their volume of methane, but the technology to mine these hydrates is still at its infancy. Petroleum secretary M. S. Srinivasan said the vast gas hydrate reserves can meet the energy needs for centuries ${ }^{106}$.

\section{Gas Hydrate Research Program}

In 1985, the first gas hydrate work regarding identification of BSRs was reported by the Oil and Natural Gas Corporation Limited (ONGC) in Andaman offshore ${ }^{107}$. Subsequently, national research institutes along with industry undertook preliminary assessment of hydrate potential in the offshore areas of India. The Ministry of Petroleum \& Natural Gas (MOP\&NG), Government of India, established an expert committee to recommend the steps to be undertaken for exploration and development of gas hydrate resources in India. Based on the recommendations, a National Gas Hydrate Program (NGHP) was instituted in 1997. Simultaneously, the Oil and Natural Gas Corporation Limited (ONGC), Gas Authority of India, limited (GAIL) and Directorate General of Hydrocarbons (DGH), private oil industry, and the national laboratories such as National Institute of Oceanography (NIO) and the National Geophysical Research Institute (NGRI) initiated in house R\&D activities related to gas hydrates for mapping and evaluation of gas hydrate resources in Indian Offshore. To give further thrust to the gas 
hydrate related activities, MOP\&NG reconstituted the NGHP in the year 2000. The ultimate goal of the program was to achieve maximum self-sufficiency in hydrocarbons through tapping this unconventional source of energy. A roadmap is in place to achieve the commercial production of gas from gas hydrates beyond $2008^{107}$.

The Director General of Directorate General of Hydrocarbons (Technical Coordinator) in consultation with other participating agencies has drawn up an ambitious plan and prepared a road map to tap these gas hydrate resources from the Indian continental margins. Using BSR (Bottom Simulating Reflection) on seismic reflection data NGHP predicted the probable occurrences of gas hydrates in marine sediments offshore India. Accordingly two offshore model laboratories, Goa and Krishna-Godavari, were identified for further investigation ${ }^{108}$.

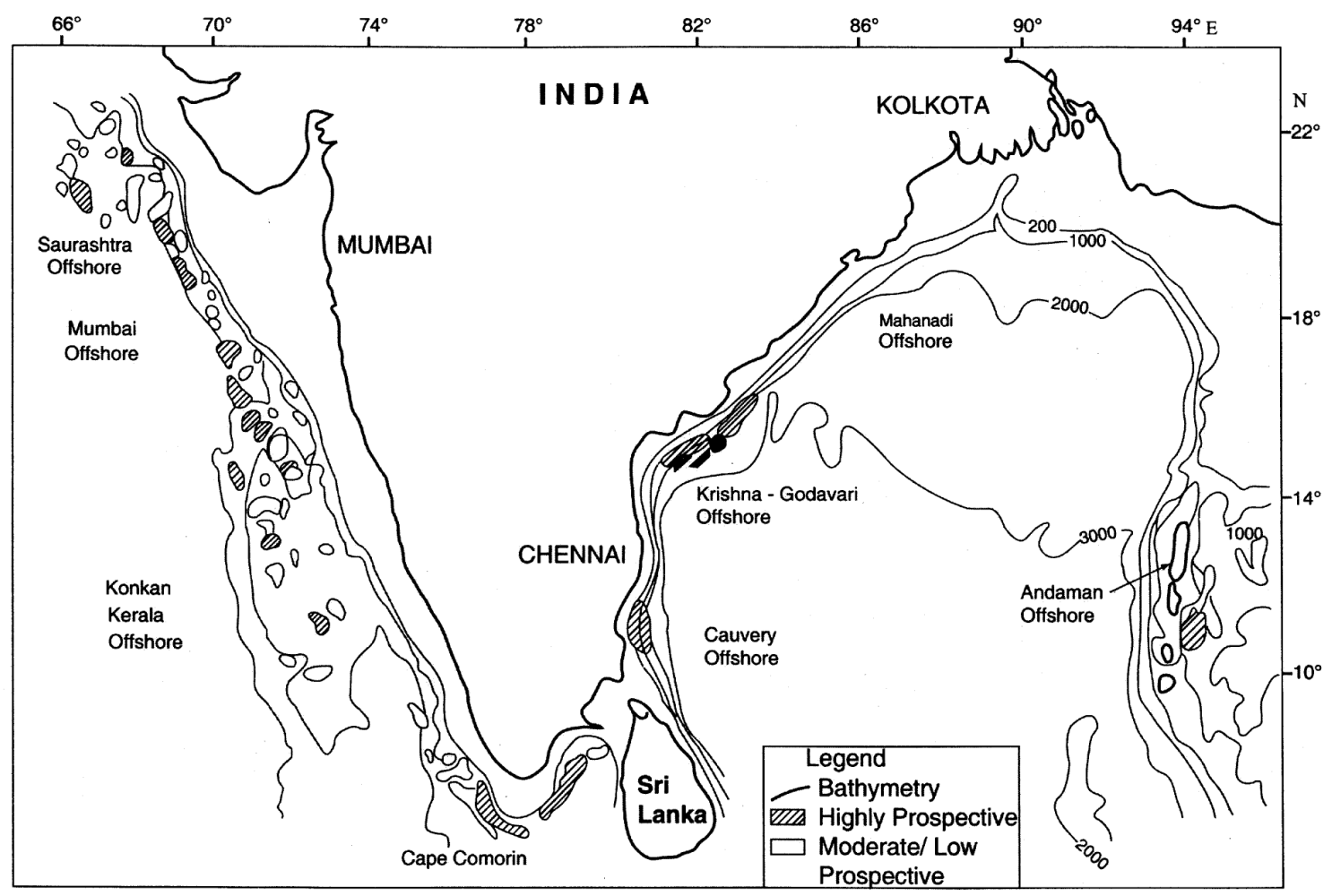

Fig.3. Map depicting prospective areas for gas hydrates along the Indian continental margins ${ }^{108}$. Locations of chirp sonar and deep tow digital side scan sonar records and station locations are indicated as thick lines and solid circles respectively.

The Indian National Institute of Oceanography (NIO) in collaboration with GAIL (India) Limited and Oil and Natural Gas Corporation Limited (ONGC) undertook multidisciplinary investigations under the aegis of the $\mathrm{NGHP}^{108}$.

The Indian National Institute of Oceanography (NIO) acquired geological, geochemical geophysical, microbial and oceanographic data sets in the Goa offshore, West Coast and Krishna-Godavari (KG) offshore, East Coast of India respectively during 2002-03 onboard Research Vessels ORV Sagar Kanya and AA Sidorenko, and completed 
the analyses, inferred some proxies related to gas hydrates and the two technical reports were submitted to the DG of $\mathrm{DGH}^{107}$.

\section{International Cooperative Research Projects}

India and Russia have been successfully executing research cooperation for more than twenty years ${ }^{83}$. The Science \& Technology interaction between India and Russia is conducted through two types of programs:

\section{(i) Programs Based on Inter-Governmental Bilateral Agreements:}

These include the Integrated Long-Term Program of Cooperation (ILTP), the Working Group on Science \& Technology, and the Academy Exchange Program.

\section{(ii) Programs Based on Agreements between Governmental Agencies:}

These programs are based on Protocols, Memoranda of Intent (MoUs), and Agreements between Russian and Indian agencies ${ }^{83}$.

The agreement on the Integrated Long-Term Program of Cooperation (ILTP) was signed on July 3, 1987 by H. E. Mr. Mikhail Gorbachev, the then President of the erstwhile Soviet Union and H. E. Mr. Rajiv Gandhi, the then Prime Minister of India. It has been renewed for another 10 years on $3^{\text {rd }}$ October, 2000. Currently, about 150 joint research projects are being implemented and one joint center in the areas of Biomedical Instrumentation is in operation. ILTP comprises of cooperation in 11 thrust areas related to frontiers of $S \& T^{84}$.

Under this program six joint Indo- Russian centers have been established to pursue research work. In the area of gas hydrates the Indo-Russian Centre for Gas Hydrates is the latest addition to the list of Centers of excellence created under ILTP. The agreement for establishment of this Centre was formally concluded during the visit of Indian Prime Minister, A. B. Vajpayee, to Russia in November 2003 between the department of Science \& Technology on the Indian side and the Russian Academy of Sciences on the Russian side. The Centre was inaugurated at National Institute of Ocean Technology, Chennai on $12^{\text {th }}$ March $2004^{84}$.

India and Korea signed in 2005 six memoranda of understanding (MoUs) for cooperation in the hydrocarbon sector. A MoU on Gas Hydrate related technical collaboration was signed between Director Genral of Hydrocarbons, Ministry of Petroleum \& Natural Gas Shri V.K. Sibal and Director GHDO of Korea, Mr. Kem Pil Park. The MoU was signed for collaboration between the two countries for R\&D in the field of gas hydrates, which is a large unconventional resource of energy of future. The most important field of R\&D is to establish a commercial technology to produce gas from gas hydrates, which so far does not exist anywhere in the world ${ }^{103}$.

Based on the results obtained from the integrated studies and critical reevaluation of the multichannel seismic reflection (both 2D and 3D data), the NGHP Technical Committee recommended for field validation studies. As an outcome of the recommendations, the drill ship "JOIDES Resolution" was utilized for R\&D purposes 
through an agreement between Directorate-General of Hydrocarbons and the US Geological Survey which was involved in drilling Gas hydrates in the Indian offshore waters (May-Aug 2006) ${ }^{109}$. An international consortium of more than 100 scientists conducted the research program.

The drill ship "JOIDES Resolution" left Mumbai on April 30, 2006 to conduct drilling, coring and logging activities. The drilling program consisted of three legs carried out in 113 days, at a budgeted cost of about $\$ 36$ million funded by the Oil Industry Development Board ${ }^{110}$.

In mid-August, 2006 a team of scientists from India, North America, and Europe, led by the Indian Directorate General of Hydrocarbons (DGH) and the U.S. Geological Survey (USGS), completed a four-month expedition aboard the drillship "JOIDES Resolution" to explore for the occurrence of gas hydrates in the offshore of India. The field trip successfully established the presence of sizeable reserves of good quality gas hydrates in the sedimentary basins of the country. According to an official release, results from a site in Krishna-Godavari $(\mathrm{KG})$ basin are particularly remarkable showing a presence of $128 \mathrm{~m}$ thick gas hydrate layer, the statement said. India is the third country in the world after the US and Japan to collect gas hydrate samples in its deep waters ${ }^{109}$.

Some results from the field work carried out during this project were presented in the meeting of the American Geophysical Union (AGU) held in San Francisco, California during December 10-14 2007 111 .

More results were released on February 7, 2008. This was the first modern gas hydrate research and exploration program conducted in India's offshore through Indian National Gas Hydrate Program (NGHP) Expedition 01. Scientists conducted ocean drilling, coring, logging and analytical activities to assess the geologic occurrence, regional context and characteristics of gas hydrate deposits along India. An international team led by the USGS and the Directorate General of Hydrocarbons, which is under the government of India's Ministry of Petroleum and Natural Gas, conducted the expedition ${ }^{105}$.

Highlights include:

- Gas hydrate was discovered in numerous complex geologic settings and an unprecedented number of gas hydrate cores and scientific data were collected.

- One of the richest marine gas hydrate accumulations ever discovered was delineated and sampled in the Krishna-Godavari Basin.

- One of the thickest and deepest gas hydrate occurrences yet known was discovered offshore of the Andaman Islands and revealed gas hydrate-bearing volcanic ash layers as deep as 600 meters below the seafloor.

- For the first time, a fully developed gas hydrate system was established in the Mahanadi Basin of the Bay of Bengal. 
A number of research and operational organizations were involved in the research expedition. Indian NGHP Expedition 01 was collaboratively planned and managed by the Directorate General of Hydrocarbons, the USGS and the Consortium for Scientific Methane Hydrate Investigations, led by Overseas Drilling Ltd (ODL) and Fugro McClelland Marine Geosciences (FUGRO).

The platform for the drilling operation was the research drill ship Joint Oceanographic Institutions for Deep Earth Sampling (JOIDES) Resolution, operated by ODL. Much of the drilling and coring equipment used was provided by the Integrated Ocean Drilling Program through a loan agreement with the U.S. National Science Foundation.

Wireline pressure coring systems and supporting laboratories were provided by Integrated Ocean Drilling Program (IODP), Texas A\&M University, FUGRO, USGS, the U.S. Department of Energy (DOE) and Hyacinth/GeoTek. Downhole logging operational and technical support were provided by Lamont-Doherty Earth Observatory of Columbia University.

Participants in Indian NGHP Expedition 01 presented study results at the February Indian National Gas Hydrate Program Gas Hydrate Conference in New Delhi. These results, documented in the NGHP Expedition 01 Initial Reports released at the conference, included the operational history and scientific data collected during the expedition.

From April 28 - Aug. 19, 2006, scientists explored and collected data from 21 sites, penetrated more than 9,250 meters of sedimentary section and recovered nearly 2,850 meters of core, according to USGS ${ }^{105}$.

India has started looking for ships and submersibles adequately prepared for extraction of gas hydrates from sea bed as the country is having a vast $7500 \mathrm{~km}$ plus coast line. The vessel requirements to extract gas hydrates are,

- $\quad$ ships capable of extracting gas hydrates

- manned or unmanned submersibles to explore sea bed

In 2008 the ship Sagar Nidhi was commissioned for this especial purpose. It is an Italian built, 104 metres long vessel with dynamic positioning system and with a winch to hoist 60 tons from a depth of 6,000 meters has joined the fleet of Indian research vessels capable of launching submersibles to a depth of 6000 meters for exploring the ocean floor $^{112}$.

India has already developed a remotely operated unmanned submersible which is 2.53 $\mathrm{m}$ long, $1.80 \mathrm{~m}$ wide with height of $1.70 \mathrm{~m}$. This can carry a payload of $150 \mathrm{~kg}$. Further India is going ahead to build a manned submersible to explore the oceans at 6000 meters $\operatorname{depth}^{112}$.

In April and June 2008, the U.S. Department of Energy signed agreements for cooperative research efforts with representatives from three countries with gas hydrate 
research programs: India, Korea and $\operatorname{Japan}^{50}$. Officials from DOE and the Indian government signed a Memorandum of Understanding for Cooperation in Methane Hydrate Research and Development in New Delhi on April 4, 2008. The agreement provides for exchange of information and personnel in the areas of exploration and quantification of natural gas hydrates, resource assessments, laboratory characterization, and production testing ${ }^{104}$.

\section{CHINA}

China has shown recent interest in gas hydrates exploration in the South China Sea. The South China Sea is the largest marginal sea in the western Pacific, and it is well known for its abundant oil and gas reserves. A broad and wide continental slope 210,000 $\mathrm{km}^{2}$ in area extends to the northern parts of the South China Sea. This area is a good site for gas hydrate formation and conservation. Furthermore, bottom simulating reflectors (BSRs) have been found on the Northern slope (Song ${ }^{113}$, 2001). Sites 1144 and 1148 located on Donsha region north of South China Sea and lowermost continental slop off southern China have been studied ${ }^{114}$ by using seismic, sonic logging and geothermal data. Bottom simulating reflectors (BSRs) and amplitude blanking zone were found in seismic profiles. And high-velocity interval and velocity reverse were distinguished in sonic logging curves at both sites. The gas hydrates stability zone (GHSZ) based on a conduction thermal flow model and BSR at site 1144 are basically in agreement, while the GHSZ calculated from using a geothermal gradient conduction model is smaller than the one predicted from the BSR seismic method at site 1148 . Chen et al. ${ }^{114}$ tried to explain the differences between the two sites by using a one-dimensional model of gas hydrate formation and evolution in which they considered the effects of multiple gas composition. The authors conducted a comparison between seismic data and simulation results. They concluded, based on their convection and conduction mixed thermal flow model that the GHSZ in both sites is much deeper than GHDZ predicted from the BSR ${ }^{114}$.

According to an AP release from August 23, 2006 ${ }^{115}$ China decided to spend 800 million yuans, or U\$S 100 million, over the next decade on studying natural gas hydrates, an alternative fuel Beijing hopes might help to limit its growing reliance on oil imports. Trial exploration of methane hydrate, a crystalline compound of water and natural gas, is expected to become viable between 2010 and 2015, the government planning agency said in a report on its Web site ${ }^{115}$. The report said that China planned to work with German researchers to sample hydrate deposits in the northern part of the South China Sea within a year. The report also says that China so far has discovered enormous reserves of gas hydrates in offshore areas; those spotted in the northern part of the South China Sea are expected to amount to half the country's onshore oil resources.

China announced on June 6, 2007 a major breakthrough in excavating natural gas hydrates. Zhang Hongtao, deputy director-general of China Geological Survey (CGS), said gas hydrate samples were successfully collected from the northern part of the South China Sea in May, 2007. China is the fourth country after the United States, Japan and 
India to achieve such technological feat. Initial estimates indicate the potential volume of gas hydrates around continental slopes in the area exceeds 100 million tons of oil equivalent, Zhang said. The samples were collected from two different stations in the Shenhu (Magic Fox) continental slope on May 1 and May 15, he said ${ }^{116}$. China's research into alternative energy sources is still in its initial stages, a spokesperson with the Ministry of Land and Resources (MLR) said. Since 1999, the ministry has spent 500 million yuan on gas hydrate research projects in the sea, including an unsuccessful joint attempt by Chinese and German geologists to recover gas hydrates in 2004, when thick carbonate crust produced from methane and water molecules smashed the detection ${ }^{116}$.

In June, 2007, the geotechnical drillship SRV Bavenit sailed into Shenzhen, People's Republic of China, with a cargo of frozen gas hydrate samples. China's first gas hydrate drilling expedition, GMGS-1, was carried out by Fugro and Geotek for the Guangzhou Marine Geological Survey (GMGS), China Geological Survey (CGS), and the Ministry of Land and Resources of P. R. China. The expedition, which comprised two legs from April 21st-May 18th and May 19th-June 12th, visited eight sites in the northern South China Sea and described a new gas hydrate province ${ }^{117}$.

Gas hydrate was detected at three of the five sites cored. The sediments were predominantly clay, with a variable amount of silt-sized particles including foraminifera. Methane was the predominant gas within core voids as well as in gas hydrate; ethane was $0.1 \%$ or less of most gas samples (maximum ethane concentration $0.8 \%$ ). Even at relatively high gas hydrate saturations, all the gas hydrate found during the expedition was dispersed within the pore spaces of the sediment as determined from the nondestructive analyses of pressure cores. Quantification of gas hydrate from both pressure core methane mass balance and porewater freshening analysis confirmed that the hydrate-bearing sediment layers contained $20-40 \%$ gas hydrate as a percentage of pore volume. These gas-hydrate-containing sediment layers were 10 to 25 meters thick and were situated directly above the base of gas hydrate stability zone, which was near 200 meters below seafloor. No other gas hydrate was found within the stability field above these layers, which was supported by the pressure core data which indicated undersaturation of methane in the porewater above the gas-hydrate-rich layers. The presence and absence of gas hydrate correlated well with electrical resistivity log data at all five sites cored, and despite the relatively low values of the resistivity anomalies, there appeared to be a direct relationship between the resistivity and the measured gas hydrate concentrations in the cores. While there was no obvious correlation between gas hydrate occurrence and seismic data, further research on this topic is ongoing.

The gas hydrate found in the Shenhu area in the northern South China Sea was the first recorded gas hydrate drilled in the South China Sea. The distribution of gas hydrate in these passive margin sediments, in a relatively homogenous layer, limited to the strata immediately above the base of gas hydrate stability, is the type of distribution predicted from simple models of gas hydrate formation (e.g. Hyndman and Davis ${ }^{118}$, 1992; Xu and Ruppel $^{119}$, 1999). However, a clear field example of such a gas hydrate distribution has not previously been reported. This occurrence of thick $(>10 \mathrm{~m})$ and uniform (all samples 
with gas hydrate at $20-40 \%$ of pore space) gas hydrate just above the bottom simulating reflector (BSR) makes the Shenhu region very appealing for studies connecting modeling of gas hydrate formation with real field data ${ }^{117}$.

Further analysis of samples and data collected during the expedition will continue at GMGS and throughout China. Cores will be split, described, and sampled at GMGS in the coming months. Analysis of the samples taken on board the ship is underway, including samples of gas-hydrate-bearing sediments preserved in liquid nitrogen. The core data will be correlated with the downhole log data, especially the electrical resistivity, to improve predictive models of gas hydrate concentration for future expeditions to the Shenhu region, and both the core and log data will be used to closely re examine the seismic data to develop predictive capability from remote data sets ${ }^{117}$.

\section{MINOR PLAYERS}

\section{Research in Taiwan}

In February 2004, the Central Geological Survey of the Ministry of Economic Affairs, ROC launched a 4-year gas hydrate investigation program for the purposes of understanding the gas hydrate distribution and its geological controls offshore southwestern Taiwan, and to estimate its energy potentials. Results from the first 2 years of investigation reveal that BSRs are widely distributed in both the active accretionary wedge and the passive continental slope regions. Geological and geochemical studies have found evidences of methane vents and authigenic carbonates. This workshop, held in the mid-point of the 4-year gas hydrate program, served as a platform to present, discuss and integrate investigation results from different colleagues in Taiwan who had been engaged in gas hydrate research work using various geophysical, geological and geochemical techniques ${ }^{120}$.

In the fall of 2004, four profiles of a total length of about $80 \mathrm{~km}$ and 24 recovered Ocean Bottom Seismometers (OBSs) were acquired along offshore southwestern Taiwan. These profiles were oriented in E-W and N-S directions to map the velocity structure of sediments by modeling the vertical component of OBS data. The thickness of sedimentary layers ranges from a few hundred meters to about $2 \mathrm{~km}$, with the largest thickness being found beneath ridges. The most striking feature in the velocity models along E-W profiles was the relatively high velocity wedges, extending from the seafloor to about $2 \mathrm{~km}$ in depth; these could be interpreted as a series of westward upthrust faults. The feature of relatively high P-wave velocity was considered a result of local lowering of the base of the gas hydrate stability zone, caused by ascending flows of deep fluids passing through the fault zone. In the N-S profiles, a dome-like high velocity structure was observed and could be associated with the phenomenon of hydrate/gas phase boundary fluctuation. After erosion, the sub-seafloor temperature gradient redistributes and results in the hydrate/gas phase boundary moving downward. The results obtained in this study show that tectonic control is an important factor in determining bottomsimulating reflector (BSR) distributions offshore of southwestern Taiwan ${ }^{121}$. 


\section{Research in Spain}

In Spain active research has been conducted in the gulf of Cadiz. This research program has been sponsored by UNESCO through the Training Through Research program (TTR). The oceanographic cruise TTR-10 was coordinated by Prof. Michael Ivanov of the University of Moscow, Luis Pinheiro of the IGM (Geological Survey of Portugal) and by Dr. Luis Somoza, marine investigator of the ITGE like part of the project TASYO framed in the Spanish program of Sciences and Marine Technologies ${ }^{122}$.

The discovery of deposits of gas hydrates in the submarine floor of the Gulf of Cadiz, by investigators of the University of Moscow, Instituto Geologico e Minheiro de Portugal (IGN) and of marine geology of the Institute Geològico y Minero de España (IGME) opens new perspectives in the investigation of the natural resources of the marine seabed in the bordering countries.

In the year 1999, the presence of gas hydrates in the Gulf of Cadiz have caused the interest of other international organisms of investigation. A Naval Research Laboratory of the United States has carried out in 1999 a series of studies using multibeam echo sounding of wide range with the objective of mapping those big submarine deposits in the Moroccan area of the one Gulf of the Cadiz. On the other hand, the Floating University of the University of Moscow, through the program TTR, financed by the Commission International Oceanographic (COI) of UNESCO has carried out studies in the Gulf of Cadiz in several submarine areas and found equivalent amounts of gas hydrates in the Moroccan and Spanish-Portuguese areas using the oceanographic ship "Professor Logachev ${ }^{122}$."

In the year 2000, during the month of May, oceanographic research was carried out in waters of the Gulf of Cadiz by the ship BIO "Hesperides," The objective was the prospecting of gas hydrates deposits in the slope of the Hispanic-Portuguese continental margin. This ship is endowed with modern geologic oceanography instrumentation, such as, multi-beam echo-sound and multifold seismic reflection. As complement of this campaign, in September of 2000, the ship Cornide of Saavedra of the Spanish Institute of Oceanography took samples and analyzed silts samples in the Gulf of Cádiz ${ }^{122}$.

Another study was carried out as a part of the joint Dutch-Russian NWO/RFBR Dutch-Russian cooperative project (047.017.003) between the Royal NIOZ and the UNESCO/MSU Center for Marine Geology and Geophysics entitled "Evolution and Ecology of Cold Seep Structures in the Gulf of Cadiz".

The gas hydrate formation in the Gulf of Cadiz depend on the following: temperature of the near bottom water that varied from 12 (near Gibraltar and shelf) to 2-4 degree C (at the deep water areas) due to climate, shallow-water environment of the shelf water areas, and due an influence of the warm Mediterranean outflow or cold Atlantic waters. Both gas hydrates of cubic structures I and II are known in the Gulf o Cadiz. This fact implies different PT conditions necessary for the hydrate formation; all known to be found in the Gulf of Cadiz. Gas hydrate occurrences are associated with mud volcanism suggesting a 
specific mechanism for the gas hydrate formation, and defining the size and shape of the gas hydrate accumulations. The gas hydrate accumulation occurs at the water depth defining PT conditions which are close to the stability boundary (GHSZ) for the methane hydrate formation under the temperature of the bottom water of about 11 degree $\mathrm{C}$. Thus, the upper boundary of the GHSZ is limited by the $800-900 \mathrm{~m}$ depth level (for the structure II gas hydrates ${ }^{85}$ ).

For the formation of structure I hydrate the water depth must be greater. The lower GHSZ boundary is outlined by the continental slop line. The deepest gas hydrate accumulation associated with the Porto mud volcano occurs at water depth of about 4000 $\mathrm{m}$.

In the Gulf of Cadiz about 20 mud volcanoes are known within the limits of the GHSZ, nine of them are gas hydrate-bearing. In fact, the number of the mud volcanoes situated within the limits of the GHSZ should be at list several times more. The sizes of the gas hydrate accumulations roughly correspond to the size of mud volcanoes and are approximated by circles with diameters varying from 1.5 to $4 \mathrm{~km}$. The total gas budget captured by hydrates at these accumulations is estimated to be as much as $2.810^{10}$ cubic meters of gas. It should be noted, that the gas hydrates resource potential of the Gulf of Cadiz should be greater because the number of discovered mud volcanoes increases year after year ${ }^{85}$.

The $19^{\text {th }}$ Petroleum Congress was held in Madrid, Spain during June $29^{\text {th }}$ to July $3^{\text {rd }}$, 2008. There was a section on gas hydrates (13F). Two relevant articles about research done on India ${ }^{123}$ and South Korea ${ }^{124}$ were presented.

\section{Research in Nigeria}

Gas hydrates have been collected in 6-meter piston cores during surface geochemical exploration (SGE) surveys in the deep and ultra deep-waters of Nigeria in 1991, 1996, and 1998. To date, gas hydrates have been collected in $\sim 21$ cores out of the $>800$ core collections on the Nigerian margin. This represents a $2.5 \%$ recovery ratio of gas hydrate bearing cores on this margin at sites that are potential conduits for the upward migration of hydrocarbons (i.e., core locations are sited based on 2-D and 3-D seismic over faults, mounds, acoustic wipe-outs, etc.). All the gas hydrate collections offshore Nigeria to date have been primarily biogenic in nature (methane $>99 \%$ of the hydrocarbon gases; -60 to $117 \%$ ). A few of these gas hydrate sites contain a mixed thermogenic gas component (ethane to butane gases up to a few hundred ppm of total hydrocarbon gas), but even at these sites the primary gas in the hydrates is methane ${ }^{125}$.

There is migration of liquid hydrocarbons to shallow sediments that is common on the Nigerian continental margin. For example, a SGE coring survey on the Nigerian ultra deep water continental margin in 1996 collected 10 cores out of 130 with visible liquid hydrocarbons within portions of the 4.0 to 5.0 meters of sediment generally retrieved by the piston cores. However, in many cases there is little gas associated with these sites and the collection of gas hydrate bearing cores is generally independent of the macroseepage 
of liquid hydrocarbon core sites. Bottom Simulating Reflectors (BSRs) are often associated with the macroseepage core sites in Nigeria. BSRs are common on the seismic records of the Nigerian continental slope. The sub-bottom depth of the BSRs range between $\sim 200$ to $\sim 500$ meters and are often associated with various geological structures such as faults. When gas hydrates are collected in cores they often consist of disseminated nodules of a few centimeters in diameter within the mud matrix a few meters sub-bottom or are massive ( 5 to $10+\mathrm{cm}$ thick) and come up as the bottom of the core. The depth of the BSRs are found generally at similar or shallower depths than the calculated base of the methane hydrate stability zone using known bottom water temperatures and thermal gradients for the region ${ }^{125}$.

\section{Research in Chile}

Chile has already started exploration work on this field, in areas that according previous research should have hydrates deposits. The Chilean convergent margin is one of the most dynamic regions on Earth. The tectonic activity is intense as manifested in tectonic uplift, folding and fracturing. Over time, tectonics has produced a dominant morphology, steeped topography gradient between the Peru-Chile trench and the Andes Mountains that often exceeds the $12 \mathrm{Km}$ change in elevation over a horizontal distance of $250 \mathrm{~km}$. Although the rate of convergence between the plates change only gradually with latitude and ages of the two plates along the join, only a relatively small amount vary, marked along-trench variations in trench depth, trench curvature, slope gradient, coastal geology, elevations of the Andes mountains, volcanism, and depths to earthquake hypocenters indicate that the subduction process is indeed variable and complex ${ }^{126}$.

At the Chilean margin, seismic marine studies have allowed the identification of gas hydrates by means of bottom-simulating reflection (BSR) identification. The survey area was located across the Chilean convergent margin between approximately $35^{\circ}$ and $45^{\circ} \mathrm{S}$.

Leg 141 drilling of ODP in the vicinity of Chile triple junction has confirmed the presence of gas hydrate layer where the BSR was mostly predominant. The concentration of hydrate estimated from geophysical $\log$ at site 859 ranges from $10 \%$ to $18 \%$ of the pore space. The modeling of seismic data for observing AVO effect of the BSR indicates that small quantities of free gas (approx. 1\%) were probably present below the $\mathrm{BSR}^{127}$.

The line Enap I cover from the outer trench slope across the continental shelf for 155 $\mathrm{km}$, in the mean latitude of $35^{\circ} 57^{\prime} \mathrm{S}$. The BSR, in an almost continuous line at a distance ranging 400 to $700 \mathrm{~m}$ depth, at the upper slope, where the water depth equals $750 \mathrm{~m}$. Through a distance of approximately $35 \mathrm{~km}$ long, there can be observed three well developed basins of $1200 \mathrm{~m} ; 1200 \mathrm{~m}$, and $800 \mathrm{~m}$ thick, respectively ${ }^{126}$.

The line ENAP2 in the mean latitude of $36^{\circ} 15^{\prime} \mathrm{S}$ extends $146.5 \mathrm{~km}$ from the outer trench slope to the continental shelf. In this area a series of slope basins showing a staircase-like shape can be observed. The BSR can be followed from one of the basins 
with $1300 \mathrm{~m}$ to the basins of $1650 \mathrm{~m}$ thick and lies at a depth of 400 to $600 \mathrm{~m}$ for $25 \mathrm{~km}$ of longitude ${ }^{128}$.

\section{Research in Colombia}

Colombian Caribbean gas hydrate occurrence was first described by Shipley et al. ${ }^{129}$ (1979) based on the Bottom-Simulating reflector (BSR). Nevertheless, only few studies have derived thermal information from the occurrence of hydrates. Based upon four seismic lines acquired by Lamont Doherty Observatory in 1977, Ladd et al. ${ }^{130}$ (1984) interpreted the BSR along the South Caribbean deformed belt, between depths of 2, 3 to 4.2 kilometers. They calculated the geothermal gradient from the observed BSR, obtaining a value of $313,15 \mathrm{~K} / \mathrm{km}$. Gomez and León ${ }^{131}$ (2000), evaluated the existence of methane hydrates in the Colombian Basin, concluding that hydrate deposits could store methane gas in the order of 22 TCM, based on regional seismic lines. Applying gas flow in porous media, heat conduction, and gas hydrate properties equations, Caicedo and Pinto $^{132}$ (2003), validated a mathematical model obtained from de-pressurization of a hydrate deposit in contact with a gas layer, by using computer software (SDYHGAS). Lópe $^{133}$ (2005) determined the geothermal gradient from the BSR assuming that it represents the base of the gas hydrate stability zone. However a map of the regional heat flow variation does not yet exist.

Geothermal heat flow in gas hydrate zones can be determined theoretically from the Bottom-Simulating Reflector. A Bottom-Simulating Reflector (BSR) has been observed in multichannel seismic data from the Caribbean offshore Colombia. This anomalous reflector, known to correspond with the base of the Gas Hydrate Stability Zone (GHSZ), can be used to estimate a range of possible values for the local heat flow using the stability field of gas hydrates and the thermal conductivity of the sediments. The study area extends from northern Guajira in the north to the Gulf of Uraba in the south, covering some $18000 \mathrm{~km}^{2}$. The heat flow was found to be $27,6 \pm 4 \mathrm{~mW} / \mathrm{m}^{2}$ off the coast of Barranquilla, $37,9 \pm 3,6 \mathrm{~mW} / \mathrm{m}^{2}$ for northern Guajira, 33,2 $\pm 5,5 \mathrm{~mW} / \mathrm{m}^{2}$ for the central Guajira and $34,7 \pm 9,4 \mathrm{~mW} / \mathrm{m}^{2}$ for the Cartagena -Gulf of Uraba offshore areas. These results are comparable to heat flow estimates of 30 and $42 \mathrm{~mW} / \mathrm{m}^{2}$ obtained for the south Caribbean by others using alternate methods. The estimated heat flow is relatively low in relation to other continental margins. The continuous and fast sedimentation rate from the Magdalena River may explain the anomalously low heat flow in the river delta area. The Cartagena-Gulf of Uraba zone evidences the presence of advection heat loss in the accretionary wedge of the South Caribbean deformation front ${ }^{134}$.

\section{Research in New Zealand}

Methane hydrates are abundant on the two active continental margin regions of offshore New Zealand. The New Zealand crust consists of a rifted fragment of Gondwana that now straddles the Pacific / Australian plate boundary. Along the east coast of the North Island, oceanic Pacific crust subducts under a continental block of the Australian Plate along the Hikurangi margin; to the west of Fiordland on the South Island, oceanic Australian crust subducts under a continental block on the Pacific Plate. Gas hydrate 
accumulations along these margins occur over well-constrained pressure and temperature ranges in the upper $500 \mathrm{~m}$ or so of seafloor sediments and in water depths of at least 600 m. Over the past few years, researchers at the University of Otago and GNS Science (New Zealand's geologically oriented crown research institute) have made use of existing industry and government seismic data sets to assess the extent of gas hydrates on New Zealand's margins and to estimate volumes of methane associated with them. This has primarily been done by the identification and analysis of bottom simulating reflectors (BSRs) in the seismic data. In active margins, such as the subduction related Hikurangi and Fiordland margins, high fluid flux often results in the maintenance of a free-gas reservoir under any significant hydrate accumulation. As a result, regions of high concentrations of hydrate will often correspond to zones of significant BSRs ${ }^{135}$.

\section{Research in Peru}

In Peru seismic reflection data recorded near ODP site 688, offshore Peru, exhibited a persistent BSR from the base of theoretical stability field. Concentrations of gas hydrate that fill fractures were observed in the split cores, and an especially large sample was extracted from the core at $141 \mathrm{~m}$ depth. The association of gas hydrate with the black organic-rich sediment suggests a source of methane in the former from the latter ${ }^{136}$.

\section{RECENT Corporate/Joint-Projects}

\section{Japanese Companies Involved in Gas Hydrates Research}

Japan Oil, Gas and Metals National Corporation (JOGMEC) was established in February 2004 with the mission of securing a stable supply of oil, natural gas, nonferrous metals and minerals to Japan, and controlling pollution caused by metal mining activities. The corporation provides financial assistance to support Japanese private companies' exploration, production and stockpiling activities in the fields of oil, natural gas and metals, and assists pollution control activities for metal mining in Japan. The corporation also collects, analyzes and disseminates information about the global energy industry and natural resources to companies in Japan ${ }^{27}$.

JOGMEC conducts a wide range of activities inside and outside Japan in the oil field. Some of these activities include support to the oil industry in several countries all over the world, including Kuwait, Saudi Arabia, and Iraq, among others. The corporation also occupies a leadership position in gas hydrate exploration ${ }^{27}$.

Japan Petroleum Exploration Co. (JAPEX) is a leading Japanese upstream company engaged in oil and natural gas E\&P activities both in Japan and overseas. Its main operating areas are Hokkaido, Akita, Yamagata and Niigata in Japan, and Canada, Indonesia, China, the Philippines, Libya, and other world regions ${ }^{29}$.

Several private companies are also involved in gas hydrates research, for example: Teikoku Oil Co., Ltd. (TOC) has been a frequent partner in several government funded research projects ${ }^{28}$. 
JAPEX was founded in December 1955 as a special purpose company through a government initiative and has continued to explore and produce oil and natural gas in Japan and expand its activities overseas. JAPEX was established in April 1970 as a private company under the former Commercial Code. JAPEX listed on the First Section of the Tokyo Stock Exchange in December 2003. JAPEX has been actively involved in the development of gas hydrate technology, playing a central role in joint research carried out between 1995 and1999 with JNOC (JNOC changed its name to Japan Oil, Gas and Metals National Corporation (JOGMEC)) and a number of private-sector companies. In fiscal 1999, JAPEX became the first company in Japan to successfully drill and core a methane hydrate layer in domestic waters. In 2001, the company began full-scale joint research into possible uses for methane hydrate with a number of public and private agencies. The research carried out includes the start of drilling and survey activities off the east coast of Japan's Tokai region in January 2004, with JAPEX selected as the operator. The company plans to play a leadership role in research and development into methane hydrates in Japan ${ }^{29}$.

\section{Preliminary Results from the Chevron-Texaco Gulf of Mexico Gas Hydrates Joint Industrial Project (JIP): Hydrocarbon Gases in Sediments}

The Gulf of Mexico Gas Hydrates (JIP), in collaboration with the U.S. Department of Energy, is investigating naturally occurring gas hydrates in the Gulf of Mexico. The role in the JIP is to relate gas composition to gas hydrate formation and free gas deposits both in and out of the gas hydrate stability field. Pore water hydrocarbon gas composition in conjunction with chloride concentrations and geothermal gradients are important factors that dictate gas hydrate phase boundaries ${ }^{3}$. During April and May 2005, cores were taken and sampled for gases in lease blocks Atwater Valley 13 and 14 and Keathley Canyon 151. Sample types included sediment headspace gas, free gas derived from sediment gas ex-solution, and gas ex-solution from controlled degassing of pressurized cores. The gases measured both onboard and in shore-based labs were nitrogen, oxygen, hydrogen sulfide, carbon dioxide, and the hydrocarbons methane through hexane. Sediment gases at the Atwater Valley sites, where seafloor mounds and adjacent sediments were cored, strongly suggest a microbial source of methane, with very little thermogenic gas input. Methane concentrations in free gas ranged from about 96 to 99.9 percent, with the balance composed of carbon dioxide. Methane to ethane ratios are greater than 1000 and often over 10,000 indicating a microbial gas source. Gases from cores at Keathley Canyon were similar to those at Atwater Valley, however, deeper cores contained increasing concentrations of ethane, propane, and butane suggesting that low concentrations of thermogenic gases are present. The gas composition of sediment and free gas in these sites suggests that gas hydrate is composed mainly of methane, and that the gas hydrate is likely structure 1 . Thus, models of gas hydrate occurrence in these areas need to consider methane hydrate ${ }^{137}$. More information can be found under the Japanese research program. 


\section{BP Drills Alaska North Slope Gas Hydrate Test Well to Assess Potential Energy Resource}

BP Exploration (Alaska) Inc. successfully drilled a research well on the North Slope in partnership with the U.S. Department of Energy and the U.S. Geological Survey (USGS) to collect samples and gather knowledge about gas hydrate, a potential long-term unconventional gas energy resource. The stratigraphic test well enabled BP and the Department of Energy (DOE) to gather core, log, reservoir performance and fluid data from an ice pad location at Milne Point. The drilling began Feb 3, 2007. Field teams began pulling hydrate core samples on Feb. 10. Extensive well logging and wireline formation testing was completed between Feb. 14-18 $8^{138}$.

This test well is part of the ongoing research partnership between BP and the Department of Energy, which began in 2002. DOE identified gas hydrate as a research target and funded the estimated $\$ 4.6$ million cost of drilling the Milne test well. BP contributed seismic data, staffing and program oversight. The on-site coring and data team included scientists from the USGS, DOE, Oregon State University and an observer from India's hydrate program. Drilling crews and research team members collected about 430 feet of core samples. The cylindrical core segments, about 3 inches in diameter, were initially sub-sampled and analyzed on site due to the time-and temperature-dependent data requirements. They were shipped to Anchorage for temporary storage before being distributed to gas hydrate researchers around the country. Subsequent data collection and analysis was continue for several months ${ }^{138}$.

BP's current focus is on the successful completion of this stratigraphic test well, and subsequent analysis of the data. The direction of potential future program efforts will be determined with DOE following those evaluations. However, the results of the research program could lead to a hydrates production test ${ }^{138}$.

\section{Findings from the 2005 Drilling Campaign of the Gulf of Mexico Gas Hydrates Joint Industry Project}

In 2005, the DOE-Chevron Gas Hydrates Joint Industry Project (JIP) conducted a drilling, logging, and coring expedition designed to address concerns related to the safe drilling of deepwater oil and gas wells through gas-hydrate bearing strata. The two sites selected provided opportunities to test different geological settings for the fine-grained sediments typical of those found throughout the Gulf ${ }^{137}$. Wellbore stability modeling, as calibrated by the JIP drilling results, indicate that gas hydrates contained in the finegrained sediments of the Gulf of Mexico can pose hazards to drilling, but these hazards can be effectively managed. As for any other hydrocarbon, good drilling practices that promote wellbore stability are essential for safe and cost effective exploitation of gas hydrates reserves. The use of properly weighted drilling mud, washout mitigation procedures, adequate well cleaning, and identification of shallow hazards, are standard measures taken by industry when drilling in environments typical of those in which gas hydrates can be found. However many unique drilling hazards have been associated with gas hydrates. These include: (a) Loss of well control due to the influx of gas generated by 
drilling induced dissociation, (b) Borehole failure caused by the loss of formation competence accompanying dissociation, and (c) Loss of well control when drilling into overpressured gas below the hydrate stability zone. While these hazards may exist, recent experience suggests that they can be addressed through proper planning aimed at preventing gas hydrate dissociation and avoiding gas kicks due to an influx of free gas ${ }^{139}$.

In support of the 2005 Gulf of Mexico drilling campaign of the Chevron Joint Industry Participation Project (JIP) co-sponsored by the U.S. Department of Energy, extensive pre-drill planning was undertaken to determine the locations of overpressured zones and the conditions under which gas hydrates would dissociate during drilling. Temperature simulations indicated that controlling the circulation rate was the key to minimizing the thermal disturbance to the formation caused by drilling ${ }^{139}$. More information on the Chevron JIP project can be found under the Japanese research program.

\section{Comparison of Drilling Results to Pre-Drill estimates of Gas Hydrate Occurrence in 'Mount Elbert' Test Site in Alaska North Slope}

In February, 2007, the U.S. DOE, BP Exploration (Alaska), and the U.S. Geological Survey teamed to conduct a gas hydrates drilling, coring, and testing program at the "Mount Elbert" site on the Alaska North Slope ${ }^{140}$. This note describes the pre-drill geophysical characterization of the target zones at the Mount Elbert site, and compares those predictions with the drilling results. It is believed these results demonstrate the soundness of the geophysical techniques employed while indicating areas for further improvement of the methodology. The seismic prospecting that resulted in the selection of the Mount Elbert test site utilized 3-D seismic data for the Milne Point area of the larger Prudhoe Bay production region ${ }^{140}$.

Analysis of the data revealed a number of anomalous seismic events within the section between the base of the ice bearing permafrost and the estimated base of the gas hydrate stability zones. Overall, fourteen seismic anomalies consistent with significant intervals of anomalously high acoustic velocities suggesting gas hydrate occurrence were delineated. The seismic data were correlated to the existing well data to link each event to regional reservoir sand horizons. None of these anomalies had been penetrated by earlier drilling. In fact, no wells in the Milne Point area had encountered more than 20 feet of total gas hydrate ${ }^{140}$.

\section{MMS Releases Preliminary Results of Gulf of Mexico In-Place Natural Gas Hydrate Assessment}

The U.S. Minerals Management Service (MMS) has recently released the results of a systematic geological and statistical assessment of in-place gas hydrate resources in the Gulf of Mexico (GOM). This assessment incorporates the latest science with regard to the geological and geochemical controls on gas hydrate occurrence, and provides a mean volume of 607 trillion cubic meters (TCM) or 21444 trillion cubic feet (TCF) of methane in-place in hydrate form. In addition, the assessment has determined that a mean of 190 
TCM (6710 TCF) of this resource occurs as relatively high-concentration accumulations within sand reservoirs, with the remainder occurring within clay-dominated sediments ${ }^{141}$.

Recently, the MMS launched an effort to assess the natural gas hydrate resource potential across the entire area including the Alaskan, Atlantic, Gulf of Mexico, and Pacific margins. The goal of this ongoing project is to deliver, in succession, estimates of in-place, technically-recoverable, and economically-recoverable gas hydrates resources $^{141}$.

\section{Analysis of Pressure Test Data from the 'Mount Elbert' Gas Hydrates Well}

Since 2006, an international code comparison group (CCG) has collaborated in an effort to apply the leading gas hydrate numerical simulators to a series of idealized problems of increasing complexity. The CCG has completed work on the initial five problems, which moved from simple 1-D heat and mass transfer problems through a complex 3-D simulation of gas hydrate dissociation in an idealized reservoir ${ }^{142}$. Given the lack of real-world data on gas hydrate producibility, this effort provided the best opportunity for model verification and calibration, and has resulted in meaningful improvements to the codes employed by all the members of the $\mathrm{CCG}^{142}$.

In February, 2007, DOE-NETL, the USGS, and BP Exploration (Alaska), Inc., conducted an extensive research program at the "Mount Elbert" well site in the Milne Point region on the Alaska North Slope ${ }^{143}$. As part of this program, a series of experiments were conducted with Schlumberger's Modular Dynamic Tester (MDT) tool to explore the petrophysical properties of a highly gas hydrate saturated sandstone reservoir. Four zones were tested. In each zone a 1 meter section of wellbore was sealed off and testing proceeded through a series of stages. Each stage consisted of a period in which fluids were pumped from the formation, and a second period in which the pump was stopped and the pressure response observed. Gas and water samples were collected during selected flow periods and a fluid analyzer on the MDT tool enabled the identification (but not volumetric measurement) of gas and water as it entered the tool. Lastly, the team was able to emplace a small programmable sensor on the outside of the tool in order to monitor temperature changes during the operations ${ }^{143}$.

The only prior systematic tests of formation pressure response of a gas hydrate reservoir were conducted during the Mallik research program in $2002^{65,66}$. A unique aspect of the Mount Elbert program was the fact that these experiments were conducted in the open hole, removing many complexities related to the nature and effect of casing perforations. In addition, the individual Mount Elbert tests were of much longer duration, with the test lengths ranging from 6 to nearly 12 hours. Notably, these four tests produced consistent formation responses to depressurization. To provide an additional data set, the CCG agreed to attempt to history match the data from the "C-2" test as the $6^{\text {th }}$ problem of their collaborative effort ${ }^{143}$.

The C-2 MDT test was one of four tests conducted and was marked by three primary experimental phases. Initially, the reservoir was pumped for 15.5 minutes in a manner that did not reduce formation pressure below that which would cause hydrate 
dissociation. Upon shut-in, the reservoir pressure built back up in a manner consistent with a "porous media" response. This initial phase is significant in that it confirmed the ability of a highly-saturated gas hydrate reservoir to flow formation water in response to depressurization. Such flow is critical to the ability to depressurize gas hydrate reservoirs that are not in direct communication with subjacent free gas or free water zones. All members of the CCG team were able to history match this first data set with little difficulty. Furthermore, all team members reported estimates of formation permeability within a narrow range (from 0.12 to $0.17 \mathrm{md}$ - slightly higher than that estimated from the Mallik tests and slightly greater than that typically used as an upper limit defining a tight gas reservoir, $0.1 \mathrm{md}$ ). The second experimental phase of the $\mathrm{C}-2$ test included another 15.7 minute flow, this time with pressure drop sufficient to initiate hydrate dissociation. Upon shut-in, the pressure response was observed to be much slower, or muted. A third phase involved a 116.9 minute flow during which a fluid (gas and/or water) was extracted, followed by more than four hours of shut-in. Pressure response in this phase was even more restricted than in phase 2 . In addition, both the $2^{\text {nd }}$ and $3^{\text {rd }}$ shut-ins showed an unexpected "kink" within the early stages of the pressure build-up. Both phenomena, the muted responses after shut-in following hydrate dissociation and the "kink," were repeated in other MDT tests and are clearly manifestations of some as yet poorly understood process ${ }^{143}$.

\section{Acoustic Imaging of Gas Hydrate and Free Gas at the Storegga Slide}

Analysis of $\mathrm{P}$ wave velocities of an ocean-bottom cable (OBC) data set demonstrated the existence of gas hydrates and free gas on the northern flank of the Storegga Slide, in the North $\mathrm{Sea}^{144}$.

The distribution and concentration of gas hydrates and free gas showed significant variation over the length of the OBC. Average gas hydrate saturation of pore space was $5 \%$, when modeled by effective-medium theory with hydrates as a sediment-frame component. Average gas saturation was $0.45 \%$ assuming homogeneous distribution. The bottom-simulating reflector (BSR) is generally identified as termination of enhanced reflection, but in some places appeared as a reflection proper. Amplitude anomalies related to the BSR are primarily caused by the gas and not the hydrates. The gas hydrates at the Storegga Slide developed from gas-rich fluids migrating into the gas-hydrate stability zone (GHSZ) from the sediments below. Development of polygonal faults and the related expulsion of formation water might drive the fluid flow in the area. The physical and geological properties of the sediments control the distribution and concentration of gas, which migrates predominantly along strata rather than along the base of the GHSZ. This migration mechanism controls the flux of gas-rich fluids into the GHSZ and hence the distribution of gas hydrates and the variation in gas hydrate concentration $^{144}$.

\section{DOE-Sponsored Beaufort Sea Climate Studies}

On September 26, 2009, the U.S. Naval Research Laboratory (NRL) in collaboration with the U.S. Department of Energy National Energy Technology Laboratory (NETL), 
the Royal Netherlands Institute for Sea Research (NIOZ), and a team of 32 university and government scientists from the U.S., Netherlands, Belgium and Germany completed an expedition in the Beaufort Sea. The 12 days Methane in the Arctic Shelf/Slope (MITAS) expedition represents the first step in a thorough evaluation of the distributions and concentrations of methane and methane hydrates in the U.S. portion of the Arctic ocean $^{145}$.

The Methane in the Arctic Shelf/Slope expedition was one of the first major field projects to place a dominant focus on the global climate aspects of this issue in the United States. The 12 days expedition, the first comprehensive and dedicated study of the continental shelf and slope found under the U.S. Beaufort Sea, accomplished an extensive set of goals, including, obtaining data to help understand the source and fate of methane fluxes in this region. These fluxes can be found in a variety of environments including: permafrost, deep gas hydrate reservoirs, or shallow marine sediments. The data also helped characterize the potential pathways in which methane enters the overlying water column and then, potentially, the atmosphere ${ }^{145}$.

\section{Brief Review of Gas Hydrate Research by USA Agencies and Companies}

Gas hydrates research conducted in and by United States agencies has not been a formal part of this research project. However, information about many different research activities has surfaced under the different international research programs. A short summary is included here for completeness. Gas hydrate research has also a long history in the USA. The USA Department of Energy (DOE) has carried groundbreaking research under the 2000 Gas Hydrates Research and Development Act of Congress that allocated funds for a period of five years with an extension for other five. Osadek et. al. ${ }^{146}$ reported that in 2000 the United States House of Representative authorized U\$S165 million over five years for new research. This information includes renewal for five more years of the House of Representatives Methane Hydrates Research and Development Act of 2000 (H. R. 1753) ${ }^{147}$. The original act of Congress allocated U\$S 47.5 millions. However, the US Department of Energy (DOE) got significantly less funds than the original authorized amounts $^{148}$. An extension of five more years has been authorized; however, is still unknown if the originally authorized amounts have been provided ${ }^{149}$.

DOE has not been the sole sponsor of methane hydrates research. The US Geological Survey (USGS), Materials Management Service (MMS), National Science Foundation (NSF), and Naval Research Laboratory (NRL) all have funded hydrate-related $\operatorname{research}^{150}$.

Several Universities and private companies have been also involved in this research area. As of 2000, USGS supported U\$S 700,000-800,000 yearly in research funding. NSF allocated approximately U\$S 750,000-1 million, and NRL planned U\$S 1 million per year through $2004^{150}$.

In April 2007, the 'Technical Coordination Team of the National Methane Hydrate R\&D Program" established a five year research plan to achieve the long-term goals of the 
National Methane Hydrate R\&D program. The document sets clear goals for several federal agencies ${ }^{151}$.

There has also been a long USA participation in the research been carried out in the Canadian Arctic 46, 47, 65, 66. US researchers have been involved in many efforts in association with India ${ }^{105,111}$, South Korea ${ }^{98,100}$, and Japan ${ }^{43,46,47,55}$, among others.

In April and June 2008, the U.S. Department of Energy signed agreements for cooperative research efforts with representatives from three countries with gas hydrate research programs: India, Korea and $\operatorname{Japan}^{50}$. Officials from DOE and the Indian government signed a Memorandum of Understanding for Cooperation in Methane Hydrate Research and Development in New Delhi on April 4. The agreement provides for exchange of information and personnel in the areas of exploration and quantification of natural gas hydrates, resource assessments, laboratory characterization, and production testing. On April 18, 2008 Energy Secretary Samuel Bodman and South Korea Minister Lee Youn-ho signed a Statement of Intent to exchange information on gas hydrate topics and technologies. Korea is looking to gas hydrates as a future energy source and hopes to take part in U.S. pilot testing early next year ${ }^{104}$. On June 6, 2008, Secretary Bodman and Japanese Minister of Economy, Trade and Industry, Akira Amari signed a Statement of Intent for cooperation in methane hydrate research and development. Japan has an active methane hydrate R\&D program that has resulted in the discovery of large offshore hydrate deposits and successful short-term production testing in the Canadian arctic ${ }^{104}$.

\section{SUMMARY}

The amount of methane sequestered in gas hydrates is enormous, but estimates of the amounts are speculative and range over three orders-of-magnitude from about 100,000 to $270,000,000$ trillion cubic feet ${ }^{2}$. Per unit volume, gas hydrates contain a tremendous amount of gas. It is likely that the amount of gas in the hydrate reservoirs of the world greatly exceeds the volume of known conventional gas reserves. Gas hydrate samples have currently been recovered from 19 or more areas worldwide and are believed to occur at about 77 locations including Antarctica and Siberia ${ }^{7}$. In general, gas hydrates are found in marine shelf sediments and on-shore polar regions beneath the permafrost because in these two types of settings the pressure-temperature conditions are within the hydrate stability field ${ }^{8}$.

The work done in Russia and the former Soviet Union is the most important from the historical point of view. The comparison of the temperature and pressure conditions found at a section of rock in the Markhinskaya well drilled in 1963 in Yakutiya with hydrate formation conditions allowed scientists to propose the existence of gas-hydrate accumulations in the cooled layers (Makogon ${ }^{71}$, 1965). This concept received experimental confirmation when hydrates of natural gas were formed in laboratory in 1966 in porous media and in real core samples at the Gubkin Oil Institute in Moscow 
(Makogon $\left.{ }^{72}, 1966\right)$. These results were recorded as the scientific discovery of natural gas-hydrates.

The first gas-hydrate deposit found was in the Messoyakha field in the Transarctic, on the eastern border of Western Siberia (Makogon et al ${ }^{73}, 1970$ and Makogon et al. ${ }^{74}$, 1971). The Messoyakha field, with original reserves of about 30 billion $\mathrm{m}^{3}$, was a catalyst in the growth of studies of natural gas-hydrates in the world. The Messoyakha field provided confirmation of the presence of gas-hydrate deposits and the possibility of their commercial development ${ }^{77}$.

Russia has abundant sediments of gas hydrates both in marine shelf sediments and on-shore regions beneath permafrost. Gas hydrates have been recovered in gravity cores in sediments of the Black Sea, the Caspian Sea, the Bering Sea, and the Sea of Okhotsk ${ }^{69}$. At the same time fresh water gas hydrates have found in Lake Baikal. Lake Baikal contains about $20 \%$ of the world's fresh water and presents a rare occurrence of fresh water gas hydrates ${ }^{70}$.

Methane hydrate is currently being eagerly examined in Japan as a next-generation energy resource to replace oil and natural gas. It is estimated that the methane hydrate reserves around Japan would be sufficient to last over 100 years, based on present levels of natural gas consumption ${ }^{20}$. The Japanese research program in gas hydrates is currently the most advanced in the world ${ }^{21}$. This program comprises strong basic and applied research components. The program includes scientific studies, exploration and production tests. Main domestic research activities are directed to the area around the Japanese home islands, especially the Nankai Trough area in the southern Sea of Japan. Japan participates in many international activities in cooperation with several nations within the framework of several international organizations ${ }^{22,23,24,25}$. The gas hydrate research program is funded by an array of government and private organizations. The most important governmental institution is the Ministry of Economy, Trade and Industry $(\mathrm{METI})^{26}$. Other important public organizations involved in gas hydrates research are, Japan Oil Gas and Metals National Corporation (JOGMEC), Geological Survey of Japan (GSJ), Japan Agency for Marine-Earth Science and Technology (JAMSTEC), National Institute for Resources and Environment (NIRE), among others.

In order to advance into gas hydrates production METI established an Advisory Committee for National Methane Hydrate Exploitation Program, led by Tokyo University Professor Emeritus Shoichi Tanaka. This committee prepared a long-term research program entitled "Japan's Methane Hydrate Exploitation Program ${ }^{20}$." This program, presented in July 2001, is divided into three phases, extending over 16 years (20012016). The first phase (2001-2008) involved development of basic research technologies survey techniques, fundamental physical properties, dissociation/generation technology, etc.). The second phase (2009-2011) involves development of basic research technologies such as, production technologies, environmental impact assessment, etc. The third phase (2012-2016) aspires to develop the technologies for commercial production and evaluate economic feasibility, environmental impact, etc. 
The Research Consortium for Methane Hydrate Resources in Japan (also known as the MH21 Research Consortium) was established to undertake research in accordance with this $\operatorname{plan}^{20}$.

Field studies of natural gas hydrates have been carried out in Canada for many years by the Geological Survey of Canada and by a number of universities. The two largest field programs are: Arctic permafrost-related hydrate studies, including the Mallik research drilling site on the Mackenzie Delta and Geophysical studies and ODP drilling of marine gas hydrate beneath the continental slope off Canada's west coast. Early arctic hydrate work led to a much larger effort in drilling on the Mackenzie Delta of the first arctic research well specifically for gas hydrate research. The well was an effort by a consortium including the Japan National Oil Corporation (JNOC), the Geological Survey of Canada, and principal collaborators, the Japan Petroleum Exploration Company (JAPEX) and the U.S. Geological Survey. The research well (JAPEX/JNOC/GSC Mallik 2L-38) was drilled to a depth of $1150 \mathrm{~m}$ on the north coast of the Mackenzie Delta near the site of an existing industry exploration well. Many of the results have been published in a series of articles in the Geological Survey of Canada (GSC) Bulletin 544 (Dallimore et al., 1999) ${ }^{24}$. Three 1,200-m-deep wells, a main production research well and two nearby scientific observation wells, were drilled in 2002 in the Mackenzie Delta region of the Northwest Territories, Canada, to explore the presence of sub-permafrost gas hydrate $^{63}$. The Mallik 2002 Gas Hydrate Production Research Well Program was one of the most complex undertakings to explore natural-gas hydrate in a natural setting. The drilling project, involved more than 60 scientists and engineers and 250 support staff from six countries. The drill holes were located in the Mallik gas-hydrate field next to the Beaufort Sea on the northern part of Richards Island, and were near the Mallik 2L-38 well drilled in 1998.

Five years later Japanese and Canadian researchers re-united in the town of Inuvik. The goal was to undertake a longer test and advance new research and development studies utilizing a simple depressurization technique. The two-winter research program was successfully completed in April $2008^{28}$. The Japanese and Canadian parts adopted a simple depressurization technique as the gas hydrate production method to simplify the operational conditions of the test and to minimize unknown variables. The field scale verification of the technique was defined as the main objective of the project ${ }^{29}$. A well drilled for a 1998 research program (Japex/JNOC/GSC Mallik 2L-38) was modified to establish a production test well by reaming, casing, and cementing. The production test operation started on April 2, 2007. Sand production prevented continuous pumping, and the operation was terminated 60 hours after the start of pumping. However, during the most successful 12.5 hours of the test, at least $830 \mathrm{~m}^{3}$ of gas were produced and accumulated in the borehole. In winter 2008 field activities were undertaken to achieve longer term gas hydrate production by implementing countermeasures to overcome the problems encountered in 2007. This new attempt was successful. Six days of continuous pump operation established stable pressure conditions at the bottom of the hole. 
Pressure, temperature, and gas and liquid flow rate data were measured at the bottom of the hole and at the surface ${ }^{28}$.

The 2008 testing program at Mallik produced continuous gas flow ranging from 2000 to $4000 \mathrm{~m}^{3} /$ day. This flow was maintained throughout the course of the six-day (139hour) test. Cumulative gas production volume was approximately $13,000 \mathrm{~m}^{3}$. Initial data confirmed that the depressurization method is the correct approach ${ }^{28}$.

India, South Korea and China are showing increased interest in gas production from hydrates sediments. The directorate-general of Hydrocarbons (DGH) reported that has been estimated than India has around 2,000 trillion cubic feet of gas hydrates reserves off the country's east coast ${ }^{105}$. The Directorate General of Hydrocarbons (DGH) of India in consultation with other participating agencies has predicted the probable occurrences of gas hydrates in marine sediments offshore India ${ }^{108}$. The Ministry of Petroleum \& Natural Gas (MOP\&NG), Government of India, established an expert committee to recommend the steps to be undertaken for exploration and development of gas hydrate resources in India. Based on their recommendations, a National Gas Hydrate Program (NGHP) was instituted in 1997. In mid-August, 2006 a team of scientists from India, North America, and Europe, led by the Indian Directorate General of Hydrocarbons (DGH) and the U.S. Geological Survey (USGS), completed a four-month expedition aboard the drillship "JOIDES Resolution" to search for gas hydrates in the sea offshore India. The field trip successfully established the presence of sizeable reserves of good quality gas hydrates in the sedimentary basins of the country. Results from a site in Krishna-Godavari $(\mathrm{KG})$ basin showed the presence of a $128 \mathrm{~m}$ thick gas hydrate layer. India is the third country in the world after the USA and Japan to collect gas hydrate samples in its deep waters ${ }^{109}$.

The government of South Korea is pursuing a 10-year national project to develop natural gas hydrate in Korea's East Sea. In July 2005, a gas hydrate development team was formed that includes state-owned Korea National Oil Corporation (KNOC), Korea Gas Corporation (KOGAS) and the Korea Institute of Geosciences and Mineral Resources (KIGAM). The project is managed by the Gas Hydrate R\&D Organization (GHDO) and funded through the Ministry of Commerce, Industry and Energy (MOCIE). The team has been conducting surveys in the East Sea ${ }^{100}$.The country has earmarked Won 225.7 billion ( $\$ 243.5$ million) for the project through 2014 . The endeavor is a three-stage gas hydrate project that runs from 2005 to 2014. In the first stage that ended in 2008, 66.7 billion won were spent. After a series of surveys in the East Sea in 2005-2006, Korean engineers picked 14 locations for drilling ${ }^{100}$.

South Korea conducted during November 2007 the first large-scale gas hydrate exploration and drilling expedition in the East Sea: Ulleung Basin Gas Hydrate Expedition 1 (UBGH1), which successfully explored gas-hydrate-bearing sediments and recovered samples at three different locations in the Ulleung Basin ${ }^{102}$.

China decided in 2006 to spend 800 million yuans, or U\$S 100 million, over the next ten years studying natural gas hydrates, an alternative fuel Beijing hopes might help to 
limit its growing reliance on oil imports ${ }^{115}$. China announced on June 6, 2007 a major breakthrough in excavating natural gas hydrates. Zhang Hongtao, deputy directorgeneral of China Geological Survey (CGS), said gas hydrate samples were successfully collected from the northern part of the South China Sea in May, 2007. China is the fourth country after the United States, Japan and India to achieve such technological feat. Initial estimates indicate the potential volume of gas hydrates around continental slopes in the area exceeds 100 million tons of oil equivalent, Zhang said. The samples were collected from two different stations in the Shenhu (Magic Fox) continental slope on May 1 and May 15, 2007 he said ${ }^{116}$.

Many different countries such as, Taiwan ${ }^{120}$, Spain ${ }^{85}$, Nigeria ${ }^{125}$, Chile ${ }^{126}$, Colombia $^{129,}{ }^{130}$, New Zealand ${ }^{135}$, and Peru ${ }^{136}$, among others have shown interest in gas hydrates research.

Universities and research institutions in Germany, France, Netherlands and Belgium have also participated in several joint research projects $22,23,51,64,68,81,92,116,145$.

There are many joint projects among many different international partners including private companies. The research carried out by many international agencies in the Mallik site in the Mackenzie delta in the Canadian Arctic is a clear example of this joint approach. During the 2002 drilling project at the Mallik site more than 60 scientists and engineers and 250 support staff from six countries were involved ${ }^{66}$.

The Gulf of Mexico Gas Hydrates Joint Industry Project (JIP), in collaboration with the U.S. Department of Energy, is investigating naturally occurring gas hydrates in the Gulf of Mexico. The role of the JIP is to relate gas composition to gas hydrate formation and free gas deposits both in and out of the gas hydrate stability field ${ }^{137}$. In 2005, the DOE-Chevron Gas Hydrates JIP conducted a drilling, logging, and coring expedition designed to address concerns related to the safe drilling of deepwater oil and gas wells through gas-hydrate bearing strata. The two sites selected provided opportunities to test different geological settings for the fine-grained sediments typical of those found throughout the Gulf ${ }^{137}$.

BP Exploration (Alaska) Inc. successfully drilled a research well on the North Slope in partnership with the U.S. Department of Energy and the U.S. Geological Survey (USGS) to collect samples and gather knowledge about gas hydrates. The stratigraphic test well enabled BP and the Department of Energy (DOE) to gather core, log, reservoir performance and fluid data from an ice pad location at Milne Point ${ }^{138}$. In February, 2007, the U.S. DOE, BP Exploration (Alaska), and the U.S. Geological Survey teamed to conduct a gas hydrates drilling, coring, and testing program at the "Mount Elbert" site on the Alaska North Slope ${ }^{140}$. It is believed these results demonstrated the soundness of the geophysical techniques employed while indicating areas for further improvement of the methodology. The seismic prospecting that resulted in the selection of the Mount Elbert test site utilized 3-D seismic data for the Milne Point area of the larger Prudhoe Bay production region ${ }^{140}$. 
The U.S. Naval Research Laboratory (NRL) in collaboration with the U.S. Department of Energy National Energy Technology Laboratory (NETL), the Royal Netherlands Institute for Sea Research (NIOZ), and a team of 32 university and government scientists from the U.S., Netherlands, Belgium and Germany completed an expedition in the Beaufort Sea. The 12-day Methane in the Arctic Shelf/Slope (MITAS) expedition represents the first step in a thorough evaluation of the distributions and concentrations of methane and methane hydrates in the U.S. portion of the Arctic ocean $^{145}$.

There have been also many smaller research endeavors involving a small number of partners $49,85,98,103,104,122$.

Gas hydrates research conducted in and by United States agencies has not been a formal part of this research project. However, gas hydrate research has also a long history in the USA. The USA Department of Energy has carried groundbreaking research under the Gas Hydrates Research and Development Act of Congress that allocated funds for a period of five years with an extension for other five.

USA agencies and Universities have entered into several partnerships with different international agencies and industrial partners ${ }^{43}, 46,65,98,104,105$. In 2008, the U.S. Department of Energy signed agreements for cooperative research efforts with representatives from India, Korea and Japan ${ }^{104}$.

\section{CONCLUSIONS}

The amount of methane sequestered in gas hydrates is enormous, but estimates of the amounts are speculative and range over three orders-of-magnitude from about 100,000 to 270,000,000 trillion cubic feet.

The work done in Russia and the former Soviet Union is the most important from the historical point of view. The first gas-hydrate deposit found was in the Messoyakha field in the Transarctic, on the eastern border of Western Siberia. The Messoyakha field provided confirmation of the presence of gas-hydrate deposits and the possibility of their commercial development.

The Japanese research program in gas hydrates is currently the most advanced in the world. This program comprises strong basic and applied research components. The program includes scientific studies, exploration and production tests. Main domestic research activities are directed to the area around the Japanese home islands, especially the Nankai Trough area in the southern Sea of Japan. Japan participates in many international activities in cooperation with several nations within the framework of several international organizations. The gas hydrate research program is funded by an array of government and private organizations.

Field studies and pilot exploitation projects of natural gas hydrates have been carried out in Canada for many years by the Geological Survey of Canada and by a number of 
universities. The two largest field programs are: Arctic permafrost-related hydrate studies, including the Mallik research drilling on the Mackenzie Delta and Geophysical studies and ODP drilling of marine gas hydrate beneath the continental slope off Canada's west coast.

India, South Korea and China are showing increased interest in gas production from hydrates sediments. All these countries have carried out recently successful field work in their respective territorial waters. They have started gas hydrates research and entered in several international projects in association with international research agencies and/or industry.

Many different countries such as, Taiwan, Spain, Nigeria, Chile, Colombia, New Zealand, Peru, among others, have shown interest in gas hydrates research. Many different universities and research institutions from many different countries are actively involved in gas hydrates research. Industrial companies have shown interest in gas hydrates research starting several partnerships with international agencies and other companies.

The USA has also a long and prestigious gas hydrates research program that participated, and participates, in many joint research projects.

\section{ACKNOWLEDGEMENTS}

The support from the US Department of Energy that allowed this project to be completed is kindly acknowledged. The suggestions/recommendations of the different project managers assigned to this project are also acknowledged. Finally, this research

project could not have been completed without the hard work of all the graduate and undergraduate students who participated in the project. 


\section{REFERENCES}

1. Collett, T. S., "Potential of gas hydrates outlined": Oil and Gas Journal, June 22, p. 84-87, 1992.

2. Kvenvolden, K. A., "Gas hydrates as a potential energy resource -- A review of their methane content", in Howell, D.G., ed., The Future of Energy Gases: U.S. Geological Survey Professional Paper 1570, p. 555-561, 1993.

3. Kvenvolden, K. A., "A primer on gas hydrates," in D. G. Howell, ed., The Future of Energy Gases - U.S. Geological Survey Professional Paper 1570: Washington, United States Government Printing Office, p. 279-291, 1993.

4. Edmonds, B., Moorwood, R., and Szczepanski, R. "A Practical Model for the Effect of Salinity on Gas Hydrate Formation,” SPE Paper 35569: SPE, 1996.

5. Koh, C. A. "Towards a fundamental understanding of natural gas hydrates," Chemical Society Reviews, vol. 31, no. 3, pp. 157-167, 2002.

6. Sloan, E.D., "Clathrate hydrates of natural gases": New York, Marcel Dekker, Inc., $641 \mathrm{p} ., 1990$.

7. Kvenvolden, K. A., and T. D. Lorenson, "The global occurrence of natural gas hydrate," in C. K. Paull, and W. P. Dillon, eds., Natural Gas Hydrates: Occurrence, Distribution, and Dynamics, AGU Monograph, p. 55, 2000.

8. Lerche, I., and E. Bagirov, "Guide to gas hydrate stability in various geological settings," Marine and Petroleum Geology, v. 15, p. 427-438, 1998.

9. Collett, T. S., "Natural gas hydrates of the Prudhoe Bay and Kuparuk River area, North Slope, Alaska": American Association of Petroleum Geologists Bulletin, v. 77, no. 5 , p. 793-812, 1993.

10. Collett, T. S. "Natural-gas hydrates; resource of the twenty first century?" Journal of the American Association of Petroleum Geologists, vol. 74, pp. 85-108, 2001.

11. Gabitto, J. F. and Tsouris C. "Physical Properties of Gas Hydrates: A Review." Journal of Thermodynamics, Hindawi Publishing Corp., Vol. 2010, Article ID271291, 12 pages, 2010.

12. Klaeschen, D., Zillmer, M., and Bialas, J. "IFM-GEOMAR Report 2002-2004," chapter 3, 2004. Download from: http://www.ifm-geomar.de/index.php/id=3500.

13. Goel, N., M. Wiggins, and S. Shah, "Analytical modeling of gas recovery from in situ hydrates dissociation:" Journal of Petroleum Science and Engineering, v. 29 (2), p. 115-127, 2001.

14. Sawyer, W., C. Boyer, J. Franz, and A. Yost, 2000, "Comparative Assessment of Natural Gas Hydrate Production Models," SPE Paper 62513: SPE, 2000.

15. Booth, J. S.; Rowe, M. M.; Fischer, K. M., "Offshore gas hydrate sample database with an overview and preliminary analysis," U.S. Geol. Survey, Open-File Report 96272, 1996.

16. Ohgaki, K.; Takano, K.; Moritoki, M., "Exploitation of $\mathrm{CH}_{4}$ hydrates under the Nankai Trough in Combination with $\mathrm{CO}_{2}$ storage," Kagaku Kogaku Robunshu, 20, 121-123, 1994. 
17. Ohgaki, K.; Takano, K.; Sangawa, H.; Matsubara, T.; Nakano, S., "Methane Exploitation by Carbon Dioxide From Gas Hydrates - Phase Equilibria For CO2CH4 Mixed Hydrate System," Journal of Chemical Engineering of Japan, 29, 478483, 1996.

18. Gabitto, J. F., and Tsouris, Costas, "Hydrogen Storage Using Clathrates Compounds," paper presented at the XII Separation Society Meeting, Gattlinburg, Tennessee, October 2003.

19. Mao W. L. et al., "Hydrogen Clusters in Clathrate Hydrate," Science, 297, 2247-2249 (2002).

20. Research Consortium for Methane Hydrate Resources in Japan (MH21) homepage: http://www.mh21japan.gr.jp/english/.

21. Yokoi, K.; Nakamizu, M.; Saeki, T.; Fujii, T.; and Tsuji, Y. Recent progress of Japan's Methane Hydrates Exploitation Program in the Nankai Trough, offshore central Japan. Paper OS41F-02 presented at the Western Pacific Geophysics Meeting. July 24-27, 2006, Beijing, China, 2006.

22. Shoji, H. and Soloviev, V A., The CHAOS Project (Okhotsk Sea) for Methane Hydrate Studies. Western Pacific Geophysics Meeting, Honolulu, Hawaii, 16-20 August 2004.

23. Nouzé1, H; Henry, P.; Noble M.; Martin, V.; and Pascal, G. "Large Gas Hydrate Accumulations On The Eastern Nankai Trough Inferred From New High-Resolution 2-D Seismic Data.” Geophysical Research Letters; 31(13): NIL_27-NIL_30. American Geophysical Union, 2004.

24. Dallimore, S. R., T. Uchida, and T. S. Collett, "Scientific Results from JAPEX/JNOC/GSC Mallik 2L-38 Gas Hydrate Research Well, Mackenzie Delta, Northwest Territories, Canada," Geological Survey of Canada Bulletin 544, 403 p (32 articles), 1999.

25. Coffin, M.F., and Gahagan, L.M. “Ontong Java and Kerguelen Plateaux: Cretaceous Icelands" Journal of the Geological Society, London, 152, 1047-1052, 2005.

26. Japan Ministry of Economy, Trade and Industry. Website: http://www.meti.go.jp/english/.

27. Japan Oil, Gas and Metals National Corporation (JOGMEC). Website: http://www.jogmec.go.jp/english/aboutus/index.html.

28. The History of Teikoku Oil is the History of Japan's Energy Development. Website: http://www.teikokuoil.co.jp/eteiseki/company/history.html.

29. Japan Petroleum Exploration Co., Ltd. (JAPEX). Website: http://www.japex.co.jp/english/business/index.html.

30. Dooley, J. J. Energy Research and Development in Japan. PNNL-12214 Washington, DC. May 1999. http://energytrends.pnl.gov/japan/ja001.htm. 
31. Home Page of WWW server of Marine Geology Department, Geological Survey of Japan. http://www.aist.go.jp/GSJ/dMG/1stPage.html.

32. Aoki, Y.; Shimizu, S.; Yamane, T.; Tanaka, T.; Nakayama, K.; Hayashi, T.; and Okuda, Y. Methane Hydrate Accumulation along the Western Nankai Trough. Ann NY Acad Sci 2000 912: 136-145.

33. Uchida, T. et al., "Japan's Efforts to Explore Marine gas Hydrates off Tokai at the Nankai Trough and their Occurrences," abstract, Western Pacific Geophysics Meeting, American Geophysical Union, 2000.

34. National Institute for Resources and Environment (NIRE). "Technologies to Minimize Environmental Burden and Maximize Resource Utilization, Part I: New Energy." It can be downloaded from: http://Www.nire.go.jp/nire_WWW/eco_tec/new_ene/energy_e.htm.

35. New Sunshine Program: R\&D Program on Energy and Environmental Technologies. Agency of Industrial Science and Technology, Ministry of International Trade and Industry Japan. http://www.aist.go.jp/nss/text/solar.htm

36. New Energy Resources Research Center. Kitami Institute of Technology. http://www-ner.office.kitami-it.ac.jp/main-e.html.

37. Deep Sea Drilling Project. Information in: http://www.infoplease.com/ce6/sci/A0814954.html.

38. Ocean Drilling Program website: http://www-odp.tamu.edu/.

39. Ocean Drilling Program Completed Legs. ODP/TAMU Science Operator. Cruise Information. Website: www.odp.tamu.edu/sched.html.

40. Hill, I.; Taira, A.; and Firth, J. "Ocean Drilling Program: Leg 131 Scientific Prospectus." Download from: http://www.odp.tamu.edu/publications/prosp/digital/131prosp.pdf.

41. Moore, G. F.; Mikada, H.; Moore, J. C.; Becker, K.; and Taira, A. “1. Legs 190 and 196 Synthesis: Deformation and Fluid Flow Processes in the Nankai Trough Accretionary Prism." Download from: http://www.odp.tamu.edu/publications/190196SR/synth/synth.htm.

42. Integrated Ocean Drilling Program. Home website: http://www.iodp.org/.

43. Hiroshi, O.; Tetsuya, F.; Ichikawa, Y.; Kawasaki, M.; Tomoharu, O.; Yonezawa, T.; Yasuda, Y.; and Tsuji, Y. "Gulf of Mexico Survey JIP with Chevron/DOE and others.” Annual Report of TRC's Activities, Vol. 2003, 196-197, 2004.

44. Luan, X., Jin, Y., A. Obzhirov A., and Yue B "Free gas in gas hydrate stability zonedata from Okhotsk Sea," Geophysical Research Abstracts, Vol. 10, EGU2008-A12229, 2008. EGU General Assembly 200. 
45. Brodie, T. "Researchers Extract Methane Gas from under Permafrost," Northern News Services, March 31, 2008. Download from: http://nnsl.com/northern-newsservices/stories/papers/mar31 08ma.html.

46. Yamamoto, K. and Dallimore, S. "Aurora-JOGMEC-NRCan Mallik 2006-2008 Gas Hydrate Research Project Progress." Fire in the Ice, Methane Hydrate Newsletter, US. Department of Energy. Office of Fossil Energy. National Energy Technology Laboratory. Summer 2008.

47. Dallimore, S. "Community Update on the 2006-2008 JOGMEC/NRCan/Aurora Mallik Gas Hydrate Production Research Program. Northwest Territories, Canada." Fire in the Ice, Methane Hydrate Newsletter, US. Department of Energy. Office of Fossil Energy. National Energy Technology Laboratory. Spring/Summer 2007.

48. Anderson, B., Wilder, J. W., Collet, T., Hunter, R., Kurihara, M., Masuda, Y., McGrail, P., Moridis, G., Narita, H., Pooladi-Darvish, M., White, M., and Wilson, S. "International Methane Hydrate Code Comparison Project Simulates Relevant Problems." Fire in the Ice, Methane Hydrate Newsletter, US. Department of Energy. Office of Fossil Energy. National Energy Technology Laboratory. Winter 2007.

49. Nishio, Sh., Abe, T., Yamashita, S. and Khlystov, O. "Cone Penetration Tests at Gas Hydrate Bearing Sediments in Lake Baikal," section GAH-01. International Geological Congress Oslo 2008, August 6-14, 2008.

50. "International Cooperation in R\&D." The National Methane Hydrates R\&D Program Highlights Archive. US. Department of Energy. Office of Fossil Energy. National Energy Technology Laboratory, June 2008. Download from: http://www.netl.doe.gov/technologies/oilgas/futuresupply/methanehydrates/MH_Highlights_Archive.html.

51. Takahashi, H., Yonezawa, T., and Fercho, E. "Operation Overview of the 2002 Mallik Gas Hydrate Production Research Well Program at the Mackenzie Delta in the Canadian Artic." OTC15124 presented at the 2003 Offshore Technology Conference, Houston, May 5-8 2003.

52. Davis, E., Becker, K., Wang, K., Obara, K., Ito, Y., Kinoshita, M., "A Discrete Episode of Seismic and Aseismic Deformation of the Nankai Trough Subduction Zone Accretionary Prism and Incoming Philippine Sea Plate." Earth and Planetary Science Letter 242, pp. 73-84, 2006.

53. Ike, T., More, G., Okano, T., Kuramoto, S., Taira, A. "Along Strike Changes in Basement Topography and Sediment Thickness in the Northern Shikoku Basin: Variable Inputs to the Nankai Trough Seismogenic Zone." EOS Transaction, American Geophyiscal Union, vol. 85, Fall Meeting Supplements, 2004.

54. Takahashi, H. and Tsuji, Y. "Multi-Well Exploration Program in 2004 for Natural Hydrate in the Nankai-Trough Offshore Japan." OTC17162 presented at the 2005 Offshore Technology Conference, Houston, May 2-5 2005. 
55. Colwell, F., Matsumoto, R., Reed, D., "A Review Of Gas Hydrate, Geology And Biology of the Nankai Trough.” Chemical Geology, v. 205, pp. 391-404, 2004.

56. Satoh, M.; Maekawa, T.; and Okuda, Y. "Estimation of the Amount of Methane and Resources of Natural Gas Hydrates in the World and Around Japan." Journal Geol. Soc. Japan, 102, 1996.

57. Takahashi, H.; Yonezawa, T.; and Takedomi, Y. "Exploration for Natural Hydrate in Nankai-Trough Wells." OTC13040 presented at the 2001 Offshore Technology Conference, Houston, April 30 - May 3, 2001.

58. Kastner, "Gas Hydrates in Convergent Margins: Formation, Occurrence, Geochemistry, and Global Significance." Natural Gas Hydrates: Occurrence, Distribution and Detection. Geophysical Monograph, vol. 124. American Geophysical Union Washington, DC, pp. 67-86, 2001.

59. Collett, T. S. "Energy Resources Potential of Natural Gas Hydrates.” AAPG Bulletin, v. 86, pp. 1971-92, 2002.

60. Saito, H. and Suzki, N. "Terrestrial Organic Matter Controlling Gas Hydrate Formation in the Nankai Trough Accretionary Prism, Offshore Shikoku, Japan." Journal of Geochemical Exploration, v. 95, pp. 88-100, 2007.

61. Matsuzawa, M.; Umezu, S.; and Yamamoto, K. "Evaluation of Experiment Program 2004: Natural Hydrate Exploration Campaign in the Nankai-Trough Offshore Japan." IADC/SPE 98960 presented at the IADC/SPE Drilling Conference, Miami, Florida USA, February 21-23 2006.

62. Smith, S.L., and A.S. Judge, A. S. "Estimates of methane hydrate volumes in the Beaufort-Mackenzie region, Northwest Territories," in Current Research, 1995-B, Geological Survey of Canada, 81-88 (also Geological Survey of Canada Open File 2746, 1993).

63. Hyndman, R. D. and Dallimore, S. R., "Natural Gas Hydrates in Canada," article published in the Recorder, 26, 11-20, 2001, Canadian Society of Exploration Geophysicists, 2001.Available at http://gsc.nrcan.gc.ca/gashydrates/canada/index_e.php.

64. Winters, B. "Gas Hydrate research Wells Completed in the Canadian Arctic," published in US Geological Survey Sound Waves Monthly Newsletter, April 2002. Available at http://soundwaves.usgs.gov/2002/04/.

65. "Mallik 2002 Gas Hydrate Production Research Well Program,” Natural Resources of Canada, Geological Survey of Canada, December 2003. Available at http://gsc.nrcan.gc.ca/gashydrates/mallik2002/press3 e.php.

66. "Scientific results from the Mallik 2002 gas hydrate production research well program," GSC Bulletin 585, August 25, 2005. Available for download at the 
Natural Resources of Canada website, http://gsc.nrcan.gc.ca/gashydrates/mallik2002/index e.php.

67. Hyndman, R. D., Spence, G. D., Yuan, T., and Davis, E. E., “ Regional geophysics and structural framework of the Vancouver Island margin accretionary prism." In Westbrook, G. K., Carson, B., Musgrave, R. J., et al., Proc. ODP, Init. Repts., 146 (Pt. 1): College Station, TX (Ocean Drilling Program), 399-419, 1994.

68. Hyndman, R. D., Spence, G. D., Chapman, R., Riedel, M., and Edwards, R. N. "Geophysical studies of marine gas hydrate in Northern Cascadia," article published in the Geological Survey of Canada website, 04/20/2006. Available at http://gsc.nrcan.gc.ca/gashydrates/ncascadia/index_e.php.

69. Makogon, Y. F.; Holditch, S. A., and Makogon, T. Y. (2004). Proven Reserves and Basics for Development of Gas Hydrate Deposits, AAPG, Vankouver.

70. Schultheiss, P. and Holland, M. "Fresh Water Hydrates from Lake Baikal," Fire in the Ice, p. 13, Fall 2007.

71. Makogon, Y. F. (1965). A gas hydrate formation in the gas saturated layers under low temperature, Gas Ind. 5.

72. Makogon, Y. F. (1966). Peculiarities a Gas-Field Development in Permafrost, Nedra, Moscow (1966).

73. Makogon, Y. F.; Tsarev, V. P.; and Chersky, N. V. (1970). Gas-hydrate resource in offshore, 17 World Gas Congress, Moscow.

74. Makogon, Y.F.; Trebin, F.A.; and Trofimuk, A.A. (1971). Finding of a Pool of Gas in the Hydrate State. Moscow, DAN SSSR. vol. 196, No.1, 197-206.

75. Beznosikov, A. F.(1970). Thermodynamic studies of the Messoyakha deposit, Oil and Gas Tumeni vol. N8 Tumen.

76. Ben'aminovich, A. F.; Lenda, S. M.; Yefremov, I. D.; and Sapir, M. Kh. (1972). Effect of gas hydrates on the geophysical characteristics of Messoyakha field, VNIIONG vol. 8.

77. Makogon, Y.F.; Holditch, S.A.; and Makogon, T. Y. (2007). Natural Gas Hydrates A Potential Energy Source for the $21^{\text {st }}$ Century, Journal of Petroleum Science and Engineering, Vol. 56, No 1-3, March 2007, Pages 14-31.

78. Makogon, Y.F. (1984). Production from natural gas hydrate deposits, Gazovaya Promishlennost, v. 10, p. 24-26.

79. Yakushev, V. Web Homepage:www.geocities.com/ResearchTriangle/Node/1622.

80. Collett, T.S., and Ginsburg, G.D. (1997). Gas hydrates in the Messoyakha gas field of the West Siberian Basin -- A re-examination of the geologic evidence: Seventh International Offshore and Polar Engineering Conference, May 25-30, 1997. Honolulu, USA, Proceedings, v. 1, p. 96-103. 
81. Shoji, H. et al., "Hydrate-Bearing Structures in the Sea of Okhotsk," Eos, Transactions American Geophysical Union, Vol. 86, No. 2, Doi:10.1029/2005eo020001, 2005.

82. Nishio, Sh., Abe, T., Yamashita, S. and Khlystov, O. "Cone penetration tests at gas hydrate bearing sediments in Lake Baikal," section GAH-01. International Geological Congress Oslo 2008, August 6-14, 2008.

83. "India-Russia to Jointly Explore Alternative Source of Energy." The Hindu. Online Edition of India's National Newspaper, November 8, 2003. Download from website: http://www.thehindu.com/thehindu/2003/11/08/stories/2003110805331200.htm

84. "Indo-Russian S\&T Cooperation." Report prepared by the Indian Embassy in Russia, Dr/ P/ Shukla Counsellor (S\&T), September 2004. Download from website: http://www.indianembassy.ru/docs-htm/en/en_17a_01_t001.htm.

85. Matveeva, T.; Mazurenko, L.; Kulikova, M.; Beketov, E.; Blinova, V.; Ivanov, M.; Stadnitskaya, A.; van Weering, T. C. E. Resources Potential of Gas Hydrate-Bearing Mud Volcanoes in the Gulf of Cadiz (2007), Geophysical Research Abstracts, Vol. 9, 07142 .

86. Perlova, E.V. (2001). Peculiarities of permafrost sediments gas content (North-West Yamal peninsula case study). Ph.D. Thesis, Moscow State University, 178 p. (in Russian).

87. Yakushev V., "Intrapermafrost Gas Hydrates at the North West Siberia," presented at the Gas Hydrates: Energy Resource Potential and Associated Geologic Hazards, AAPG HEDBERG CONFERENCE, September 12-16, 2004, Vancouver, BC, Canada.

88. Yakushev, V. S. and Collett, T. S. (1992). Gas hydrates in Arctic regions: risk to drilling and production. In: Proceedings of 2nd International Offshore and Polar Engineering Conference. San Francisco, California, v.1, p.669-673.

89. Yakushev, V. S. and Chuvilin, E. M. (2000). Natural gas and gas hydrate accumulations within permafrost in Russia. Cold Regions Science and Technology, 31(12): 189-197.

90. Bailey, A. "Bering Sea Likely Rich in Hydrates." Petroleum News, Vol. 12, No 3, January 21, 2007.

91. Semiletov, I. and Shakova, N. "The highest concentrations of dissolved methane ever measured in the Arctic Ocean found beneath the sea-ice on the Laptev Sea shelf," International Artic Research Center, May 2007. Download from: http://www.iarc.uaf.edu/highlights/2007/dissolved_methane_Laptev_Sea/

92. Methane Hydrate - Treasure beneath the Mediterranean (2008), DW World, Deutsche Welle, 01/31/2008. Downloadable from: http://www.ifm.unihamburg.de/ wwwls/M70/M70-3-SCR.pdf. 
93. Yakushev, V. S.. Research Institute of Natural Gases and Gas Technologies (VNIIGAZ), Gazprom, Russia. Web page: http://www.geocities.com/ResearchTriangle/Node/1622/

94. "South Korea - Science \& Technology Overview." Report prepared by the British Embassy in the Republic of South Korea. Download from website: http://www.britishembassy.gov.uk/servlet/Front/TextOnly?pagename=OpenMarket/X celerate $/$ ShowPage $\& c=$ Page \& $c i d=1101395195467 \&$ to $=$ true.

95. Korea National Oil Corporation (KNOC), The Korea Times, 05/10/2007, download: jinryu@koreatimes.co.kr.

96. Korea Gas Corporation homepage: http://www.kogas.or.kr/kogas_eng/01_who/01.jsp.

97. Korean Institute of Geo-Science and Mineral Resources (KIGAM), homepage: http://www.kigam.re.kr/Contents/ContentsEngView.asp?strPageID=P068.

98. Lee, J. H., Baek, Y. S., Ryu, B. J., Riedel, M., and Hyndman, R. D. “A seismic survey to detect natural gas hydrate in the East Sea of Korea," Marine Geophysical Researches, Volume 26, (1), 51-59, March 2005.

99. "South Korea Discovers $600 \mathrm{mt}$ of Gas Hydrates," Asia-Pacific LNG Rounds up a PLATTS.COM News features. Download from website: http://www.platts.com/Natural\%20Gas/Resources/News\%20Features/asiapacificlng/k orea.xml.

100. Lee, T.-S., Lee, H.-Y., and Park, K.-P. "Gas Hydrates R\&D Activities of Korea." Proceedings of the Eighteenth (2008) International Offshore and Polar Engineering Conference. Vancouver, BC, Canada, July 6-11, 2008.

101. "Gas hydrates rich waters contested between Korea and Japan." UPI Asia Online News, politics. October 11, 2007. Download from website: http://www.upiasiaonline.com/politics/2007/10/11/feature_south_korea bolstering hold over_disputed islets/.

102. Park, K-P., Bahk, J.-J., Kwon, Y., Kim, G.-Y., Riedel, M., Holland, M. Schultheiss, P., and Rose, K. "Korean National Program Expedition Confirms Rich Gas Hydrate Deposits in the Ulleung Basin, East Sea." Fire in the Ice, Methane Hydrate Newsletter, US. Department of Energy. Office of Fossil Energy. National Energy Technology Laboratory. Spring 2008.

103. "India and Korea Sign Six MOUs for Cooperation in Hydrocarbon Sector." Press Information Bureau Government of India, 11/25/2005. Download from: http://pib.nic.in/release/rel_print_page.asp?relid=13569

104. "International Cooperation on Gas hydrates Research." USA Department of Energy, 2008. Download from: http://www.fossil.energy.gov/programs/oilgas/hydrates/ 
105. Collet, T. "India Project- Results of the Indian National Gas Hydrate Program (NGHP) Expedition 01.” Web page USGS. Download from: http://energy.usgs.gov/other/gashydrates/india.html.

106. "India has 2,000 trillion cubic ft prognostic gas hydrates pool." The Financial Express. Thursday, February 07, 2008. Download from:

http://www.financialexpress.com/news/India-has-2-000-trn-cubic-ft-prognostic-gashydrates-pool/269905/.

107. Sethi, A. K., Sathe, A. V., and Ramana, M. V. "Potential Natural Gas Hydrates in Indian Offshore Areas," AAPG Hedberg Conference, September 12-16, 2004, Vancouver, BC, Canada.

108. National Institute Oceanographic of India (NIO). "Gas Hydrate Resource Map of India,” NIO/SP-25/97, prepared for Gas Authority of India, Limited, 56, 1997.

109. USGS Energy for a Changing World, "International Team Completes Landmark Gas Hydrate Expedition in the Offshore of India," USGS Home website: http://energy.usgs.gov/other/gashydrates/india.html.

110. National Institute Oceanographic of India. "Geological, geophysical, geochemical and microbial studies of the Indian continental margins to decipher gas hydrates," Home website: http://www.nio.org/projects/ramana/project_ramana.jsp.

111. "American Geophysical Union Fall Meeting." San Francisco, CA, USA, 10-14 December 2007. Information download from: http://www.agu.org/meetings/fm07/

112. "Sagar Nidhi Joins Indian Research Fleet to Extract Gas Hydrates from Sea Bed." Marine Tech., March 3, 2008 Download from:

http://www.marinebuzz.com/2008/03/03/sagar-nidhi-joins-indian-research-fleet-toextract-gas-hydrates-from-sea-bed/.

113. Song H., Geng J., Wang H. et al., "A preliminary study of gas hydrates in Dongsha region North of South China Sea." Chinese Journal of Geophysics (in Chinese), Vol. 44, (5), 687-695, 2001.

114. Chen, Z., Bai, W., and Xu, W., "Prediction of stability zones and occurrence zones of multiple composition natural gas hydrate in marine sediment." Chinese Journal of Geophysics, Vol. 48 (4), 939-945, 2005.

115. "China to spend $\$ 100$ million on research of natural gas hydrates alternative fuel," AP report, August 23, 2006, Available at:

http://www.uofaweb.ualberta.ca/chinainstitute/nav03.cfm?nav03=49596\&nav02=4 9595\&nav01=43092).

116. China Daily News Release. "Breakthrough on New Energy Source," China Daily, June 6, 2007 website: http://www.chinapage.com/energy/gashydrate/news0706.html.

117. Successful and Surprising Results for China's First Gas Hydrate Drilling Expedition," H. Zhang (CGS), S. Yang (GMGS), N. Wu (GMGS), X. Su (CUGB), 
M. Holland (Geotek), P. Schultheiss (Geotek), K. Rose (NETL), H. Butler (Fugro), G. Humphrey (Fugro), and GMGS-1 Science Team. Fire in the Ice, p. 6-9, Fall 2007.

118. Hyndman, R. D., and Davis, E. E., "A mechanism for the formation of methane hydrate and seafloor bottom simulating reflectors by vertical fluid expulsion." $J$. Geophys. Res., 97:7025-7041, 1992.

119. Xu, W., and Ruppel, C., "Predicting the occurrence, distribution, and evolution of methane gas hydrate in porous marine sediments." J. Geophys. Res, 104(B3):50815096, 1999. doi:10.1029/1998JB900092

120. Liu, C. C., "Gas hydrate research in Taiwan." In 2006 Taiwan Gas Hydrate Workshop, Taipei, Taiwan. March 14-15, 2006

121. Cheng, W.-B., Lee, Ch.-Sh., Liu, Ch.-Sh., and Schnurle, Ph., "Velocity structure in marine sediments with gas hydrates reflectors in offshore SW Taiwan, from OBS data tomography." Terr. Atmos. Ocean. Sci., vol. 17 (4), 739-756, December 2006.

122. "TTR 10 Oceanographic Campaign," TASYO/GADES Multidisciplinary Marine Research Group. Available at http://tierra.rediris.es/TASYO/index.html.

123. Kumar, P. "India's R\&D Efforts for Developing Natural Gas Hydrates as an Energy Resource." Oil and Natural Gas Corporation, India. Coauthors: Mr. Malcolm Lall, and Mr. V K Sibal, Directorate General of Hydrocarbon, India, Proceedings of the $19^{\text {th }}$ World petroleum Congress Spain Madrid 2008-07-28.

124. Huh, D. "Swapping Methane by Flue Gas in Gas Hydrates through Unconsolidated Porous Media." Korea Institute of Geoscience and Mineral Resources, Korea. Coauthors: Mr. Jahyoung Lee, Mr. Huen Lee, Korea Advanced Institute of Science and Technology, Korea. Proceedings of the $19^{\text {th }}$ World petroleum Congress Spain Madrid 2008-07-28.

125. Brooks, J. M., Bryant, W. R., Bernard. B. B., and Cameron, N. R., "The nature of gas hydrates on the Nigerian continental slope." Annals of the New York Academy of Sciences. Third International Conference on Gas Hydrates, July 18-22, 1999, Park City, Utah, USA. Version: 16 July, 1999.

126. Morales, E., "Methane Hydrates in the Chilean Continental Margin," in Biotechnology for Developing Countries, vol. 6, No 2, August 15, 2003.

127. Westbrook, G.K., B. Carson, R.J. Musgrave and Shipboard Scientists, Proceedings of the Ocean Drilling Program, Initial Reports, 146, 611 p., 1994.

128. Diaz-Naveas, J., "Sediment Subduction and Accretion at the Chilean Convergent Margin Between 35' and 40'S," Dissertation zur Etlangung des Doktorgrades. Christian-Albrechts-Universitat zu Kiel, 130 p., 1999.

129. Shipley, T. H., Houston, M. H., Buffler, R. T., Shaub, F. J., Mcmillen, K. J., Ladd, J. W., and Worzel, J. L., "Seismic reflection evidence for the widespread occurrence of possible gas-hydrate horizons on continental slopes and rises." AAPG Bulletin, 63: 2204-2213. 1979. 
130. Ladd, J. W., Truchan, M., Talwani, M., Stoffa, P. L., Buhl, P., Houtz, R., Mauffret, A., and Westbrook G., "Seismic reflection profiles across the southern margin of the Caribbean." Geological Society of America Memoir, 162: 153-159., 1984.

131. Gómez C., and León J., "Recuperación de gas metano en yacimientos de hidratos de gas en la cuenca Colombia como futura fuente de energía." Tesis de pregrado, Ingeniería Química, Universidad Industrial de Santander, Bucaramanga., 2000.

132. Caicedo, J., and Pinto, N., "Esquemas de explotación de Yacimientos de hidratos de gas, primera aproximación de un modelo matemático para el esquema de despresurización." Tesis de pregrado, Escuela de Ingeniería de Petróleos, Universidad Industrial de Santander, Bucaramanga, 150pp., 2003.

133. López, C., "Determinacion del gradiente geotérmico a partir del reflector simulador de fondo." Tesis de pregrado, Universidad Industrial de Santander, Bucaramanga, 100 pp., 2005.

134. Lopez, C. and Ojeda, G. Y., "Heat Flow in the Colombian Caribbean from the Bottom Simulating Reflector (BSR)," CT\&F - Ciencia, Tecnología y Futuro - Vol. 3 (2), Dic. 2006.

135. Gorman, A., "Seismic characterization of gas hydrates and associated fluid flow on passive and active continental margins: examples from New Zeland." Presentation at the CSEG January Meeting, January 21, 2008. CSEG Recorder January 2008.

136. Von Huene, R. and Pecher, I.A., "Neo-Tectonics and the Origins of BSRs along the Peru Margin.” Earth Planet, Sci. Lett., 166, 47-55, 1999.

137. Lorenson, T. D., Dougherty, J. A., and Claypool, G. E "Preliminary Results from the ChevronTexaco Gulf of Mexico Gas Hydrates JIP: Hydrocarbon Gases in Sediments.” OS42A-04, EOS Trans. AGU 86 (52), Fall Meeting 2005.

138. "BP Drills Alaska North Slope Gas Hydrate Test Well to Assess Potential Energy Resource," press release, 20 February $2007 . \quad$ Download from: http://www.bp.com/genericarticle.do? categoryId=2012968\&contentId=7028944.

139. Birchwood, R., Noeth, S., and Jones, E. "Safe Drilling in Gas-Hydrate Prone Sediments: Findings from the 2005 Drilling Campaign on the Gulf of Mexico Gas Hydrates Joint Industry Project (JIP)," Fire in the Ice. USDOE Methane Hydrate Newsletter, pg. 1, Winter 2008.

140. Inks, T., Lee, M., Arena, W., Collet, T., and Boswell, R. "Comparison of Drilling Results to Pre-Drill Estimates of Gas Hydrate Occurrence: "Mount Elbert" test Site, Alaska North Slope," Fire in the Ice. USDOE Methane Hydrate Newsletter, pg. 13, Winter 2008.

141. Frie, M., Grace, J., Hunt, J., Kaufman, G., Schuenemeyer, J. and Shed, B. "MMS Releases Preliminary Results of Gulf of Mexico In-Place Natural Gas Hydrate Assessment," Fire in the Ice. USDOE Methane Hydrate Newsletter, pg. 1, Spring 2008. 
142. Gas Hydrate Simulator Comparison Group. "International Methane hydrate Code Comparison Project Simulates Relevant Problems," Fire in the Ice. USDOE Methane Hydrate Newsletter, pg. 5, Winter 2007.

143. International Gas Hydrate Code Comparison Group. "Analysis of Pressure Test Data from the "Mount Elbert" Gas Hydrates Well," Fire in the Ice. USDOE Methane Hydrate Newsletter, pg. 10, Spring 2008.

144. Bunz, S. and Miernet, J. "Acoustic Imaging of Gas Hydrate and Free Gas at the Storegga Slide,” J. of Geophysical Research, 10, B04102, 2004.

145. "DOE-Sponsored Beaufort Sea Expedition Studies Methane's Role in Global Climate Cycle.” US. Department of Energy. Office of Fossil Energy. National Energy Technology Laboratory. Released November 2009. Download from: http://www.netl.doe.gov/publications/press/2009/09075Beaufort_Sea_Expedition_Studies_Me.html

146. Osadetz, K. G., Dallimore, S., Hyndman, R., Mosher, D., Wright, F., Riedel, M. Hancock, S. and Okazawa, T. "Gas Hydrates - Fuel of the Future: Characteristics, Occurrences, Significance and Resource Potential," National Energy Board of Canada, speaker presentation, April 6, 2006. Download at http://www.neb.gc.ca/energy/EnergyFutures/2006/Speakers/kirk osadetz.pdf

147. "An Act to Promote the Research, Identification, Assessment, Exploration, and Development of Methane Hydrate Resources, and for other Purposes," H. R. 1753, One Hundred Sixth Congress of the United States of America, January 24, 2000. Available at http://frwebgate.access.gpo.gov/cgibin/getdoc.cgi?dbname=106 cong_bills\&docid=f:h1753enr.txt.pdf.

148. "FY 2005 Statistical Table by Appropriation," US DOE, 2004. Available at http://www.mbe.doe.gov/budget/05budget/content/appstat.pdf.

149. "Methane Hydrate R\&D Act." (2000 with 2005 amendment). Download from USA Department of Energy:

http://www.fossil.energy.gov/programs/oilgas/publications/methane_hydrates/SEC 968.pdf

150. "Methane Hydrates in Context - US Natural Gas Overview," National Commission on Energy Policy (NCEP) Staff Background paper, 2004. Available at http://www.energycommission.org/files/finalReport/IV.1.h\%20\%20Methane $\% 20$ Hydrates.pdf.

151. Boswell, R., Amato, R., Coffin, R., Collet, T., Dellagiarino, G., Fisk, R., Gettrust, J., Haq, B., Hutchinson, D., Pugliese, K., Ray, P., and Rose, K. “An Interagency Roadmap for Gas Hydrates Rsearch and Development FY2007-FY2011," by the Technical Coordination Team of the National Methane Hydrate R\&D Program. USA Department of Energy, April 2007. Download from: http://www.fossil.energy.gov/programs/oilgas/hydrates/Interagency 5year_Plan_Apr_2007rev.pdf 